Cochrane Database of Systematic Reviews

\title{
Routine scale and polish for periodontal health in adults (Review)
}

Lamont T, Worthington HV, Clarkson JE, Beirne PV

Lamont T, Worthington HV, Clarkson JE, Beirne PV.

Routine scale and polish for periodontal health in adults.

Cochrane Database of Systematic Reviews 2018, Issue 12. Art. No.: CD004625.

DOI: 10.1002/14651858.CD004625.pub5. 
TABLE OF CONTENTS

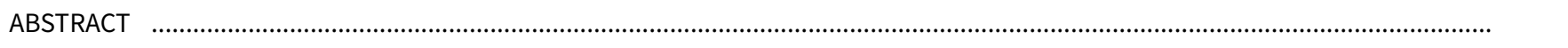

PLAIN LANGUAGE SUMMARY

SUMMARY OF FINDINGS

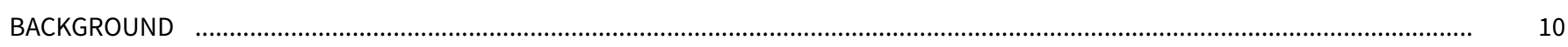

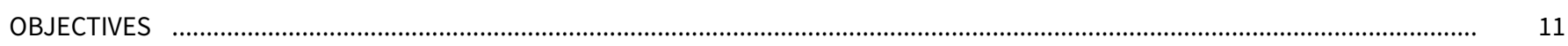

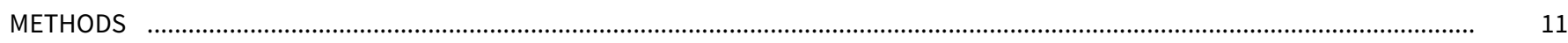

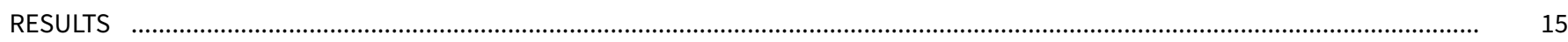

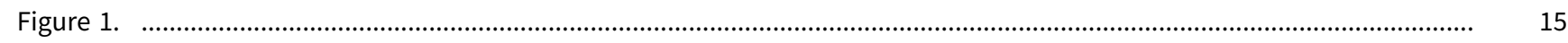

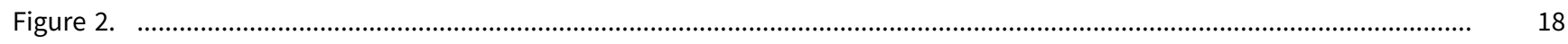

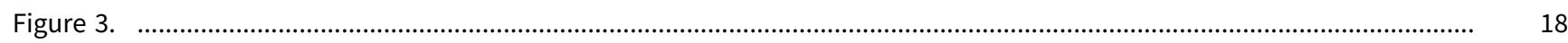

DISCUSSION

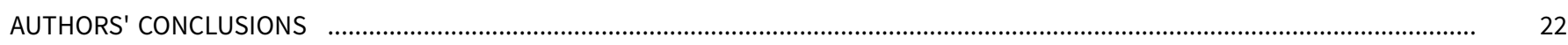

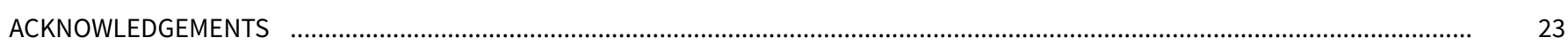

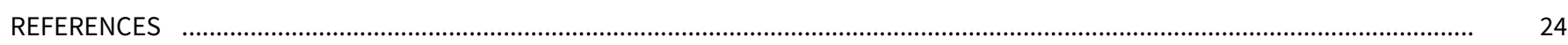

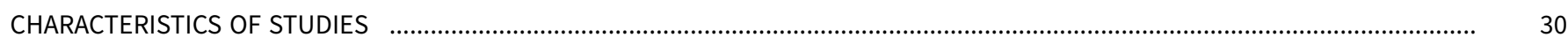

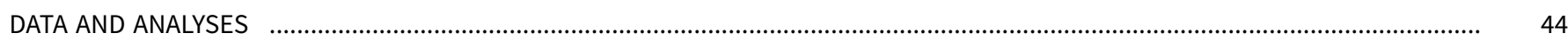

Analysis 1.1. Comparison 1 Scale and polish versus no scale and polish, Outcome 1 Gingivitis at 24-36 months. ...................... 45

Analysis 1.2. Comparison 1 Scale and polish versus no scale and polish, Outcome 2 Calculus at 24-36 months. ....................... 46

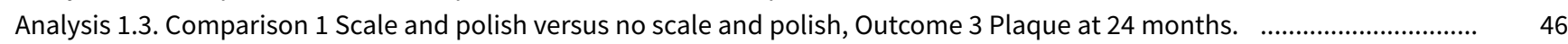

Analysis 1.4. Comparison 1 Scale and polish versus no scale and polish, Outcome 4 Probing depths at 36 months. .................. 46

Analysis 1.5. Comparison 1 Scale and polish versus no scale and polish, Outcome 5 Participant perception of oral cleanliness 46 at 24 months.

Analysis 1.6. Comparison 1 Scale and polish versus no scale and polish, Outcome 6 Quality of life at 36 months. ....................

Analysis 1.7. Comparison 1 Scale and polish versus no scale and polish, Outcome 7 Cost (NHS perspective) at 36 months. .....

Analysis 2.1. Comparison 2 Scale and polish at a fixed interval versus scale and polish at a different fixed interval, Outcome 1 Gingivitis at 24-36 months.

Analysis 2.2. Comparison 2 Scale and polish at a fixed interval versus scale and polish at a different fixed interval, Outcome 2 Calculus at 24-36 months.

Analysis 2.3. Comparison 2 Scale and polish at a fixed interval versus scale and polish at a different fixed interval, Outcome 3 Plaque at 24 months.

Analysis 2.4. Comparison 2 Scale and polish at a fixed interval versus scale and polish at a different fixed interval, Outcome 4 Probing depths at 36 months.

Analysis 2.5. Comparison 2 Scale and polish at a fixed interval versus scale and polish at a different fixed interval, Outcome 5 Participant perception of oral cleanliness at 24 months.

Analysis 2.6. Comparison 2 Scale and polish at a fixed interval versus scale and polish at a different fixed interval, Outcome 6 Quality of life at 36 months.

Analysis 2.7. Comparison 2 Scale and polish at a fixed interval versus scale and polish at a different fixed interval, Outcome 7 Cost (NHS perspective) at 36 months.

ADDITIONAL TABLES

APPENDICES

WHAT'S NEW

HISTORY

CONTRIBUTIONS OF AUTHORS

DECLARATIONS OF INTEREST

SOURCES OF SUPPORT

DIFFERENCES BETWEEN PROTOCOL AND REVIEW

INDEX TERMS 
[Intervention Review]

\section{Routine scale and polish for periodontal health in adults}

Thomas Lamont ${ }^{1}$, Helen V Worthington ${ }^{2}$, Janet E Clarkson2,3, Paul V Beirne 4

1University of Dundee, Dental School \& Hospital, Dundee, UK. ${ }^{2}$ Cochrane Oral Health, Division of Dentistry, School of Medical Sciences, Faculty of Biology, Medicine and Health, The University of Manchester, Manchester, UK. ${ }^{3}$ Division of Oral Health Sciences, Dundee Dental School, University of Dundee, Dundee, UK. ${ }^{2}$ Department of Epidemiology and Public Health, University College Cork, Cork, Ireland

Contact: Thomas Lamont, University of Dundee, Dental School \& Hospital, Park Place, Dundee, Tayside, DD1 4HN, UK. t.lamont@dundee.ac.uk.

Editorial group: Cochrane Oral Health Group.

Publication status and date: Edited (no change to conclusions), published in Issue 4, 2020.

Citation: Lamont T, Worthington HV, Clarkson JE, Beirne PV. Routine scale and polish for periodontal health in adults. Cochrane Database of Systematic Reviews 2018, Issue 12. Art. No.: CD004625. DOI: 10.1002/14651858.CD004625.pub5.

Copyright @ 2020 The Cochrane Collaboration. Published by John Wiley \& Sons, Ltd.

\section{A B S T R A C T}

\section{Background}

Many dentists or hygienists provide scaling and polishing for patients at regular intervals, even for those at low risk of developing periodontal disease. There is debate over the clinical and cost effectiveness of 'routine scaling and polishing' and the optimal frequency at which it should be provided for healthy adults.

A 'routine scale and polish' treatment is defined as scaling or polishing, or both, of the crown and root surfaces of teeth to remove local irritational factors (plaque, calculus, debris and staining), which does not involve periodontal surgery or any form of adjunctive periodontal therapy such as the use of chemotherapeutic agents or root planing. Routine scale and polish treatments are typically provided in general dental practice settings. The technique may also be referred to as prophylaxis, professional mechanical plaque removal or periodontal instrumentation.

This review updates a version published in 2013.

\section{Objectives}

1. To determine the beneficial and harmful effects of routine scaling and polishing for periodontal health.

2. To determine the beneficial and harmful effects of routine scaling and polishing at different recall intervals for periodontal health.

3. To determine the beneficial and harmful effects of routine scaling and polishing for periodontal health when the treatment is provided by dentists compared with dental care professionals (dental therapists or dental hygienists).

\section{Search methods}

Cochrane Oral Health's Information Specialist searched the following databases: Cochrane Oral Health's Trials Register (to 10 January 2018), the Cochrane Central Register of Controlled Trials (CENTRAL) (the Cochrane Library, 2017, Issue 12), MEDLINE Ovid (1946 to 10 January 2018), and Embase Ovid (1980 to 10 January 2018). The US National Institutes of Health Trials Registry (ClinicalTrials.gov) and the World Health Organization International Clinical Trials Registry Platform were searched for ongoing trials. No restrictions were placed on the language or date of publication when searching the electronic databases.

\section{Selection criteria}

Randomised controlled trials of routine scale and polish treatments, with or without oral hygiene instruction, in healthy dentate adults without severe periodontitis. We excluded split-mouth trials. 


\section{Data collection and analysis}

Two review authors screened the results of the searches against inclusion criteria, extracted data and assessed risk of bias independently and in duplicate. We calculated mean differences (MDs) (or standardised mean differences (SMDs) when different scales were reported) and $95 \%$ confidence intervals (Cls) for continuous data. We calculated risk ratios (RR) and 95\% Cls for dichotomous data. We used a fixedeffect model for meta-analyses. We contacted study authors when necessary to obtain missing information. We rated the certainty of the evidence using the GRADE approach.

\section{Main results}

We included two studies with 1711 participants in the analyses. Both studies were conducted in UK general dental practices and involved adults without severe periodontitis who were regular attenders at dental appointments. One study measured outcomes at 24 months and the other at 36 months. Neither study measured adverse effects, changes in attachment level, tooth loss or halitosis.

\section{Comparison 1: routine scaling and polishing versus no scheduled scaling and polishing}

Two studies compared planned, regular interval (six- and 12-monthly) scale and polish treatments versus no scheduled treatment. We found little or no difference between groups over a two- to three-year period for gingivitis, probing depths, oral health-related quality of life (all high-certainty evidence) and plaque (low-certainty evidence). The SMD for gingivitis when comparing six-monthly scale and polish treatment versus no scheduled treatment was $-0.01(95 \% \mathrm{Cl}-0.13$ to 0.11 ; two trials, 1087 participants), and for 12 -monthly scale and polish versus no scheduled treatment was -0.04 ( $95 \% \mathrm{Cl}-0.16$ to 0.08 ; two trials, 1091 participants).

Regular planned scale and polish treatments produced a small reduction in calculus levels over two to three years when compared with no scheduled scale and polish treatments (high-certainty evidence). The SMD for six-monthly scale and polish versus no scheduled treatment was -0.32 ( $95 \% \mathrm{Cl}-0.44$ to -0.20 ; two trials, 1088 participants) and for 12 -monthly scale and polish versus no scheduled treatment was 0.19 (95\% $\mathrm{Cl}-0.31$ to -0.07 ; two trials, 1088 participants). The clinical importance of these small reductions is unclear.

Participants' self-reported levels of oral cleanliness were higher when receiving six-and 12-monthly scale and polish treatments compared to no scheduled treatment, but the certainty of the evidence is low.

\section{Comparison 2: routine scaling and polishing at different recall intervals}

Two studies compared routine six-monthly scale and polish treatments versus 12 -monthly treatments. We found little or no difference between groups over two to three years for the outcomes of gingivitis, probing depths, oral health-related quality of life (all high-certainty evidence) and plaque (low-certainty evidence). The SMD for gingivitis was 0.03 (95\% Cl-0.09 to 0.15; two trials, 1090 participants; $12=0 \%$ ). Six- monthly scale and polish treatments produced a small reduction in calculus levels over a two- to three-year period when compared with 12-monthly treatments (SMD $-0.13(95 \% \mathrm{Cl}-0.25$ to $-0.01 ; 2$ trials, 1086 participants; high-certainty evidence). The clinical importance of this small reduction is unclear.

The comparative effects of six- and 12-monthly scale and polish treatments on patients' self-reported levels of oral cleanliness were uncertain (very low-certainty evidence).

Comparison 3: routine scaling and polishing provided by dentists compared with dental care professionals (dental therapists or hygienists)

No studies evaluated this comparison.

The review findings in relation to costs were uncertain (very low-certainty evidence).

\section{Authors' conclusions}

For adults without severe periodontitis who regularly access routine dental care, routine scale and polish treatment makes little or no difference to gingivitis, probing depths and oral health-related quality of life over two to three years follow-up when compared with no scheduled scale and polish treatments (high-certainty evidence). There may also be little or no difference in plaque levels over two years (low-certainty evidence). Routine scaling and polishing reduces calculus levels compared with no routine scaling and polishing, with sixmonthly treatments reducing calculus more than 12-monthly treatments over two to three years follow-up (high-certainty evidence), although the clinical importance of these small reductions is uncertain. Available evidence on the costs of the treatments is uncertain. The studies did not assess adverse effects.

\section{PLAIN LANGUAGESUMMARY}

Routine scale and polish for periodontal health in adults

Review question 
This review examined evidence for effects of routine scale and polish treatment. It was carried out by authors working with Cochrane Oral Health to assess the effects of routine scale and polish treatments for healthy adults; to establish whether different time intervals between treatments influence these effects; and to compare the effectiveness of the treatment when given by a dentist compared to a dental therapist or hygienist.

This review updates the version published in 2013 and the evidence was up-to-date as of 10 January 2018.

\section{Background}

Scaling and polishing removes deposits such as plaque and calculus (tartar) from tooth surfaces. Over time, the regular removal of these deposits may reduce gingivitis (a mild form of gum disease) and prevent progression to periodontitis (severe gum disease). Routine scale and polish treatment is sometimes referred to as "prophylaxis", "professional mechanical plaque removal" or "periodontal instrumentation".

Many dentists or hygienists provide scaling and polishing for most patients at regular intervals even if the patients are considered to be at low risk of developing gum disease. There is debate about whether scaling and polishing is effective and the best interval between treatments. Scaling is an invasive procedure and has been associated with a number of negative side effects including damage to tooth surfaces and tooth sensitivity.

For the purposes of this review, a 'routine scale and polish' was scaling and polishing of both the tooth and the root of the tooth to remove plaque deposits (mainly bacteria), and calculus. Calculus is so hard it cannot be removed by toothbrushing alone and this along with plaque, other debris and staining on the teeth is removed by the scale and polish treatment. Scaling or removal of hardened deposits is done with specially designed dental instruments or ultrasonic scalers, and polishing is done mechanically with special pastes.

In this review, we included scaling above and below the gum level; however, we excluded any surgical procedure on the gums, any chemical washing of the space between gum and tooth (pocket) and root planing, which is more intense scraping of the root than simple scaling.

\section{Study characteristics}

We included two studies with a total of 1711 participants in our review. Both studies involved adults without severe periodontitis who were regular attenders at dental appointments in the UK. The studies were conducted in general dental practices, which is the most appropriate setting to evaluate 'routine scale and polish' treatments. One study measured outcomes at 24 months and one study at 36 months.

\section{Key results}

The studies found little or no difference between regular planned scale and polish treatments compared with no scheduled scale and polish for the early signs of gum disease (gingivitis or bleeding gums; plaque deposits; and probing depths or gum pockets). There was a small reduction in calculus (tartar) levels, but it was uncertain if this is important for patients or their dentists.

Participants receiving six-monthly and 12-monthly scale and polish treatments reported feeling that their teeth were cleaner than those who were scheduled to receive no treatment. However, there did not seem to be a difference between groups in terms of quality of life.

Available evidence on the costs of the treatments was uncertain.

Neither of the studies measured side effects (such as damage to tooth surfaces and tooth sensitivity), changes in attachment level, tooth loss or halitosis (bad breath). Neither study compared scale and polish treatments provided by different professionals, e.g. dentists, dental therapists and hygienists.

\section{Certainty of the evidence}

We judged the certainty of the evidence to be high for gingivitis, probing depths, calculus and quality of life, but low for plaque, and low to very low for patient perception of oral cleanliness. The certainty of evidence for costs was very low. The high-certainty evidence for gingivitis means that we can be confident that routine scale and polish does not significantly reduce the signs of mild gum disease when measured up to three years. 
S U M MARY OF FINDINGS

Summary of findings for the main comparison. Planned, regular routine scale and polish compared with no scheduled scale and polish treatment for periodontal health

Comparison 1: routine S\&P compared with no scheduled S\&P treatment for periodontal health

Patient: healthy dentate adults without severe periodontitis

Setting: general dental practice

Intervention: 6-monthly routine S\&P treatment (12-monthly results in 'comments' column)

Comparison: no scheduled S\&P treatment

\begin{tabular}{|c|c|c|c|c|c|c|}
\hline \multirow[t]{2}{*}{ Outcomes } & \multicolumn{2}{|c|}{ Illustrative comparative risks } & \multirow{2}{*}{$\begin{array}{l}\text { Relative effect } \\
(95 \% \mathrm{Cl})\end{array}$} & \multirow{2}{*}{$\begin{array}{l}\text { Number of par- } \\
\text { ticipants } \\
\text { (studies) }\end{array}$} & \multirow{2}{*}{$\begin{array}{l}\text { Certainty of } \\
\text { the evidence } \\
\text { (GRADE) }\end{array}$} & \multirow[t]{2}{*}{ Comments } \\
\hline & $\begin{array}{l}\text { Assumed risk } a \\
\text { No scheduled } \\
\text { S\&P }\end{array}$ & $\begin{array}{l}\text { Corresponding } \\
\text { risk } \\
\text { 6-monthly S\&P } \\
(95 \% \mathrm{Cl})\end{array}$ & & & & \\
\hline $\begin{array}{l}\text { Gingivitis } \\
\text { Assessed with different } \\
\text { indices in } 2 \text { studies } \\
\text { Follow-up: } 24-36 \\
\text { months }\end{array}$ & $b$ & $\begin{array}{l}\mathrm{SMD}^{b} 0.01 \text { low- } \\
\text { er } \\
\text { (from } 0.13 \text { low- } \\
\text { er to } 0.11 \text { high- } \\
\text { er) }\end{array}$ & - & $\begin{array}{l}2 \text { studies } \\
\text { (1087 partici- } \\
\text { pants) }\end{array}$ & $\begin{array}{l}\oplus \oplus \oplus \oplus \\
\text { High }\end{array}$ & $\begin{array}{l}\text { There was little or no difference in gingivitis be- } \\
\text { tween } 6 \text {-monthly and no scheduled S\&P treat- } \\
\text { ment. } \\
\text { The results were similar for the comparison be- } \\
\text { tween } 12 \text {-monthly S\&P treatments and no treat- } \\
\text { ment: SMD } 0.04 \text { lower (from } 0.16 \text { lower to } 0.08 \\
\text { higher; } 1091 \text { participants, } 2 \text { studies). }\end{array}$ \\
\hline $\begin{array}{l}\text { Calculus } \\
\text { Assessed with different } \\
\text { indices in } 2 \text { studies } \\
\text { Follow-up: } 24-36 \\
\text { months }\end{array}$ & $b$ & $\begin{array}{l}\mathrm{SMD}^{b} 0.32 \text { low- } \\
\text { er } \\
\text { (from } 0.44 \text { low- } \\
\text { er to } 0.20 \text { lower) }\end{array}$ & - & $\begin{array}{l}2 \text { studies } \\
\text { (1086 partici- } \\
\text { pants) }\end{array}$ & $\begin{array}{l}\oplus \oplus \oplus \oplus \\
\text { High } C\end{array}$ & $\begin{array}{l}\text { 6-monthly S\&P treatments produce a small re- } \\
\text { duction in calculus levels compared to no sched- } \\
\text { uled S\&P treatment. } \\
\text { 12-monthly S\&P treatments also produced a } \\
\text { small reduction in calculus levels compared to } \\
\text { no treatment: SMD } 0.19 \text { lower (from } 0.31 \text { lower to } \\
0.07 \text { lower; } 1088 \text { participants, } 2 \text { studies). }\end{array}$ \\
\hline $\begin{array}{l}\text { Plaque } \\
\text { Assessed with visual } \\
\text { inspection. Record- }\end{array}$ & $\begin{array}{l}\text { Mean } \% \text { of in- } \\
\text { dex teeth with } \\
\text { plaque: } 44 \%\end{array}$ & $\begin{array}{l}\text { MD } 4 \% \text { lower } \\
\text { (from } 13 \% \text { low- } \\
\text { er to } 5 \% \text { higher) }\end{array}$ & $\begin{array}{l}\text { MD }-\mathbf{0 . 0 4} \\
(-0.13 \text { to } 0.05)\end{array}$ & $\begin{array}{l}1 \text { study } \\
\text { (207 partici- } \\
\text { pants) }\end{array}$ & $\begin{array}{l}\oplus \oplus \ominus \ominus \\
\text { Low }^{d}\end{array}$ & $\begin{array}{l}\text { There may be little or no difference in plaque lev- } \\
\text { els between } 6 \text {-monthly and no scheduled S\&P } \\
\text { treatment. }\end{array}$ \\
\hline
\end{tabular}


ed as present or absent on 6 index teeth. Reported as percentage of index teeth with

plaque

Follow-up: 24 months

\section{Probing depths}

Assessed with colour-

coded UNC probe and

reported in $\mathrm{mm}$.

\begin{tabular}{ll|ll}
$\begin{array}{l}\text { Mean probing } \\
\text { depth } 1.9 \mathrm{~mm}\end{array}$ & MD 0 mm & MD 0.00 & $1 \mathrm{~s}$ \\
& $\begin{array}{l}\text { (from 0.04 } \mathrm{mm} \\
\text { lower to } 0.04 \\
\text { mm higher) }\end{array}$ & (-0.04 to 0.04) & (880 \\
& & & pa \\
& & & \\
& & &
\end{tabular}

1 study

$\oplus \oplus \oplus \oplus$

Highe

The results were similar for the comparison between 12-monthly S\&P treatments and no treatment: MD 0\% (from 10\% lower to 9\% higher; 200 participants, 1 study).

Follow-up: 36 months pants)

There was little or no difference in probing depths between 6-monthly and no scheduled S\&P treatment.

The results were similar for the comparison between 12-monthly S\&P treatments and no treatment: MD $0 \mathrm{~mm}$ (from $0.04 \mathrm{~mm}$ lower to $0.04 \mathrm{~mm}$ higher; 890 participants, 1 study).

\begin{tabular}{l|lllll}
\hline Quality of life & Mean score 5.2 & MD 0.3 points & - & 1 study $(795$ & $\oplus \oplus \oplus \oplus \quad$ A difference $<2.0$ points is unlikely to be per-
\end{tabular}

\section{Assessed with OHIP-14}

Scale from: 0 to 56

points, with lower

scores indicating bet-

ter quality of life

Follow-up: 36 months
Participant satisfac-

\section{tion}

\section{Perception of oral}

\section{cleanliness}

Assessed with a nonvalidated scale from 1 to 5 , with a score of 4 or 5 indicating a high level of cleanliness

Follow-up: 36 months

\section{Costs (NHS perspec-}

tive)

Mean cost to NHS per participant
MD 0.3 points lower

(from 1.24 lower to 0.64 high-

er) ceived as important by patients.

There was little or no difference in oral health-related quality of life between 6-monthly and no scheduled S\&P treatment.

The results were similar for the comparison between 12-monthly S\&P treatments and no treatment: MD 0.1 points higher (from 0.83 lower to 1.03 higher; 807 participants, 1 study).

\begin{tabular}{|c|c|c|c|c|c|}
\hline 30 per 100 & $\begin{array}{l}52 \text { per } 100 \\
\text { (37 to } 74 \text { ) }\end{array}$ & $\begin{array}{l}\text { RR } \mathbf{1 . 8 3} \\
\text { (1.28 to } 2.63 \text { ) }\end{array}$ & $\begin{array}{l}1 \text { study (205 } \\
\text { participants) }\end{array}$ & $\begin{array}{l}\oplus \oplus \ominus \ominus \\
\text { Low }^{f}\end{array}$ & $\begin{array}{l}\text { There may be more participants who perceived } \\
\text { their mouth as being very clean when they re- } \\
\text { ceived 6-monthly S\&P treatments compared to } \\
\text { no scheduled S\&P treatment. }\end{array}$ \\
\hline
\end{tabular}

There may also be more participants who perceived their mouth as being very clean when they received 12 -monthly S\&P treatments compared to no scheduled S\&P treatment (RR $1.65,95 \% \mathrm{Cl}$ 1.13 to $2.40 ; 198$ participants, 1 study). 
CI: confidence interval; MD: mean difference; GBP: pound sterling; NHS: National Health Service; OHIP-14: Oral Health Impact Profile-14; RR: risk ratio; S\&P: scale and polish; SMD: standardised mean difference; UNC: University of North Carolina.

\section{GRADE Working Group grades of evidence}

High certainty: we are very confident that the true effect lies close to that of the estimate of the effect.

Moderate certainty: we are moderately confident in the effect estimate; the true effect is likely to be close to the estimate of the effect, but there is a possibility that it is substantially different.

Low certainty: our confidence in the effect estimate is limited; the true effect may be substantially different from the estimate of the effect.

Very low certainty: we have very little confidence in the effect estimate; the true effect is likely to be substantially different from the estimate of effect.

$a$ The outcomes of plaque, probing depths, oral health-related quality of life, participant-reported oral cleanliness and costs were reported in single studies. The assumed risk for these outcomes was the final measurement at follow-up in the control group (no scheduled S\&P treatment) of the relevant study.

$b$ The SMD is used when an outcome has been measured using different scales, indices or units in different studies. It is difficult to interpret clinically, but as a general rule, an SMD $<0.40$ represents a small difference; 0.40 to 0.70 a moderate difference; $>0.70$ a large difference.

c Although we had concerns over the risk of bias in one of the studies included in the meta-analysis, we did not downgrade the quality of the evidence for the gingivitis and calculus outcomes. This study made a relatively small contribution to the pooled (combined) estimates and was assigned a weighting of approximately $19 \%$ in the meta-analyses. In addition, the point estimates from the two studies were similar, the Cls overlapped and the $\mathrm{I}^{2}$ values were $0 \%$. The studies were both conducted in general dental practice, which is the most appropriate setting to answer the questions of this review. Further research is very unlikely to change our confidence in the estimate of effect.

$d$ We downgraded the certainty of evidence by one level due to concerns over the risk of bias related to withdrawals and baseline imbalances in the study groups. We also downgraded by one level for indirectness due to uncertainty over the degree to which an intervention effect on this outcome would reflect an impact on long-term patient important outcomes.

e Outcome reported in one study that was judged to have a low overall risk of bias.

$f$ We downgraded the certainty of evidence by two levels: one level due to concerns over the risk of bias related to withdrawals and baseline imbalances in the study groups and one level due to the use of a non-validated measurement scale.

$g$ We downgraded the certainty of the evidence by three levels: two levels for serious imprecision (due to the very wide confidence interval accompanying the estimate) and one level for indirectness (due to uncertainty over the applicability of the results to settings outside the UK where the resources required or used for S\&P treatments may vary).

\section{Summary of findings 2 . Routine scale and polish at different frequencies for periodontal health}

\section{Comparison 2: 6-monthly S\&P compared with 12-monthly routine S\&P for periodontal health}

Patient: healthy dentate adults without severe periodontitis

Setting: general dental practices

Intervention: 6-monthly routine S\&P

Comparison: $12-$ monthly routine S\&P

$\begin{array}{lll}\text { Outcomes Illustrative comparative risks } & \text { I }\end{array}$




\begin{tabular}{|c|c|c|c|c|c|c|}
\hline & $\begin{array}{l}\text { Assumed risk } a \\
\text { 12-monthly } \\
\text { S\&P }\end{array}$ & $\begin{array}{l}\text { Corresponding } \\
\text { risk } \\
\text { 6-monthly S\&P } \\
(95 \% \mathrm{CI})\end{array}$ & & (studies) & (GRADE) & \\
\hline $\begin{array}{l}\text { Gingivitis } \\
\text { Assessed with different indices } \\
\text { in } 2 \text { studies } \\
\text { Follow-up at } 24-36 \text { months }\end{array}$ & $b$ & $\begin{array}{l}\mathrm{SMD}^{b} 0.03 \text { higher } \\
\text { (from } 0.09 \text { lower } \\
\text { to } 0.15 \text { higher) }\end{array}$ & - & $\begin{array}{l}2 \text { studies } \\
\text { (1090 partici- } \\
\text { pants) }\end{array}$ & $\begin{array}{l}\oplus \oplus \oplus \oplus \\
\text { High } c\end{array}$ & $\begin{array}{l}\text { There was little or no difference in } \\
\text { gingivitis between } 6 \text {-monthly and } 12 \text { - } \\
\text { monthly S\&P treatments. }\end{array}$ \\
\hline $\begin{array}{l}\text { Calculus } \\
\text { Assessed with different indices } \\
\text { in } 2 \text { studies } \\
\text { Follow-up at } 24-36 \text { months }\end{array}$ & $b$ & $\begin{array}{l}\mathrm{SMD}^{b} 0.13 \text { lower } \\
\text { (from } 0.25 \text { lower } \\
\text { to } 0.01 \text { lower) }\end{array}$ & - & $\begin{array}{l}2 \text { studies } \\
\text { (1086 partici- } \\
\text { pants) }\end{array}$ & $\begin{array}{l}\oplus \oplus \oplus \oplus \\
\text { High } c\end{array}$ & $\begin{array}{l}\text { 6-monthly S\&P treatments produced a } \\
\text { small reduction in calculus levels com- } \\
\text { pared to } 12 \text {-monthly treatments. The } \\
\text { clinical significance of this reduction } \\
\text { was unclear. }\end{array}$ \\
\hline $\begin{array}{l}\text { Plaque } \\
\text { Assessed with: visual inspec- } \\
\text { tion. Recorded as present or } \\
\text { absent on } 6 \text { index teeth. Re- } \\
\text { ported as percentage of index } \\
\text { teeth with plaque. } \\
\text { Follow-up: } 24 \text { months }\end{array}$ & $\begin{array}{l}\text { Mean } \% \text { of in- } \\
\text { dex teeth with } \\
\text { plaque: } 43 \%\end{array}$ & $\begin{array}{l}\text { MD } 4 \% \text { lower } \\
\text { (from } 13 \% \text { lower } \\
\text { to } 5 \% \text { higher) }\end{array}$ & - & $\begin{array}{l}1 \text { study } \\
\text { (207 partici- } \\
\text { pants) }\end{array}$ & $\begin{array}{l}\oplus \oplus \ominus \ominus \\
\text { Low } d\end{array}$ & $\begin{array}{l}\text { There may have been little or no dif- } \\
\text { ference in plaque levels between } 6 \text { - } \\
\text { monthly and 12-monthly S\&P treat- } \\
\text { ments. }\end{array}$ \\
\hline $\begin{array}{l}\text { Probing depths } \\
\text { Assessed with: colour-coded } \\
\text { UNC probe and reported in } \\
\text { mm. } \\
\text { Follow-up: } 36 \text { months }\end{array}$ & $\begin{array}{l}\text { Mean probing } \\
\text { depth } 1.9 \mathrm{~mm}\end{array}$ & $\begin{array}{l}\text { MD } 0 \mathrm{~mm} \\
\text { (from } 0.04 \mathrm{~mm} \\
\text { lower to } 0.04 \mathrm{~mm} \\
\text { higher) }\end{array}$ & $\begin{array}{l}\text { MD } 0.00(-0.04 \\
\text { to } 0.04)\end{array}$ & $\begin{array}{l}1 \text { study } \\
\text { (882 partici- } \\
\text { pants) }\end{array}$ & $\begin{array}{l}\oplus \oplus \oplus \oplus \\
\text { Highe }\end{array}$ & $\begin{array}{l}\text { There was little or no difference in } \\
\text { probing depths between } 6 \text {-monthly } \\
\text { and } 12 \text {-monthly S\&P treatments. }\end{array}$ \\
\hline $\begin{array}{l}\text { Quality of life } \\
\text { Assessed with: OHIP-14 } \\
\text { Scale from: } 0 \text { to } 56 \text { points, with } \\
\text { lower scores indicating better } \\
\text { quality of life } \\
\text { Follow-up: } 36 \text { months }\end{array}$ & Mean score 5.3 & $\begin{array}{l}\text { MD } 0.4 \text { points } \\
\text { lower } \\
\text { (from } 1.34 \text { lower } \\
\text { to } 0.54 \text { higher) }\end{array}$ & $\begin{array}{l}\text { MD }-\mathbf{0 . 4 0}(-1.34 \\
\text { to } 0.54)\end{array}$ & $\begin{array}{l}1 \text { study (786 } \\
\text { participants) }\end{array}$ & $\begin{array}{l}\oplus \oplus \oplus \oplus \\
\text { Highe }\end{array}$ & $\begin{array}{l}\text { There was little or no difference in oral } \\
\text { health-related quality of life between } \\
6 \text {-monthly and } 12 \text {-monthly S\&P treat- } \\
\text { ments. } \\
\text { A difference of }<2.0 \text { points is unlike- } \\
\text { ly to be perceived as important by pa- } \\
\text { tients. }\end{array}$ \\
\hline
\end{tabular}




\begin{tabular}{|c|c|c|c|c|c|c|}
\hline $\begin{array}{l}\text { Participant satisfaction } \\
\text { Perception of oral cleanliness } \\
\text { Assessed with: a non-validated } \\
\text { scale from } 1 \text { to } 5 \text {, with a score of } \\
4 \text { or } 5 \text { indicating a high level of } \\
\text { cleanliness } \\
\text { Follow-up: } 36 \text { months }\end{array}$ & 47 per 100 & $\begin{array}{l}52 \text { per } 100 \\
\text { (40 to } 69 \text { ) }\end{array}$ & $\begin{array}{l}\text { RR } \mathbf{1 . 1 1} \text { (0.85 to } \\
1.47)\end{array}$ & $\begin{array}{l}1 \text { study (207 } \\
\text { participants) }\end{array}$ & $\begin{array}{l}\oplus \ominus \ominus \ominus \\
\text { Very low } f\end{array}$ & $\begin{array}{l}\text { It was unclear if there was a difference } \\
\text { in participant-reported high levels of } \\
\text { oral cleanliness between } 6 \text {-monthly } \\
\text { and } 12 \text {-monthly S\&P treatments. } \\
\text { The estimate was imprecise. The mag- } \\
\text { nitude of the difference, if any, was un- } \\
\text { certain. }\end{array}$ \\
\hline $\begin{array}{l}\text { Costs (NHS perspective) } \\
\text { Mean cost to NHS per partici- } \\
\text { pant } \\
\text { Currency: GBP }\end{array}$ & $\begin{array}{l}\text { Mean cost was } \\
81.37 \mathrm{GBP}\end{array}$ & $\begin{array}{l}\text { MD GBP } 7.62 \text { less } \\
\text { (GBP } 28.39 \text { less to } \\
\text { GBP } 13.15 \text { more) }\end{array}$ & & $\begin{array}{l}1 \text { study (556 } \\
\text { participants) }\end{array}$ & $\begin{array}{l}\oplus \ominus \ominus \ominus \\
\text { Very lowg }\end{array}$ & The estimate was very uncertain. \\
\hline
\end{tabular}

CI: confidence interval; MD: mean difference; GBP: pound sterling; NHS: National Health Service; OHIP-14: Oral Health Impact Profile-14; RR: risk ratio; S\&P: scale and polish; SMD: standardised mean difference; UNC: University of North Carolina.

\section{GRADE Working Group grades of evidence}

High certainty: we are very confident that the true effect lies close to that of the estimate of the effect.

Moderate certainty: we are moderately confident in the effect estimate; the true effect is likely to be close to the estimate of the effect, but there is a possibility that it is substantially different.

Low certainty: our confidence in the effect estimate is limited; the true effect may be substantially different from the estimate of the effect.

Very low certainty: we have very little confidence in the effect estimate; the true effect is likely to be substantially different from the estimate of effect.

a The outcomes of plaque, probing depths, oral health-related quality of life, participant-reported oral cleanliness and costs were reported in single studies. The assumed risk for these outcomes is the final measurement at follow-up in the group of study participants assigned to 12-monthly scale and polish treatment in the relevant study.

$b$ The SMD is used when an outcome has been measured using different scales, indices or units in different studies. It is difficult to interpret clinically, but as a general rule, an SMD $<0.40$ represents a small difference; 0.40 to 0.70 a moderate difference; $>0.70$ a large difference.

c Two studies were conducted in general dental practice, the most appropriate setting to answer the questions for this review. Although we had concerns over the risk of bias in one of the studies included in the meta-analysis, we did not downgrade the certainty of the evidence for the gingivitis and calculus outcomes. This study made a relatively small contribution to the pooled (combined) estimates and was assigned a weighting of approximately $19 \%$ in the meta-analyses. In addition, the point estimates from the two studies were similar, the Cls overlapped and the $\mathrm{I}^{2}$ values were $0 \%$.

$d$ We downgraded the certainty of evidence by one level due to concerns over the risk of bias related to withdrawals and baseline imbalances in the study groups. We also downgraded by one level for indirectness due to uncertainty over the degree to which an intervention effect on this outcome would reflect an impact on long-term patient important outcomes.

e Outcome reported in one study that was judged to have a low overall risk of bias.

$f$ We downgraded the certainty of evidence by three levels: two levels due to concerns over the risk of bias related to 1 . withdrawals and baseline imbalances in the study groups and 2. use of a non-validated measurement scale; we also downgraded by one level for imprecision as the $95 \% \mathrm{Cl}$ included no difference between the interventions and an appreciable difference exceeding a minimal important difference.

$g$ We downgraded the certainty of the evidence by three levels: two levels for serious imprecision (due to the very wide confidence interval accompanying the estimate) and one level for indirectness (due to uncertainty over the applicability of the results to settings outside the UK where the resources required or used for S\&P treatments may vary). 
Summary of findings 3. Routine scale and polish undertaken by dentist or dental care professional for periodontal health

Comparison 3: routine scale and polish undertaken by dentist or dental care professional for periodontal health

Patient: healthy dentate adults

Setting: general dental practice

Intervention: routine scale and polish by dentist

Comparison: routine scale and polish by dental care professional

\begin{tabular}{llll}
\hline Outcomes & $\begin{array}{l}\text { Relative effect } \\
(95 \% \mathrm{Cl})\end{array}$ & $\begin{array}{l}\text { Number of participants } \\
\text { (studies) }\end{array}$ & $\begin{array}{l}\text { Certainty of the evidence } \\
\text { (GRADE) }\end{array}$ \\
\hline Gingivitis & No studies & \\
\hline Calculus & No studies & \\
\hline Plaque & No studies \\
\hline Probing depth & No studies \\
\hline Quality of life & No studies \\
\hline Participant satisfaction & No studies \\
\hline Costs (NHS perspective) & No studies \\
\hline
\end{tabular}

\section{GRADE Working Group grades of evidence}

High certainty: we are very confident that the true effect lies close to that of the estimate of the effect.

Moderate certainty: we are moderately confident in the effect estimate; the true effect is likely to be close to the estimate of the effect, but there is a possibility that it is substantially different.

Low certainty: our confidence in the effect estimate is limited; the true effect may be substantially different from the estimate of the effect.

Very low certainty: we have very little confidence in the effect estimate; the true effect is likely to be substantially different from the estimate of effect. 


\section{B A C K G R O U N D}

\section{Description of the condition}

'Periodontal (gum) disease' is a broad term that encompasses a cluster of diseases that result in inflammatory responses and chronic destruction of the tissues that surround and support the teeth, namely the gingiva, periodontal ligament, cementum and alveolar bone (collectively referred to as the 'periodontium'). The diseases can be reversible (gingivitis) or can cause irreversible destruction of tissues (periodontitis).

Dental plaque is the principal aetiological factor in the pathogenesis of the most prevalent forms of periodontal disease (Lang 2009). Plaque is necessary but is not sufficient for periodontal disease to occur. The host response, the modifying effect of various risk factors and the bacterial attack from dental plaque can account for a variety of disease patterns, both between different people and between different sites in the mouth within the same person. Calcified plaque (calculus) does not have a major role in the pathogenesis of periodontal disease, although it does act as a 'retention web' for bacteria (Ismail 1994), and reduces the effectiveness of personal oral hygiene control.

Gingivitis is a reversible disease and can be defined as the presence of gingival bleeding on probing (where the gum bleeds on touch) without loss of connective tissue attachment. Gingivitis is a precursor to periodontitis in some people, that is, gingivitis does not inevitably progress to periodontitis. Periodontitis can be defined as the presence of gingival inflammation at sites where there has been a pathological loss of attachment and bone (AAP 2015). This loss of attachment contributes to pocket formation and the cementum may become contaminated by micro-organisms and their products (Jenkins 2003).

Our improved understanding of the causes and development of periodontal disease led the American Academy of Periodontology (AAP) and the European Federation of Periodontology (EFP) to update classification scheme for periodontal and peri-implant diseases and conditions in 2018 (Caton 2018). This new framework also allows the destructive irreversible periodontal disease to be further classified on stage (severity) and grade (risk of progression).

Epidemiological studies of periodontal diseases are difficult to interpret due to the diversity of measures used to describe and quantify disease and the absence of uniform definition and classification. This is reflected in the World Health Organization Global Data Bank estimates (WHO 2004), which state that the prevalence of moderate-severity disease ranges from $2 \%$ to $67 \%$ and that advanced disease occurs in $1 \%$ to $79 \%$ of the population. Gingivitis is highly prevalent in most populations and at most ages (Albandar 2002; Corbet 2002; Sheiham 1986), with global values ranging from $50 \%$ to $90 \%$. In the UK, the 2009 Adult Dental Health Survey reported that $45 \%$ of dentate adults had some periodontal pocketing of $4 \mathrm{~mm}$ or more and $8 \%$ had deep pocketing (of $6 \mathrm{~mm}$ or more), and that $66 \%$ of adults aged 55 years and over had some loss of attachment of $4 \mathrm{~mm}$ or more and $21 \%$ had loss of attachment of $6 \mathrm{~mm}$ or more (White 2011). The prevalence of pocketing and loss of attachment increased with age. For example, the proportion of dentate adults with some loss of attachment increased from $61 \%$ among people aged 16 to 24 years to $76 \%$ among people aged 75 to 84 years. The Global Burden of Diseases study of 2010 estimated that the global age-standardised prevalence of severe periodontitis was $10.8 \%$ or 743 million people worldwide (Kassebaum 2014).

The goals of periodontal therapy have been defined in many different ways. Some authors have defined the ultimate aim of periodontal treatment as being to control disease progression or achieve a rate of progression which is compatible with a functional dentition for the person's lifetime (Pilot 1980; Sheiham 2002; Wennstrom 1990). Other authors have defined the key goals as improving periodontal health and thereby satisfying a person's aesthetic and functional needs or demands. Currently accepted clinical signs of a healthy periodontium include the absence of inflammatory signs of disease such as redness, swelling, suppuration and bleeding on probing; maintenance of a functional periodontal attachment level; minimal or no recession in the absence of interproximal bone loss and, where present, functional dental implants (AAP 2001).

A fundamental component of the preventive management of periodontal disease is the control of dental plaque by the patient. Hence, patient education and training in personal oral hygiene should form an integral part of any treatment plan for a person with periodontal disease. Conventional periodontal therapy also includes non-surgical treatment and a variety of surgical approaches (Mailoa 2015; Needleman 2002; Tonetti 2014). The precise choice of intervention may be influenced by the clinical severity of the disease, with surgery generally reserved for cases of advanced disease to allow for adequate access to, and full debridement of, areas with deep pocketing.

\section{Description of the intervention}

Scaling and polishing of the teeth by a dentist or a dental care professional (DCP) (dental therapist or dental hygienist), also known as prophylaxis, professional mechanical plaque removal or periodontal instrumentation, is a non-surgical intervention that is intended to supplement (and is not a substitute for) the patient's home-care plaque control. This treatment is frequently provided as part of the dental recall appointment (Riley 2013). Scaling is the removal of plaque, mineralised plaque deposits (also referred to as calculus or tartar), debris and staining from the crown and root surfaces of the teeth. Specially designed sharp dental instruments ('hand scalers and curettes') or ultrasonic scalers can be used to perform the scaling procedure. Polishing is the mechanical removal of any residual extrinsic stains and deposits, typically undertaken by using a rubber cup or bristle brush loaded with a prophylaxis paste. Scaling and polishing can be used with or without a variety of adjuncts such as antimicrobial agents (either topical or systemic), gingival crevice irrigation and root planing. Root planing is a procedure for smoothening the root surface of a tooth that involves the "removal of cementum or surface dentin that is rough or impregnated with calculus, toxins or microorganisms" (Greenstein 1992). The rationale for root planing is to allow the gingival tissue to heal close to the root, shrinking the tissue and reducing the depth of the pocket that has formed (Bonito 2004).

Within the confines of this updated Cochrane Review a 'routine scale and polish' (S\&P) is defined as scaling or polishing (or both) of the crown and root surfaces of teeth to remove local irritational factors (plaque, calculus, debris and staining), that does not involve periodontal surgery or any form of adjunctive periodontal therapy such as the use of chemotherapeutic agents or root planing. The definition includes both supragingival and subgingival scaling. The 
use of the term 'routine' is intended to highlight two important features of the intervention considered in this review. First, 'routine' indicates that the review focuses on S\&P treatment as it is routinely delivered in everyday general dental practice settings (i.e. the review is concerned with evaluating the effects of S\&P treatments in 'real-world' primary care settings). Second, the term 'routine' indicates that the S\&P is "a regular course or procedure" (Oxford Dictionary 1995), that is, the S\&P is an intervention that is typically provided at 'regular intervals' to patients, but without specifying any one particular frequency (e.g. every six months, every 12 months) at which patients may receive this intervention. In this context, a key objective of this review is to evaluate the effects on periodontal health of providing S\&P treatments at different recall intervals in primary care settings.

\section{How the intervention might work}

Scaling and polishing of the teeth removes local irritational factors (plaque, calculus, debris and staining). The removal of these irritants at regular intervals may reduce the occurrence of gingivitis and, over time, may prevent progression to periodontitis or reduce the rate of progression of periodontitis.

\section{Why it is important to do this review}

Cochrane Oral Health undertook an extensive prioritisation exercise in 2014 to identify a core portfolio of titles that were the most clinically important ones to maintain on the Cochrane Library (Worthington 2015). This review was identified as a priority title by the periodontal expert panel (Cochrane Oral Health priority review portfolio).

Scaling and polishing of the teeth is a commonly provided intervention in general dental practice, with significant cost implications. In the UK, approximately $46 \%$ of all adult courses of treatment provided under the National Health Service (NHS) (General Dental Services) regulations "consist of the patient having nothing more than an examination (and a) scale and polish" (DoH 2000). In 2016/2017, 2.3 million S\&P courses of treatment were provided for NHS patients in Scotland at a gross cost to the NHS of GBP 33.2 million (Primary Care Dentistry in Scotland 2017), and in England, 13.1 million S\&P courses of treatment were provided for NHS patients (NHS Dental Statistics for England 2017).

Scaling and polishing is also frequently provided for patients irrespective of their risk of developing periodontal disease. In a survey of general dental practitioners' preventive recommendations in western New York State, $86 \%$ of respondents stated that they would recommend scaling and polishing every six months for 'low-risk' patients of all ages (a 'low risk' patient was defined as a people having "adequate brushing and flossing habits" and "no history of periodontal disease") (Frame 2000).

There is ongoing debate over the clinical effectiveness and cost effectiveness of routine scaling and polishing of teeth and how often it should be provided. This debate is complicated by the fact that a 'routine S\&P' is not a precisely defined intervention in periodontal disease management and there is no universally accepted definition of the term. In the USA, the term 'oral prophylaxis' is most often used and has been defined as "the removal of plaque, calculus and stain from exposed and unexposed surfaces of the teeth by scaling and polishing as a preventive measure for the control of local irritational factors" (AAP 1992). We have clearly defined the term routine S\&P used within this review in the Description of the intervention section.

The role and contribution of DCPs (dental hygienists and dental therapists) in maintaining periodontal health has increased in recent years. Any differences in treatment outcome following intervention by a dentist or DCP are not well understood and require investigation.

This review updates previous versions (Beirne 2005; Beirne 2007; Worthington 2013). Since the first version of this review was published (Beirne 2005), the evidence base has developed considerably. We have made appropriate amendments to the initial review objectives and the eligibility criteria to ensure that the review continues to provide the most relevant evidence for dentists working in primary care and patients attending for treatment in general dental practice. We have provided a detailed justification for these amendments in the Differences between protocol and review. We have also provided an updated explanation of the term 'routine S\&P' in the Description of the intervention section.

\section{O B JECTIVES}

1. To determine the beneficial and harmful effects of routine scaling and polishing for periodontal health.

2. To determine the beneficial and harmful effects of routine scaling and polishing at different recall intervals for periodontal health.

3. To determine the beneficial and harmful effects of routine scaling and polishing for periodontal health when the treatment is provided by dentists compared with dental care professionals (dental therapists or dental hygienists).

\section{METHODS}

\section{Criteria for considering studies for this review}

\section{Types of studies}

We included randomised controlled trials (RCTs) with at least six months' follow-up. We excluded split-mouth studies as this design does not reflect the manner in which a routine S\&P is delivered in practice.

\section{Types of participants}

We included studies involving dentate adults regularly attending for dental care in primary care settings. We excluded trials where participants were described as having severe periodontal disease (e.g. alveolar bone loss involving most teeth, or people requiring referral for specialist (surgical) periodontal treatment). We also excluded trials where participants had previously undergone specialist periodontal treatment and were in the post-treatment 'maintenance phase'.

\section{Types of interventions}

A "routine scale and polish (S\&P) treatment" is defined in the Description of the intervention section of the review. We included trials where routine S\&P treatments with or without oral hygiene instruction were provided by a dentist, dental hygienist or therapist and that made one or more of the following comparisons.

- Comparison 1: S\&P treatment at a planned, regular interval (e.g. every six months, every 12 months) versus no scheduled S\&P treatment for the duration of the trial. 
- Comparison 2: S\&P treatment at a planned, regular interval (e.g. every six months) versus S\&P treatment at a different planned, regular interval (e.g. every 12 months).

- Comparison 3: S\&P treatment provided by a dentist at a planned, regular interval (e.g. every six months) versus S\&P treatment provided by a dental hygienist or dental therapist at the same planned, regular interval.

\section{Types of outcome measures}

We included trials reporting clinical status, participant-centred outcomes and cost outcomes.

\section{Primary outcomes}

- Periodontal disease, assessed by gingivitis indices (both inflammatory and bleeding on probing).

\section{Secondary outcomes}

\section{Clinical status factors}

- Calculus and plaque indices.

- Changes in probing depths.

- Changes in attachment level.

- Periodontal indices.

- Tooth loss.

- Adverse events.

\section{Participant-centred factors}

- Halitosis.

- Participant satisfaction; for example, with oral comfort, oral cleanliness, appearance (including gingival recession), care received and provider of care (i.e. dentist, therapist or hygienist).

- Oral-health related quality of life.

\section{Economic cost factors}

- Costs of S\&P.

\section{Search methods for identification of studies}

\section{Electronic searches}

Cochrane Oral Health's Information Specialist conducted systematic searches in the following databases for RCTs and controlled clinical trials. There were no language, publication year or publication status restrictions.

- Cochrane Oral Health's Trials Register (searched 10 January 2018; Appendix 1);

- Cochrane Central Register of Controlled Trials (CENTRAL; 2017, Issue 12) in the Cochrane Library (searched 10 January 2018; Appendix 2);

- MEDLINE Ovid (1946 to 10 January 2018) (Appendix 3);

- Embase Ovid (1980 to 10 January 2018) (Appendix 4).

Subject strategies were modelled on the search strategy designed for MEDLINE Ovid. Where appropriate, they were combined with subject strategy adaptations of the highly sensitive search strategy designed by Cochrane for identifying RCTs and controlled clinical trials as described in the Cochrane Handbook for Systematic Reviews of Interventions (Lefebvre 2011).

\section{Searching other resources}

The following trial registries were searched for ongoing studies on 10 January 2018:

- US National Institutes of Health Ongoing Trials Register ClinicalTrials.gov (clinicaltrials.gov; Appendix 5);

- World Health Organization International Clinical Trials Registry Platform (apps.who.int/trialsearch; Appendix 6).

We checked the reference lists of related review articles and all articles obtained for further trials. We contacted the author(s) of some eligible studies and any researchers involved in the ongoing debate on scale and polish recall intervals, where possible and when considered necessary, to obtain the information on additional published or unpublished studies possibly eligible for inclusion.

We did not perform a separate search for adverse effects of interventions used; we considered adverse effects described in included studies only.

\section{Data collection and analysis}

\section{Selection of studies}

Two review authors independently assessed titles, keywords and abstracts. The review authors remained unblinded regarding the author(s), institutional affiliations and site of publication of reports. The search was sensitive and included controlled clinical trials; these were filtered out early in the selection process if they were not randomised. We obtained the full report for all studies appearing to meet the inclusion criteria or in instances where there was insufficient information from the title, keywords and abstract to make a clear decision. At least two review authors independently assessed potentially relevant studies for eligibility. Instances of disagreement in the study selection process were referred to the other members of the review team and ultimately resolved by mutual discussion among all review team members. We recorded studies rejected at this or subsequent stages in the Characteristics of excluded studies table, and noted reasons for exclusion. We assessed all studies meeting the inclusion criteria for risk of bias and extracted data.

\section{Data extraction and management}

One or two review authors extracted data using a piloted data extraction form. We recorded the following data.

- Study design, location, funding, number of centres.

- Inclusion and exclusion criteria, number of participants recruited, number of participants randomised to each group, number of participants withdrawn, numbers evaluated.

- Intervention(s), comparator, provider characteristics (dentist, hygienist, dental therapist or other), diagnostic criteria and diagnostic thresholds used.

- Primary and secondary outcomes, times measured, numbers of participants included in the outcome evaluation, costs.

- Whether a sample size calculation was performed.

We entered information into the Characteristics of included studies table and an Excel spreadsheet from which a summary of the characteristics of the studies was made. Where the published paper was unclear concerning aspects of trial design, we attempted to 
contact the study authors for clarification or more information, or both.

\section{Assessment of risk of bias in included studies}

We conducted risk of bias assessment using the recommended Cochrane approach (Higgins 2011). We used the two-part tool, addressing six specific domains (sequence generation, allocation concealment, blinding of outcome assessment, incomplete outcome data, selective outcome reporting and other bias). Each domain included one specific entry in the 'Risk of bias' table. Within each study, the first part of the tool involved describing what was reported to have happened in the study. The second part of the tool involved assigning a judgement relating to the risk of bias for that entry. This was achieved by answering a prespecified question about the adequacy of the study in relation to the entry, such that a judgement of 'low' indicated low risk of bias, 'high' indicated high risk of bias, and 'unclear' indicated unclear or unknown risk of bias.

The domains of sequence generation, allocation concealment, incomplete outcome data, selective outcome reporting and other sources of bias were each addressed in the tool by a single entry for each study. It was not possible to blind participants to which S\&P intervention they were receiving. We did not consider participant or care provider knowledge of the assigned recall interval between scale and polish treatments as a risk of bias domain in this review. We explain the rationale underpinning this decision below.

As described in the Description of the intervention section, this review focuses on S\&P treatments "routinely delivered in everyday general dental practice settings". Delivery of S\&P and the alteration of the recall interval between such treatments can be considered as a complex intervention that may involve a number of separate but interacting components that can impact on clinical outcomes in unpredictable ways. For example, a component of many complex healthcare interventions is the "therapeutic relationship" or "patient-practitioner interaction" (Foster 2012). Reducing the frequency of such interactions by lengthening the recall interval between scale and polish treatments might be anticipated to have a detrimental impact on oral health outcomes. However, any negative impact could potentially be countered by other plausible changes in patient or provider behaviour. For example, those attending less frequently may adopt more intensive personal oral hygiene practices or may seek additional (private) scale and polish treatments to reduce the risk of a deterioration in oral health. In addition, dental care providers may (consciously or unconsciously) engage in greater advocacy of oral hygiene measures or provide more stringent than usual periodontal instrumentation to patients attending less frequently. In RCTs that seek to estimate complex intervention effects in real world settings, any such changes in patient and provider behaviour should be regarded as integral components of the complex intervention and not as forms of performance bias per se, i.e. behaviour changes should be incorporated into estimates of effectiveness, thereby rendering the findings more applicable to usual care settings. We therefore did not consider participant or care provider knowledge of the assigned recall interval between scale and polish treatments as a risk of bias issue in this review. Our decision also took into account contemporary debates around blinding in pragmatic RCTs that aim to evaluate 'real world' effects of interventions. It has been argued that blinding in such trials may neither be feasible nor desirable (Mansournia 2017), and furthermore, that pragmatism is heavily compromised by blinding (Dal-Ré 2018). In accordance with recommendations specified in the CONSORT extension for pragmatic trials, we considered blinding of outcome assessors as a risk of bias issue because "in pragmatic trials it is still desirable and often possible to blind the assessor or obtain an objective source of data for evaluation of outcomes" (Zwarenstein 2008). Where outcomes were assessed by participants, we noted this in the review.

For trials involving cluster randomisation, we also assessed the risk of the following biases, as recommended in Section 16.3.2 of the Cochrane Handbook for Systematic Reviews of Interventions (Higgins 2011): recruitment bias; baseline imbalance; loss of clusters; incorrect analysis (unit of analysis errors) and comparability with individually randomised trials.

Two review authors, independently and in duplicate, assessed the risk of bias in one study as part of the data extraction process. The other study was assessed by the author (PB) who had not been involved in its conduct.

After taking into account any additional information provided by the authors of the trials, we grouped studies into the following categories.

- Low risk of bias (plausible bias unlikely to seriously alter the results) for all key domains.

- Unclear risk of bias (plausible bias that raised some doubt about the results) if one or more key domains were assessed as unclear.

- High risk of bias (plausible bias that seriously weakened confidence in the results) if one or more key domains were assessed to be at high risk of bias.

We completed a 'Risk of bias' table for each included study and presented the results graphically.

\section{Measures of treatment effect}

For continuous outcomes, we used mean differences (MD) and standard deviations to summarise the data for each group (we used standardised mean differences (SMD) were studies used when different scales that measuring the same concept) with $95 \%$ confidence intervals ( $\mathrm{Cl})$. We interpreted SMD effect sizes using the following "rule of thumb" as outlined in Section 12.6.2 of the Cochrane Handbook for Systematic Reviews of Interventions (Higgins 2011: less than $0.40=$ small; 0.40 to $0.70=$ moderate; greater than $0.70=$ large). For dichotomous outcomes, we expressed the estimates of effect as risk ratios (RR) together with $95 \% \mathrm{Cls}$.

\section{Unit of analysis issues}

We used standard methodological procedures expected by Cochrane when incorporating the results from cluster-randomised trials and individually randomised trials in the same meta-analysis, as outlined in Chapter 16 of the Cochrane Handbook for Systematic Reviews of Interventions (Higgins 2011).

\section{Dealing with missing data}

Where data were missing from the published report of a trial, we attempted to contact the author(s) to obtain the data and clarify any uncertainty over the reasons for missing data. The analysis generally included only the available data (ignoring missing data); however, we planned to use methods for estimating missing standard deviations as described in Section 7.7.3 of the Cochrane 
Handbook for Systematic Reviews of Interventions if necessary (Higgins 2011). Otherwise, we did not intend to undertake any imputations or to use statistical methods to allow for missing data.

\section{Assessment of heterogeneity}

We planned to assess heterogeneity by inspection of the point estimates and $\mathrm{Cls}$ on the forest plots. We assessed the variation in treatment effects by means of Cochrane's test for heterogeneity and quantified by the 12 statistic. Heterogeneity was considered statistically significant at $\mathrm{P}$ less than 0.1 . An approximate guide to the interpretation of the $\mathrm{I}^{2}$ statistic given in the Cochrane Handbook for Systematic Reviews of Interventions was: $0 \%$ to $40 \%$ might not be important, $30 \%$ to $60 \%$ might represent moderate heterogeneity, $50 \%$ to $90 \%$ might represent substantial heterogeneity and $75 \%$ to $100 \%$ represents considerable heterogeneity (Higgins 2011).

\section{Assessment of reporting biases}

If there had been sufficient numbers of trials (more than 10) in any meta-analysis, we would have assessed publication bias according to the recommendations on testing for funnel plot asymmetry (Egger 1997), as described in the Cochrane Handbook for Systematic Reviews of Interventions (Higgins 2011). If asymmetry had been identified, we would have examined possible causes.

\section{Data synthesis}

We conducted meta-analysis only when there were studies of similar comparisons reporting the same outcome measures. We used a fixed-effect model as we combined data from only two studies, with one study providing most of the data. Furthermore, both studies were conducted in similar settings and involved similar populations and there was no reason to assume that the intervention effect would vary between studies. We therefore deemed it appropriate to use the fixed-effect model, which assumes that there is one true effect size shared by the included studies.

\section{Subgroup analysis and investigation of heterogeneity}

We planned to investigate clinical heterogeneity. Providing there were sufficient studies (at least 10) of each intervention and outcome, we planned a priori to conduct subgroup analyses for age, sex, smoking status, oral cleanliness and degree of periodontal disease at baseline and different groups of systemically compromised adults.

\section{Sensitivity analysis}

Provided there were sufficient studies for each outcome and intervention, we planned to undertake sensitivity analysis to investigate the impact on results of including in analyses only those trials judged to have a low overall risk of bias.

\section{'Summary of findings' tables and methods used to assess the certainty of evidence}

We produced a 'Summary of findings' table for each comparison using the GRADEpro GDT online tool (www.guidelinedevelopment.org). We included the following outcomes: gingivitis, calculus and plaque, probing depths, participant satisfaction, quality of life, and cost and resource use. We assessed the certainty of the body of evidence in relation to each comparison and outcome using the evidence grading system developed by the GRADE collaboration (Schünemann 2009). We took the following factors into account when deciding whether or not to downgrade the certainty of evidence in relation to each outcome.

\section{Risk of bias}

The procedure used to assess the risk of bias is described in Assessment of risk of bias in included studies. We planned to downgrade the certainty of evidence by one level if we judged that there was a plausible source of bias that raised some doubt about the results and reduced our confidence in an effect estimate. We planned to downgrade the certainty of evidence by two levels if we judged that there was a crucial risk of bias that seriously weakened our confidence in an effect estimate. Where trials with differing overall risk of bias judgements were combined in meta-analyses (e.g. meta-analyses of trials with low overall risk of bias and trials of unclear or high risk of bias), our judgements about whether or not to downgrade the evidence took into account the degree to which each trial contributed to the pooled effect size.

\section{Inconsistency}

We assessed inconsistency by examining: any variations between the point estimates reported in included trials; the degree of overlap of the $\mathrm{Cls}$ accompanying effect estimates; and the results of any statistical tests for heterogeneity in meta-analyses and the value of the 12 statistic (which describes the percentage of total variation across studies that is due to heterogeneity rather than chance). We planned to downgrade the certainty of evidence if inconsistency was large and unexplained, particularly if there were some trials suggesting substantial benefit and others indicating no effect or harm. For outcomes reported in only a single trial, we judged that inconsistency was not applicable and we did not downgrade the certainty of evidence.

\section{Imprecision}

We assessed imprecision by considering the numbers of participants included in analyses and the $\mathrm{Cls}$ around effect estimates. We planned to downgrade for imprecision where the $\mathrm{Cl}$ accompanying an effect estimate included little or no effect and appreciable benefit or appreciable harm. For dichotomous outcomes, we used the suggested GRADE threshold for appreciable benefit or appreciable harm of a relative risk reduction or a relative risk increase greater than $25 \%$. For continuous outcomes, the use of minimal important differences (MIDs) as decision thresholds for appreciable benefit or harm is desirable. Reported MIDs for oral health-related quality of life measured using the Oral Health Impact Profile-14 (OHIP-14) depend on population and the type of treatment received and have varied from five scale points (in elderly people undergoing routine dental treatment) (Locker 2004), to two points in people undergoing prosthodontic treatment (Bassetti 2016). In this updated review, we used a conservative two-point difference as the MID (approximately 3.5\% of the scale range of 56 points). There is no general consensus on the MIDs for many of the other continuous outcomes reported in this review. Therefore, we considered downgrading for imprecision of these outcomes if the $\mathrm{Cl}$ for a point estimate included little or no effect and if the upper or lower confidence limits crossed an effect size (SMD) of 0.5 in either direction, as suggested by Ryan 2016.

\section{Indirectness}

We assessed indirectness by considering: 
- populations (i.e. differences between the characteristics of trial participants and the population of interest in the review);

- interventions (i.e. differences between the intervention or manner of intervention delivery in trials (including rigour, intensity of delivery and delivery setting) and the intervention as defined in the review);

- comparisons (i.e. the absence of direct 'head-to-head' comparisons between two or more interventions of interest);

- outcomes (i.e. the use of surrogate endpoints in place of participant-important outcomes).

Taking these assessments into account, we judged the degree to which the evidence we found directly answered the review question and addressed the review objectives. We planned to downgrade by one level if we judged that some indirectness existed or by two levels if we deemed indirectness to be severe or if there were several of sources of indirectness.

\section{Publication bias}

We assessed publication bias by considering the size of the included studies and the number of included events. We planned to conduct tests for funnel plot asymmetry if at least 10 trials were included in a meta-analysis (Sterne 2011). However, only two trials were included in our review and therefore no funnel plot was constructed. We planned to downgrade the certainty of evidence by a maximum of one level only if publication bias was strongly suspected. We planned not to downgrade if publication bias was either undetected or was deemed unlikely to have occurred based on our search strategy.

\section{RES U L T S}

\section{Description of studies}

\section{Results of the search}

The updated literature search resulted in 1002 records following deduplication. Two review authors independently screened the titles and abstracts against the inclusion criteria, and found 1001 records ineligible. The remaining record was the study protocol for the Ramsay 2018 trial, which was subsequently published. We obtained a full-text copy of the paper and the trial authors also provided unpublished data. This process is illustrated in Figure 1.

\section{Figure 1. Study flow diagram}

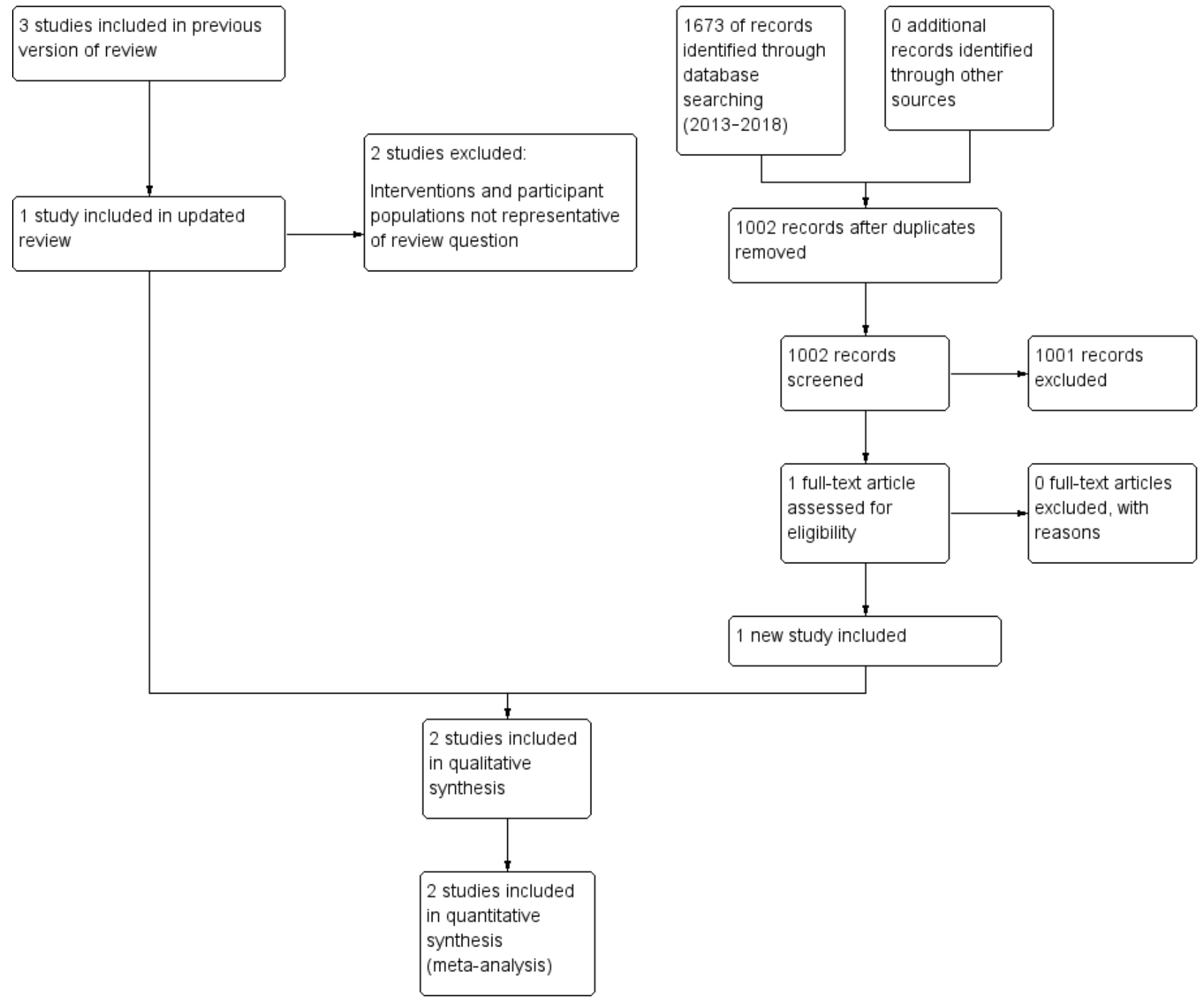


The previous edition of this review (Worthington 2013) included three studies (Jones 2011; Lightner 1971; Listgarten 1985). We excluded two of these studies as they were not representative of the intervention being assessed in this review as they were not delivered in general dental practice (Lightner 1971; Listgarten 1985).

\section{Included studies}

Following detailed assessment of all of the potentially relevant papers, we judged three papers reporting two studies to have satisfied the eligibility criteria for the review (Jones 2011; Ramsay 2018). See Characteristics of included studies table for further details.

\section{Trial settings and investigators}

Both studies were conducted in general dental practice setting in the UK (Jones 2011; Ramsay 2018).

Ramsay 2018 provided treatment according to the routine protocol of the dental practices, which included dentists, hygienists and therapists and Jones 2011 used a pool of nine therapists and hygienists.

Both trials blinded outcome assessment, by dentists, hygienists and therapists in Ramsay 2018 and by dentists in Jones 2011.

The National Institute for Health Research Health Technology Assessment funded the Ramsay 2018 study. A university provided a grant for Jones 2011.

\section{Participants}

Ramsay 2018 included 1406 participants and Jones 2011 included 305 participants in the analyses, giving a total of 1711 participants in this review. Participants were adults aged 18 to 92 years in Ramsay 2018 and aged 18 to 73 years in Jones 2011.

Ramsay 2018 enrolled people with Basic Periodontal Examination (BPE) scores of three or less, attending general dental practices across Scotland and the North-East of England. Jones 2011 enrolled people attending one of three general dental practices for checkup appointments. This study only included people with calculus or bleeding on probing and no pockets greater than $3.5 \mathrm{~mm}$.

\section{Interventions}

Details of the interventions provided in the included trials are presented in the Characteristics of included studies.

Comparison 1: scale and polish treatment at a planned, regular interval (e.g. every six months, every 12 months) versus no scheduled scale and polish treatment for the duration of the trial

In Ramsay 2018, participants received a S\&P at baseline, and then were randomly allocated to be scheduled to receive S\&P treatment every six months, every 12 months or no further S\&P treatment during the study period (three years). The study recorded the number of S\&P treatments delivered to participants through routine data and participant-reported questionnaire data. There was a difference in the number of S\&P treatments in each randomised group: the no scheduled S\&P treatment group had on average one S\&P throughout the trial; the 12-monthly group had two S\&P treatments; and the six-monthly group had three S\&P treatments throughout the duration of the three-year trial.

In Jones 2011, all participants received a S\&P at baseline, and then were randomly allocated to a further S\&P every six months, every 12 months or no further S\&P during the study period (two years).

Comparison 2: scale and polish treatment at a planned, regular interval (e.g. every six months) versus scale and polish treatment at a different planned, regular interval (e.g. every 12 months)

Both studies provided data for the comparison of S\&P at different fixed intervals (six-monthly and 12-monthly).

Comparison 3: scale and polish treatment provided by a dentist at a planned, regular interval versus scale and polish treatment provided by a dental hygienist or dental therapist at the same planned, regular interval

We found no studies for this comparison.

\section{Outcomes}

We have presented details of the different indices used in each individual trial to record the outcomes in Table 1.

Details of the outcomes recorded in both studies, the time points when measured and the frequency of provision of S\&P are presented in Table 2 for Comparison 1 (S\&P versus no S\&P) and in Table 3 for Comparison 2 (S\&P versus S\&P at a different interval).

One of the trials included in the review randomised at the individual level only (Jones 2011). The second trial was a split-plot, multicentre, multilevel factorial trial that employed a combination of cluster and individual participant randomisation: dental practices were cluster randomised to routine or personalised oral hygiene advice $(\mathrm{OHA})$ and individual participants within practices were randomised to S\&P treatments at different recall intervals (Ramsay 2018). There was no significant interaction effect between the OHA and S\&P interventions. In the absence of interaction, and taking into account the fact that the participant populations were similar in the two trials, there was no reason to suspect that there would be substantive differences in effect sizes estimated in Ramsay 2018 and effect sizes estimated in Jones 2011. Therefore, we considered it appropriate to combine the results of the two trials in instances where they reported the same or similar outcomes.

\section{Primary outcome}

\section{Gingivitis indices (inflammatory and bleeding)}

Both studies used gingivitis/gingival bleeding as an outcome measured at the following data points:

- 24 months recorded according to a dichotomous scale for each tooth: present/not present (Jones 2011);

- 36 months calculated by adding all the sites where bleeding was observed and dividing it by the number of sites (twice the number of teeth) and presented as a percentage (Ramsay 2018).

Secondary outcomes

Clinical status factors

Calculus 
- Ramsay 2018 calculated the calculus scores at 36 months by adding all the sites where calculus was observed and dividing by the number of teeth and presented it as a percentage.

- Jones 2011 calculated the mean calculus scores at 24 months from one measurement in millimetres confined to the lingual surfaces of the mandibular incisor and canine teeth.

Plaque

- Jones 2011 measured the visual presence of plaque (dichotomous) at 24 months.

Changes in probing depths

- Ramsay 2018 reported changes in probing depths measured at 36 months.

Changes in attachment level

- Neither study reported changes in attachment level.

Periodontal indices

- Neither study reported periodontal indices.

Tooth loss

- Neither study reported tooth loss.

Adverse events

- Neither study reported adverse effects.

\section{Patient-centred factors}

Halitosis

- Neither study reported halitosis.

Participant satisfaction

Jones 2011 used a five-point non-validated scale to evaluate participant perception of oral cleanliness.

Quality of life

Both studies measured some participant-reported factors. Ramsay 2018 measured oral health-related quality of life using the OHIP-14, a 14-item self-report questionnaire about oral health symptoms experienced in the past 12 months.

\section{Economic cost factors.}

Only one study reported economic cost outcomes (Ramsay 2018). The primary economic evaluation in Ramsay 2018 was a costbenefit analysis (CBA), where the cost component consisted of costs to the UK NHS and participant costs and the benefit component was comprised of a willingness to pay (WTP) estimation derived from a discrete choice experiment (DCE). In this review, we only considered costs to the UK NHS measured in pounds sterling (GBP). This decision took into account the following factors: firstly, in relation to the primary review outcome (gingivitis), there was no clinically meaningful benefit of one S\&P recall interval over another (see Effects of interventions). In the absence of a discernible clinical benefit, we considered it appropriate to focus solely on costs to the NHS and not to consider WTP estimations. In addition, the DCE in Ramsay 2018 did not involve the trial participants but was based on a separate sample obtained from the UK general population. Finally, we did not consider cost data for trial participants who received personalised $\mathrm{OHA}$; we considered only the data for trial participants who received routine $\mathrm{OHA}$. We judged that the provision of S\&P with routine OHA most closely resembled current NHS practice.

\section{Excluded studies}

In the previous and current editions of this review, 88 potentially relevant papers were considered and 86 study reports (of 77 studies) were excluded. Although many of studies could be excluded for more than one reason, in general only the main reason for exclusion has been recorded in the Characteristics of excluded studies table.

- Not routine S\&P (28 studies: Adachi 2002; Addy 1988; Axelsson 1987; Bonner 2005; Brown 2002; Chapple 1995; Godin 1976; Greenwell 1985; Hill 1981; Hoffman 2005; Hugoson 2007; Kaldahl 1988; Kinane 2000; Knöfler 2007; Kwan-Yat 2006; Loesche 2002; López 2005; Mishkin 1986; Moëne 2010; Powell 1999; Rosling 1983; Schlagenhauf 1990; Serrano 2011; Smulow 1983; Van der Weijden 1994; Wennström 2011; Westfelt 1998; Zee 2006).

- Unclear whether a RCT or judged not to be an RCT (27 studies: Axelsson 1975; Axelsson 1981; Axelsson 2004; Badersten 1984; Budtz-Jorgensen 2000; Chawla 1975; Cutress 1991; Feldman 1988; Grimm 1986; Gunay 1998; Hou 1989; Huber 1987; Ketomaki 1993; Klein 1985; Lee 2009; Lim 1996; Lunder 1994; Moimaz 2000; Mojon 1998; Rosen 2004; Saliba 1997; Sandig 1981; Schulz 1989; Suomi 1971; Suomi 1973; Tsuboi 2003), also including one cluster RCT with one cluster per intervention (Shaw 1991).

- Length of follow-up less than six months (four studies: Aldridge 1995; Tan 1978; White 1996; Zanatta 2011).

- Children with mixed dentition at baseline (four studies: Ashley 1982; Axelsson 1977; Bellini 1981; Poulsen 1976).

- All participants received S\&P (two studies: Hellström 1996; Zimmerman 1993).

- Interventions not relevant/representative of the intervention being evaluated this review (five studies: Lembariti 1998; Lightner 1971; Listgarten 1985; Rask 1988; Wang 1992).

- No S\&P (one study: Sato 2008).

- Participants had partial dentures (one study: Katay 1990).

- Participants had severe periodontal disease, or had periodontal treatment and were in maintenance phase (five studies: Glavind 1977; Listgarten 1986; Nyman 1975; Rosling 1976; Westfelt 1983).

\section{Ongoing studies}

We identified no ongoing studies that could potentially be included in this review.

\section{Risk of bias in included studies}

The review authors' judgements about each risk of bias item presented as percentages across all included studies is given in Figure 2, and the review authors' judgements about each risk of bias item for each included study is given in Figure 3. 
Figure 2. Risk of bias graph: review authors' judgements about each risk of bias item presented as percentages across all included studies.

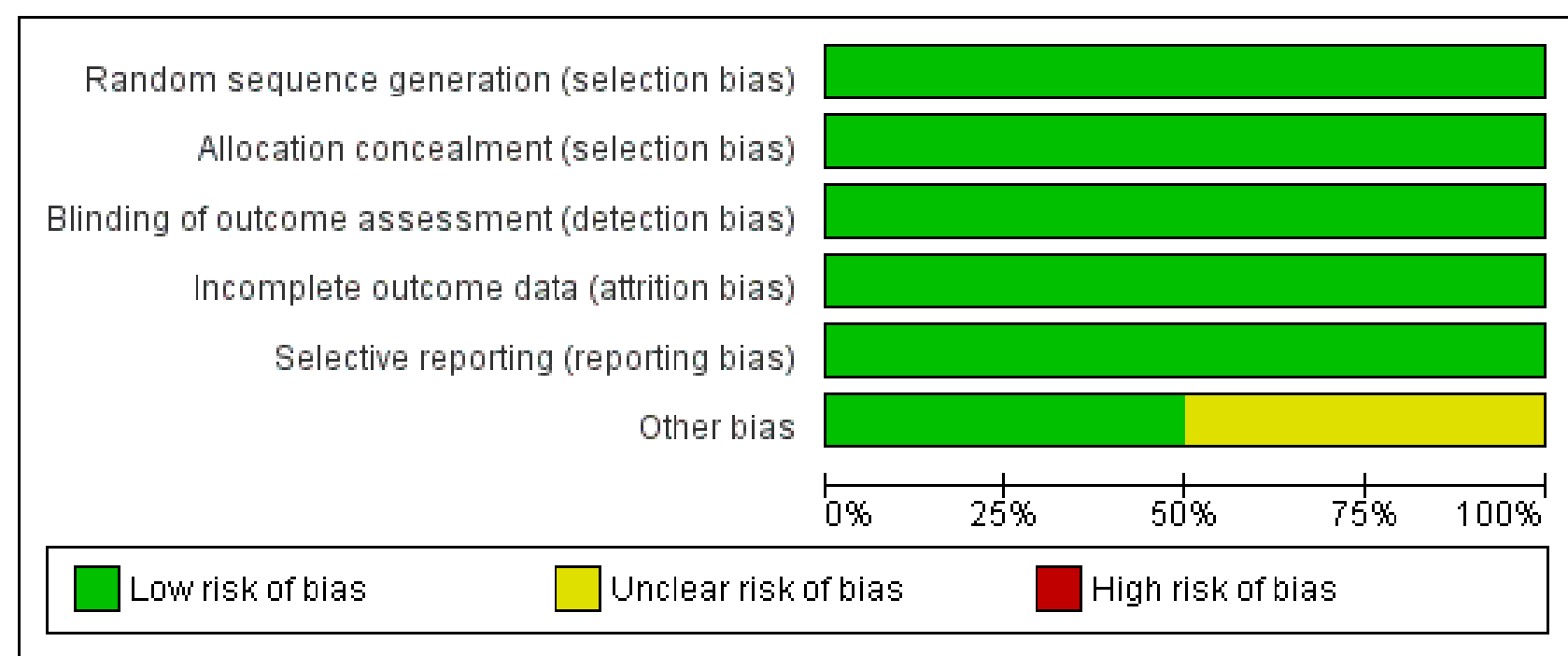

Figure 3. Risk of bias summary: review authors' judgements about each risk of bias item for each included study.

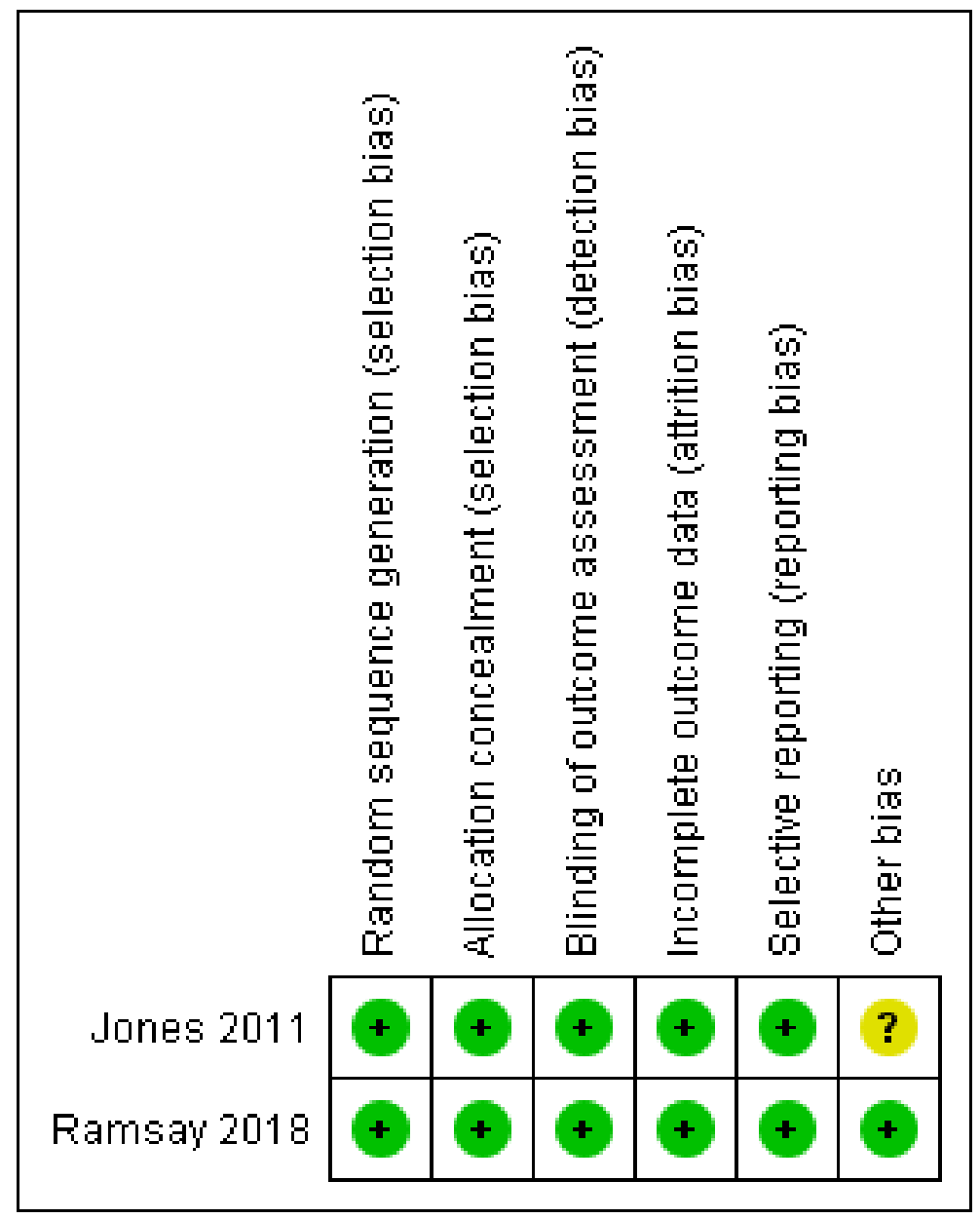




\section{Allocation}

\section{Random sequence generation}

We judged both studies at low risk of bias for random sequence generation, as they used a computer-generated sequence (Jones 2011; Ramsay 2018)

\section{Allocation concealment}

Both studies described the randomisation as centrally randomised and we judged them at low risk of bias (Jones 2011; Ramsay 2018).

\section{Blinding}

Participant blinding was not possible in any of the studies and was not considered as part of the risk of bias assessment. We assessed blinding for the outcome assessors.

Both studies described adequate outcome assessor blinding and we classified them at low risk of bias for this domain (Jones 2011; Ramsay 2018).

\section{Incomplete outcome data}

We considered both studies at low risk of attrition bias as approximately equal numbers withdrew from each treatment group (with a total of 29\% (Ramsay 2018) and 17\% (Jones 2011)). The trial authors provided full explanations of the reasons for withdrawal.

\section{Selective reporting}

Both studies reported all the outcomes planned in the methods section in full and we assessed them at low risk of reporting bias (Jones 2011; Ramsay 2018).

\section{Other potential sources of bias}

There was possible bias in Jones 2011 resulting from the withdrawal of participants by independent trial examiners due to concerns that they had developed BPE scores of 3 or greater during the course of the trial. The number of participants involved was small ( $5 \%$ of study population) and involved all three study groups. We were uncertain whether this would produce material bias and we therefore assessed this domain at unclear risk of bias. We assessed Ramsay 2018 at low risk of bias for this domain.

Overall, we judged that Ramsay 2018 was at low risk of bias and that Jones 2011 had an unclear risk of bias.

\section{Results of applying GRADE to assess the certainty of evidence}

Risk of bias

We judged that Ramsay 2018 had a low risk of bias overall and that Jones 2011 had an unclear risk of bias. In meta-analyses for the outcomes of gingivitis and calculus, Ramsay 2018 contributed most data to the pooled effect size, with weightings varying from $81 \%$ to $87 \%$. Due to the low contribution of Jones 2011 to the pooled estimates, we did not downgrade the certainty of evidence for gingivitis and calculus outcomes. We downgraded the certainty of evidence by one level for plaque and for the participant-reported outcome of perceived level of oral cleanliness because only Jones 2011 measured this outcome and the 'unclear risk of bias' in this trial related to trial withdrawals and baseline imbalances reduced our confidence in the effect estimate. We downgraded the participant-reported outcome by an additional level because it was measured using a non-validated instrument.

\section{Inconsistency}

The point estimates from the two included trials for gingivitis and calculus outcomes for all comparisons were similar, the $\mathrm{Cls}$ accompanying the point estimates overlapped and $\mathrm{I}^{2}$ values of $0 \%$ were recorded for all meta-analyses. Therefore, we did not downgrade the certainty of evidence for these outcomes. The criterion of inconsistency was deemed "not applicable" for outcomes that were reported in a single trial only (plaque, probing depth, oral health-related quality of life, perceived level of oral cleanliness, costs) and we did not downgrade the certainty of evidence.

\section{Imprecision}

We downgraded the certainty of evidence by one level for imprecision for the participant-reported outcome of perceived level of oral cleanliness when comparing six-monthly versus 12 -monthly S\&P treatments. The $95 \% \mathrm{Cl}$ accompanying the effect estimate included no difference between the groups and an appreciable difference that exceeded a minimally important difference. We downgraded the certainty of evidence by two levels for the economic outcome of costs, because the $95 \%$ Cls were extremely wide and we judged that there was "serious imprecision". We did not downgrade for imprecision for any other outcome because in instances where $\mathrm{Cls}$ accompanying effect estimates included little or no effect, the intervals were also sufficiently narrow to exclude appreciable benefit or appreciable harm.

\section{Indirectness}

The two trials included in this review were conducted in general dental practice settings and involved populations and interventions of direct relevance to the review questions and review objectives. Furthermore, the trials involved direct head-tohead comparisons between S\&P treatments delivered at specific scheduled intervals (e.g. every six months versus every 12 months) and between S\&P treatments delivered at these intervals and no scheduled S\&P. Therefore, we judged that there were no indirectness issues pertaining to populations, interventions and comparisons.

In relation to indirectness of outcomes, the nature of periodontal disease (in particular, its generally slow rate of progression) has traditionally necessitated the use of surrogate endpoints in trials. We considered that the surrogate outcomes of bleeding on probing (used to measure gingivitis) and probing (periodontal pocket) depth measured in the trials included in this review were adequately reflective of true endpoints of importance to participants and we did not downgrade the certainty of evidence. Bleeding on probing is indicative of gingival inflammation and therefore is likely to correlate with bleeding on brushing, which may be perceived as important by patients (Lang 2009). Furthermore, any beneficial effect of routine S\&P treatments on this outcome (i.e. a reduction in bleeding on brushing) would be mediated through the surrogate endpoint (i.e. via a reduction in gingival inflammation). In addition, there is evidence that the absence of bleeding on probing is a reasonable indication of periodontal stability (Lang 2009). We also considered that probing depth (as an indicator of loss of periodontal support) was a reasonable and plausible substitute outcome for the long-term patient-important 
outcomes of tooth loss or loss of masticatory efficiency associated with tooth mobility or tooth loss. These long-term outcomes cannot be feasibly measured in short-term trials conducted on the type of population considered in this review.

We downgraded the certainty of evidence by one level for indirectness in relation to the outcome of plaque. Although plaque levels are traditionally measured in many periodontal trials, the degree to which plaque accumulation measured at a single point in time is predictive of future periodontal destruction is uncertain. Furthermore, one of the trials included in this review did not measure plaque levels because that the Periodontal Advisory Group for the trial did not consider that plaque could be measured reliably (Ramsay 2018). Taking all these factors into consideration, we deemed it appropriate to downgrade the certainty of evidence for plaque by one level.

Finally, we downgraded by one level for indirectness for the economic outcome of costs. The only trial measuring costs was conducted in general dental practice settings in the UK. We considered that there was uncertainty over the applicability of these results to settings outside the UK where the resources required or used for S\&P treatments may vary.

\section{Publication bias}

Due to the small number of trials included in this review, we did not formally assess the likelihood of publication bias via the construction and examination of funnel plots. Our search for relevant trials was comprehensive and included a sensitive search, without language restrictions, of electronic databases and clinical trials registers. Although we cannot entirely exclude the possibility of publication bias, we considered that there was a low likelihood that we had overlooked relevant trials. Therefore, we did not downgrade the certainty of evidence level for publication bias.

\section{Effects of interventions}

See: Summary of findings for the main comparison Planned, regular routine scale and polish compared with no scheduled scale and polish treatment for periodontal health; Summary of findings 2 Routine scale and polish at different frequencies for periodontal health; Summary of findings 3 Routine scale and polish undertaken by dentist or dental care professional for periodontal health

Both of the included studies reported gingivitis, calculus and some participant-centred outcomes. In addition, Ramsay 2018 reported periodontal probing depths and Jones 2011 reported plaque levels. Ramsay 2018 also reported costs. Jones 2011 reported outcomes at 24 months and Ramsay 2018 reported outcomes at 36 months. Neither study measured changes in attachment level, other periodontal indices, tooth loss, adverse effects or halitosis.

Comparison 1: scale and polish treatment at a planned, regular interval (e.g. every six months, every 12 months) versus no scheduled scale and polish treatment for the duration of the trial

Both included studies had three arms and compared six-monthly S\&P versus no scheduled S\&P, and 12-monthly S\&P versus no scheduled S\&P.

Gingivitis/gingival bleeding: there was little or no difference between the groups (high-certainty evidence; Analysis 1.1).
- Six-monthly versus no scheduled S\&P: SMD $-0.01(95 \% \mathrm{Cl}-0.13$ to $0.11 ; 2$ trials, 1087 participants; $\left.\right|^{2}=0 \%$ ).

- 12-monthly versus no scheduled S\&P: SMD $-0.04(95 \% \mathrm{Cl}-0.16$ to $0.08 ; 2$ trials, 1091 participants; $\left.\right|^{2}=0 \%$ ).

Calculus: six-monthly and 12-monthly S\&P treatments resulted in small reductions in calculus levels compared to no scheduled S\&P (high-certainty evidence; Analysis 1.2).

- Six-monthly versus no scheduled S\&P: SMD $-0.32(95 \% \mathrm{Cl}-0.44$ to -0.20 ; 2 trials, 1084 participants; $12=0 \%$ ).

- 12-monthly versus no scheduled S\&P: SMD $-0.19(95 \% \mathrm{Cl}-0.31$ to -0.07 ; 2 trials, 1088 participants; $12=0 \%$ ).

Plaque (mean percentage of index teeth with plaque): there was little or no difference between the groups (low-certainty evidence; Analysis 1.3).

- Six-monthly versus no scheduled S\&P: MD $-0.04 \%(95 \% \mathrm{Cl}-0.13$ to 0.05 ; 1 trial, 207 participants).

- 12-monthly versus no scheduled S\&P: MD 0.00\% (95\% Cl -0.10 to $0.09 ; 1$ trial, 200 participants).

Probing depths: there was little or no difference between the groups (high-certainty evidence; Analysis 1.4).

- Six-monthly versus no scheduled S\&P: MD $0.00 \mathrm{~mm}(95 \% \mathrm{Cl}-$ 0.04 to $0.04 ; 1$ trial, 880 participants).

- 12-monthly versus no scheduled S\&P: MD $0.00 \mathrm{~mm}(95 \% \mathrm{Cl}-0.04$ to $0.04 ; 1$ trial, 890 participants).

Participant satisfaction - perception of oral cleanliness (proportion of participants reporting high level of oral cleanliness ('high' defined as score of 4 or 5 on a 5-point scale)): participants receiving six-monthly and 12-monthly S\&P treatments reported higher levels of oral cleanliness compared to no scheduled S\&P (low-certainty evidence; Analysis 1.5).

- Six-monthly versus no scheduled S\&P: RR $1.83(95 \% \mathrm{Cl} 1.28$ to 2.63; 1 trial, 205 participants).

- 12-monthly versus no scheduled S\&P: RR 1.65 (95\% Cl 1.13 to 2.40; 1 trial, 200 participants).

Quality of life (Oral Health Impact Profile-14): there was little or no difference between the groups (high-certainty evidence; Analysis 1.6).

- Six-monthly versus no scheduled S\&P: MD $-0.30(95 \% \mathrm{Cl}-1.24$ to 0.64; 1 trial, 795 participants).

- 12-monthly versus no scheduled S\&P: MD $0.10(95 \% \mathrm{Cl}-0.83$ to 1.03; 1 trial, 807 participants).

Cost (NHS perspective): the findings were uncertain (very lowcertainty evidence; Analysis 1.7).

- Six-monthly versus no scheduled S\&P (routine cluster only): MD GBP 00.52 (95\% Cl -18.10 to 19.14; 1 trial, 554 participants).

- 12-monthly versus no scheduled S\&P (routine cluster only): MD GBP 18.14 ( $95 \% \mathrm{Cl}-13.76$ to $30.04 ; 1$ trial, 544 participants).

Comparison 2: scale and polish treatment at a planned, regular interval (e.g. every six months) versus scale and polish 
treatment at a different planned, regular interval (e.g. every 12 months)

The two included studies provided data for direct comparisons between six-monthly and 12-monthly S\&P treatments. Jones 2011 reported outcomes at 24 months and Ramsay 2018 at 36 months.

Gingivitis/gingival bleeding: there was little or no difference between six-monthly and 12-monthly S\&P treatments (highcertainty evidence; Analysis 2.1).

- SMD $0.03\left(95 \% \mathrm{Cl}-0.09\right.$ to $0.15 ; 2$ trials, 1090 participants; $\left.\right|^{2}=$ $0 \%)$.

Calculus: six-monthly S\&P treatments resulted in a small reduction in calculus levels compared to 12-monthly treatments (highcertainty evidence; Analysis 2.2).

- SMD $-0.13\left(95 \% \mathrm{Cl}-0.25\right.$ to $-0.01 ; 2$ trials, 1086 participants; $\left.\right|^{2}$ $=0 \%)$.

Plaque (mean percentage of index teeth with plaque): there was little or no difference between six-monthly and 12-monthly S\&P treatments (low-certainty evidence; Analysis 2.3).

- $\mathrm{MD}-0.04$ ( $95 \% \mathrm{Cl}-0.13$ to $0.05 ; 1$ trial, 207 participants).

Probing depths: there was little or no difference between sixmonthly and 12-monthly S\&P treatments (high-certainty evidence; Analysis 2.4).

- $\mathrm{MD} 0.00 \mathrm{~mm}(95 \% \mathrm{Cl}-0.04$ to $0.04 ; 1$ trial, 882 participants).

Participant satisfaction - perception of oral cleanliness (proportion of participants reporting high level of oral cleanliness) ('high' defined as score of 4 or 5 on a 5-point scale)): it was unclear if there was a difference in participant-reported high levels of oral cleanliness between six-monthly and 12-monthly S\&P treatments (very low-certainty evidence; Analysis 2.5).

- RR 1.11 ( $95 \%$ Cl 0.85 to 1.47; 1 trial, 207 participants).

Quality of life (Oral Health Impact Profile-14): there was little or no difference between the groups (high-certainty evidence; Analysis 2.6).

- $\mathrm{MD}-0.40(95 \% \mathrm{Cl}-1.34$ to $0.54 ; 1$ trial, 786 participants).

Costs (NHS perspective): the findings were uncertain (very lowcertainty evidence; Analysis 2.7).

- MD GBP -7.62 (95\% Cl-28.39 to $13.15 ; 1$ trial, 556 participants).

Comparison 3: scale and polish treatment provided by a dentist at a planned, regular interval (e.g. every 6 months) versus scale and polish treatment provided by a dental hygienist or dental therapist at the same planned, regular interval (i.e. every 6 months)

We found no studies reporting this comparison.

\section{DISCUSSION}

\section{Summary of main results}

We included two studies in this review, with 1711 participants included in the analyses. Both studies were conducted in UK general dental practices and involved regularly attending adults without severe periodontitis. One study measured outcomes at 24 months (Jones 2011) and one study measured outcomes at 36 months (Ramsay 2018). The included studies provided data for two of the three comparisons of the review.

\section{Comparison 1: scale and polish treatment at a planned, regular interval (e.g. every six months, every 12 months) versus no scheduled scale and polish treatment for the duration of the trial}

The two included studies provided data for comparisons between planned, regular S\&P (six-monthly and 12-monthly) versus no scheduled S\&P treatment.

For adults without severe periodontitis accessing routine dental care, there was little or no difference in gingivitis and probing depths over a two to three year period between routinely provided six-monthly, 12-monthly and no scheduled S\&P treatments (highcertainty evidence). There may also have been little or no difference in plaque levels over two years (low-certainty evidence). Six-monthly or 12-monthly S\&P treatments produced a small reduction in calculus levels over two to three years when compared to no scheduled S\&P treatments (high-certainty evidence). The importance of this reduction for patients and clinicians was unclear.

Participants receiving scheduled S\&P treatments reported higher levels of oral cleanliness than those who do not, but there was no evidence of a difference in oral health-related quality of life. Evidence on costs was uncertain.

Comparison 2: scale and polish treatment at a planned, regular interval (e.g. every six months) versus scale and polish treatment at a different planned, regular interval (e.g. every 12 months)

The two included studies provided data for comparisons between six-monthly S\&P treatments versus 12-monthly treatments.

For adults without severe periodontitis accessing routine dental care, there was little or no difference in gingivitis and probing depths over two to three years between routinely provided sixmonthly and 12-monthly S\&P treatments (high-certainty evidence). There may also be little or no difference in plaque levels over two years (low-certainty evidence). Six-monthly S\&P treatments produced a small reduction in calculus levels over two to three years when compared to 12-monthly S\&P treatments (highcertainty evidence). The importance of this reduction for patients and clinicians was unclear.

It was unclear if there was any difference between six-monthly and 12-monthly scheduled S\&P treatments in terms of self-reported levels of oral cleanliness. There was no evidence of a difference in oral health-related quality of life. Evidence on costs was uncertain.

Comparison 3: scale and polish treatment provided by a dentist at a planned, regular interval (e.g. every six months) versus scale and polish treatment provided by a dental 
hygienist or dental therapist at the same planned, regular interval (i.e. every six months)

We found no studies reporting this comparison.

\section{Overall completeness and applicability of evidence}

Our search for relevant trials was comprehensive and included a sensitive search, without language restrictions, of electronic databases and clinical trials registers.

The two included trials addressed two of the three comparisons; however, neither trial addressed the third comparison comparing S\&P provided by a dentist to that provided by a DCP (dental therapist or dental hygienist).

The two included studies were conducted in general dental practice settings and involved populations and interventions of direct relevance to the review questions and review objectives (Jones 2011; Ramsay 2018). The studies included direct head-tohead comparisons between S\&P treatments delivered at specific scheduled intervals (e.g. every 6 months versus every 12 months) and between S\&P treatments delivered at these intervals and no scheduled S\&P.

In relation to outcomes, the review's primary outcome of gingivitis was reported by both studies. The importance of this outcome to patients and dental professionals is currently unclear. A core outcome set for effectiveness trials investigating the prevention and management of periodontal disease is currently being developed (Lamont 2017). A "core outcome set" is an agreed minimum set of outcomes that should be measured in effectiveness trials. The development of this core outcome set included the key stakeholder groups of periodontal disease, namely: patients, general dental practitioner, hygienists, therapists, periodontists and researchers. This work should ensure that future research measures outcomes are relevant to patients and dental practitioners.

\section{Quality of the evidence}

The body of evidence of comparisons 1 and 2 was high certainty for the outcomes of gingivitis, calculus, probing depths and quality of life; very low certainty for costs; low certainty for plaque; and low to very low certainty for patient perception of oral cleanliness (Summary of findings for the main comparison; Summary of findings 2). We found no studies investigating comparison 3 (Summary of findings 3 ).

\section{Potential biases in the review process}

We used a sensitive search strategy for this review and made every effort to identify all relevant studies. We excluded no studies due to language restrictions. However, it is possible that not all relevant studies were identified for inclusion in this review due to grey literature bias and the publication of studies in non-indexed journals.

The previous update of this review (Worthington 2013), made some important alterations to the selection criteria specified in the original protocol. Split-mouth study designs were excluded as they do not reflect the manner in which routine scaling and polishing is provided in practice. Studies with participants were described as having severe periodontal disease (e.g. alveolar bone loss involving most teeth or people requiring referral for specialist periodontal treatment) or having undergone specialist periodontal treatment in the six months preceding the trial and who were in the 'maintenance phase' were also excluded. These exclusions were made because best clinical practice would suggest that these categories of patients should receive more advanced periodontal treatment than the 'routine S\&P' as defined in this review.

In this review update, we further refined the original inclusion criteria as highlighted in the Differences between protocol and review section. We considered that these adjustments resulted in a review of more use to practitioners who are providing 'routine S\&P treatments' and patients who are receiving this intervention.

One included study involved three review authors (TL, JC, HW)), but they were not involved with data extraction or assessment of risk of bias of this study (Ramsay 2018.

\section{Agreements and disagreements with other studies or reviews}

Compared to Needleman 2015, our review addresses a more focused question, which explains the slight variation in findings. Needleman 2015 concluded that there was insufficient evidence to inform directly on the effects of professional mechanical plaque removal, and welcomed the publication of the NIHR HTA IQuaD trial (Ramsay 2018). This trial contributes the majority of the data in our updated review.

\section{AUTHORS' CONCLUSIONS}

\section{Implications for practice}

For adults without severe periodontitis accessing routine dental care, there is little or no difference in gingivitis, probing depths or quality of life over two to three years between routinely provided six-monthly scale and polish (S\&P) treatments, 12-monthly S\&P treatments and no scheduled S\&P treatments (high-certainty evidence). There may also be little or no difference in plaque levels over two years (low-certainty evidence). Although routine S\&P treatments produce a small reduction in calculus levels over two to three years when compared to no scheduled S\&P treatments, with six-monthly treatments reducing calculus more than 12 monthly treatments (high-certainty evidence), the importance of these reductions for patients and clinicians is unclear. The studies did not assess the adverse effects of S\&P treatments and available evidence on the costs of the treatments is uncertain.

\section{Implications for research}

Further studies comparing routine S\&P treatments (also known as prophylaxis, professional mechanical plaque removal or periodontal instrumentation) for regularly attending adults in primary care seem unnecessary, given the high certainty of the evidence for the review's primary outcome. Future research could focus on assessment of the effects and cost-effectiveness of interventions to manage moderate-to-severe periodontal disease. This may include evaluating multifaceted periodontal care packages that combine advice, recommendations for oral care products and S\&P primary dental care.

Outcomes to be measured should include clinical, patient-reported and economic factors. A core outcome set for effectiveness trials investigating the prevention and management of periodontal disease is currently being developed (Lamont 2017). Researchers 
should assess these outcomes as a minimum, and should define the level of improvement they will consider clinically significant for each outcome. Such information is needed to help guide changes in dental practice.

Any future trial should be reported according to CONSORT guidelines (www.consort-statement.org/).

\section{ACKNOWLEDGEMENTS}

This update: we wish to thank Anne Littlewood (Cochrane Oral Health) for her assistance with literature searching and the PRISMA flow diagram; and Professor Anne-Marie Glenny, Laura MacDonald and Dr Philip Riley (Cochrane Oral Health) for their help with the preparation of this review. We also thank Professor Jane Forrest, Dr Analia Veitz-Keenan, Professor Robert Weyant, Dr Alonso CarroscoLabra and Dr Jo Dumville for their comments on this update, and Anne Lawson for copy editing.
Previous versions: we would like to thank Gemma Bryan for her work on the 2013 version of this review. We acknowledge the contribution of Andrew Forgie to the protocol of the review. We wish to thank Anne Littlewood (Cochrane Oral Health) for her assistance with literature searching; Luisa Fernandez Mauleffinch and Phil Riley (Cochrane Oral Health) for their help with the preparation of this review; Regina Mitezki for translating three German articles; Mikako Hayashi for translating a Japanese study; and Lowell Smith, Ram Nanda, Jan Lindhe and Lim Lum Pen for responding to our requests for information on specific trials. The review authors are also grateful for the comments of members of the Guideline Development Group on recall intervals between routine dental examinations conducted under the auspices of the National Institute for Health and Care Excellence (NICE) and COordinated by the National Collaborating Centre for Acute Care. In particular the review authors would like to thank Jacqueline Dutchak and Nigel Pitts. 


\section{R E F E R E N C E S}

\section{References to studies included in this review}

Jones 2011 \{published data only\}

Jones CL, Macfarlane TV, Milsom KM, Ratcliffe P, Wyllie A, Tickle M. Patient perceptions regarding benefits of single visit scale and polish: a randomised controlled trial. BMC Oral Health 2013;13:50.

* Jones CL, Milsom KM, Ratcliffe P, Wyllie A, Macfarlane TV, Tickle M. Clinical outcomes of single-visit oral prophylaxis: a practice-based randomised controlled trial. BMC Oral Health 2011;11:35.

\section{Ramsay 2018 \{published data only\}}

Ramsay CR, Clarkson JE, Duncan A, Lamont TJ, Heasman PA, Boyers D, et al. Improving the Quality of Dentistry (IQuaD): a cluster factorial randomised controlled trial comparing the effectiveness and cost-benefit of oral hygiene advice and/ or periodontal instrumentation with routine care for the prevention and management of periodontal disease in dentate adults attending dental primary care. Health Technology Assessment 2018; Vol. 22:38.

\section{References to studies excluded from this review}

Adachi 2002 \{published data only\}

Adachi M, Ishihara K, Abe S, Okuda K, Ishikawa T. Effect of professional oral health care on the elderly living in nursing homes. Oral Surgery, Oral Medicine, Oral Pathology, Oral Radiology, and Endodontics 2002;94(2):191-5.

\section{Addy 1988 \{published data only\}}

Addy M, Hassan H, Moran J, Wade W, Newcombe R. Use of antimicrobial containing acrylic strips in the treatment of chronic periodontal disease. A three month follow-up study. Journal of Periodontology 1988;59(9):557-64.

\section{Aldridge 1995 \{published data only\}}

Aldridge JP, Lester V, Watts TLP, Collins A, Viberti G, Wilson RF. Single-blind studies of the effects of improved periodontal health on metabolic control in Type 1 diabetes mellitus. Journal of Clinical Periodontology 1995;22:271-5.

Ashley 1982 \{published data only\}

* Ashley FP, Sainsbury RH. Post-effects of a schoolbased plaque control programme. British Dental Journal 1982;153(9):337-8.

Ashley FP, Sainsbury RH. The effect of a school-based plaque control programme on caries and gingivitis. A 3-year study in 11 to 14-year-old girls. British Dental Journal 1981;150:41-5.

Sainsbury RH, Ashley FP. Restorative dental care of children participating in a school based plaque control programme in London. Community Dentistry and Oral Epidemiology 1984;12:155-9.
Axelsson 1975 \{published data only\}

Axelsson P, Lindhe J. Effect of fluoride on gingivitis and dental caries in a preventive program based on plaque control. Community Dentistry and Oral Epidemiology 1975;3:156-60.

\section{Axelsson 1977 \{published data only\}}

Axelsson P, Linde J. The effect of a preventive programme on dental plaque, gingivitis and caries in schoolchildren. Results after one and two years. Journal of Clinical Periodontology 1974;1:126-38.

* Axelsson P, Lindhe J. The effect of a plaque control program on gingivitis and dental caries in schoolchildren. Journal of Dental Research 1977;56:C142-8.

\section{Axelsson 1981 \{published data only\}}

Axelsson P, Lindhe J. The significance of maintenance care in the treatment of periodontal disease. Journal of Clinical Periodontology 1981;8:281-94.

\section{Axelsson 1987 \{published data only\}}

Axelsson P, Kristoffersson K, Karlsson R, Bratthall D. A 30-month longitudinal study of the effects of some oral hygiene measures on Streptococcus mutans and approximal dental caries. Journal of Dental Research 1987;66:761-5.

\section{Axelsson 2004 \{published data only\}}

Axelsson P, Lindhe J. Effect of controlled oral hygiene procedures on caries and periodontal disease in adults. Journal of Clinical Periodontology 1978;5:133-51.

Axelsson P, Lindhe J. Effect of controlled oral hygiene procedures on caries and periodontal disease in adults: results after 6 years. Journal of Clinical Periodontology 1981;8:239-48.

Axelsson P, Lindhe J, Nyström B. On the prevention of caries and periodontal disease: results of a 15 year longitudinal study in adults. Journal of Clinical Periodontology 1991;18:182-9.

* Axelsson P, Nyström B, Lindhe J. The long-term effect of a plaque control program on tooth mortality, caries and periodontal disease in adults. Journal of Clinical Periodontology 2004;31:749-57.

\section{Badersten 1984 \{published data only\}}

Badersten A, Nilveus R, Egelberg J. Effect of nonsurgical periodontal therapy: II. Severely advanced periodontitis. Journal of Clinical Periodontology 1984;11:63-76.

Bellini 1981 \{published data only\}

Bellini HT, Campi R, Denardi JL. Four years of monthly professional toothcleaning and topical fluoride application in Brazilian schoolchildren. Journal of Clinical Periodontology 1981;8:231-8

Bonner 2005 \{published data only\}

Bonner BC, Young L, Smith PA, McCombes W, Clarkson JE. A randomised controlled trial to explore attitudes to routine scale and polish and compare manual versus ultrasonic scaling in the 
general dental service in Scotland (ISRCTN99609795). BMC Oral Health 2005;5:3.

\section{Brown 2002 \{published data only\}}

Brown JB, Rosenstein D, Mullooly J, O'Keeffe Rosetti M, Robinson S, Chiodo G. Impact of intensified dental care on outcomes in human immunodeficiency virus infection. AIDS Patient Care and STDs 2002;16(10):479-86.

\section{Budtz-Jorgensen 2000 \{published data only\}}

Budtz-Jorgensen E, Mojon P, Rentsch A, Deslauriers N. Effects of an oral health program on the occurrence of oral candidosis in a long-term care facility. Community Dentistry and Oral Epidemiology 2000;28(2):141-9.

\section{Chapple 1995 \{published data only\}}

Chapple IL, Walmsley DA, Saxby MS, Moscrop H. Effect of instrument power setting during ultrasonic scaling upon treatment outcome. Journal of Periodontology 1995;66:756-60.

Chawla 1975 \{published data only\}

Chawla TN, Nanda RS, Kapoor KK. Dental prophylaxis procedures in control of periodontal disease in Lucknow (rural) India. Journal of Periodontology 1975;46(8):498-503.

\section{Cutress 1991 \{published data only\}}

Cutress TW, Powell RN, Kilisimasi S, Tomiki S, Holborow D. A 3-year community-based periodontal disease prevention programme for adults in a developing nation. International Dental Journal 1991;41(6):323-34.

\section{Feldman 1988 \{published data only\}}

Feldman CA, Bentley JM, Oler J. The rural dental health program: long-term impact of two dental delivery systems on children's oral health. Journal of Public Health Dentistry 1988;48(4):201-7.

\section{Glavind 1977 \{published data only\}}

* Glavind L. Effect of monthly professional mechanical tooth cleaning on periodontal health in adults. Journal of Clinical Periodontology 1977;4(2):100-6.

Glavind L. Effect of monthly professional tooth cleaning on periodontal health in adults. Journal of Dental Research 1976;55:D188.

\section{Godin 1976 \{published data only\}}

Godin MC. The effect of visual feedback and self-scaling on plaque control behaviour. Journal of Periodontology 1976;47(1):34-7.

\section{Greenwell 1985 \{published data only\}}

Greenwell H, Bakr A, Bissada N, Debanne S, Rowland D. The effect of the Keyes' method of oral hygiene on the subgingival microflora compared to the effect of scaling and / or surgery. Journal of Clinical Periodontology 1985;12(4):327-41.

\section{Grimm 1986 \{published data only\}}

Grimm WD, Curth K, Rumler KD, Walther C. Clinically controlled studies of the optimum recall interval of public health care patients [Klinisch-kontrollierte untersuchung uber den optimalen recallabstand dispensairebetreuter patienten]. Stomatologie der DDR 1986;36(12):728-32.

\section{Gunay 1998 \{published data only\}}

Gunay H, Dmoch-Bockhorn K, Gunay Y, Geurtsen W. Effect on caries experience of a long-term preventive program for mothers and children starting during pregnancy. Clinical Oral Investigations 1998;2(3):137-42.

\section{Hellström 1996 \{published data only\}}

Hellström M-K, Ramberg P, Krok L, Lindhe J. The effect of supragingival plaque control on the subgingival microflora in human periodontitis. Journal of Clinical Periodontology 1996;23:934-40.

\section{Hill 1981 \{published data only\}}

Hill RW, Ramfjord SP, Morrison EC, Appleberry EA, Caffesse RG, Kerry GJ, et al. Four types of periodontal treatment compared over two years. Journal of Periodontology 1981;52(11):655-62.

\section{Hoffman 2005 \{published data only\}}

Hoffman A, Marshall RI, Bartold PM. Use of the Vector ${ }^{\mathrm{TM}}$ scaling unit in supportive periodontal therapy: a subjective patient evaluation. Journal of Clinical Periodontology 2005;32:1089-93.

\section{Hou 1989 \{published data only\}}

Hou GL, Chi-Cheng T. Clinical observations of the effects of nonsurgical periodontal therapy on human periodontal disease II: ultrasonic scaling and root planing for 6 months. Kaohsiung Journal of Medical Sciences 1989;5:72-86.

\section{Huber 1987 \{published data only\}}

Huber S, Vernino AR, Nanda RS. Professional prophylaxis and its effect on the periodontium of full-banded orthodontic patients. American Journal of Orthodontics and Dentofacial Orthopedics 1987;91(4):321-7.

\section{Hugoson 2007 \{published data only\}}

* Hugoson A, Lundgren D, Asklöw B, Borgklint G. Effect of three different dental health preventive programmes on young adult individuals: a randomized, blinded, parallel group, controlled evaluation of oral hygiene behaviour on plaque and gingivitis. Journal of Clinical Periodontology 2007;34:407-15.

Hugoson A, Lundgren D, Asklöw B, Borgklint G. The effect of different dental health programmes on young adult individuals: a longitudinal evaluation of knowledge and behaviour including cost aspects. Swedish Dental Journal 2003;27(3):115-30.

Kaldahl 1988 \{published data only\}

Kaldahl WB, Kalkwarf KL, Patil K, Dyer JK, Bates RE. Evaluation of four modalities of periodontal therapy: mean probing depth, probing attachment level and recession changes. Journal of Periodontology 1988;59(12):783-93.

Katay 1990 \{published data only\}

Katay L. Intensive aftercare for patients with removable dentures. Results after four years [Intensivbetreuung von Patienten mit herausnehmbarem Zahnersatz]. Deutsche Zahnarztliche Zeitschrift 1990;45(7):410-3. 
Ketomaki 1993 \{published data only\}

Ketomaki T, Luoma AR. Dental Caries and Use of Resources in Relation to Individual Inspection Interval in Systematic Oral Health Care [Jarjestelmallisen hammashuollon yksilollisen tutkimusvalin yhteys hammaskariekseen ja voimavarojen kayttoon - den individuella undersokningsfrekvensens inverkan pa tandkaries och resursering inom den systematiska tandvarden]. Helsinki: Vantaa National Research and Development Centre for Welfare and Health, 1993.

\section{Kinane 2000 \{published data only\}}

Kinane DF. Local antimicrobial therapies in periodontal disease. Annals of the Royal Australian College of Dental Surgeons 2000;15:57-60.

\section{Klein 1985 \{published data only\}}

Klein SP, Bohannan HM, Bell RM, Disney JA, Foch CB, Graves RC. The cost and effectiveness of school-based preventive dental care. American Journal of Public Health 1985;75(4):382-91.

\section{Knöfler 2007 \{published data only\}}

Knöfler GU, Purschwitz RE, Jentsch HFR. Clinical evaluation of partial and full mouth scaling in the treatment of chronic periodontitis. Journal of Periodontology 2007;78:2135-42.

\section{Kwan-Yat 2006 \{published data only\}}

Kwan-Yat Z, Dae-Hyun L, Corbet EF. Repeated oral hygiene instructions alone, or in combination with metronidazole dental gel with or without subgingival scaling in adult periodontitis patients: a one-year clinical study. Journal of International Academy of Periodontolgy 2006;8(4):125-35.

\section{Lee 2009 \{published data only\}}

Lee H-K, Choi S-H, Wong KC, Merchant AT, Song K-B, Jeong S$\mathrm{H}$, et al. The effect of intensive oral hygiene care in gingivitis and periodontal destruction in type-2 diabetics. Yonsei Medical Journal 2009;50(4):529-36.

\section{Lembariti 1998 \{published data only\}}

Lembariti BS, van der Weijden GA, van Palenstein Helderman WH. The effect of a single scaling with or without oral hygiene instruction on gingival bleeding and calculus formation. Journal of Clinical Periodontology 1998;25(1):30-3.

\section{Lightner 1971 \{published data only\}}

Lightner LM, O'Leary JT, Drake RB, Crump PP, Allen MF. Preventive periodontic treatment procedures: results over 46 months. Journal of Periodontology 1971;42(9):555-61.

\section{Lim 1996 \{published data only\}}

Lim LP, Davies WI. Comparison of various modalities of "simple" periodontal therapy on oral cleanliness and bleeding. Journal of Clinical Periodontology 1996;23(6):595-600.

\section{Listgarten 1985 \{published data only\}}

Listgarten MA, Schifter C. Differential dark field microscopy of subgingival bacteria as an aid in selecting recall intervals: results after 18 months. Journal of Clinical Periodontology 1982;9:305-16.
* Listgarten MA, Schifter CC, Laster L. 3-year longitudinal study of the periodontal status of an adult population with gingivitis. Journal of Clinical Periodontology 1985;12(13):225-38.

\section{Listgarten 1986 \{published data only\}}

* Listgarten MA, Levin S, Schifter CC, Sullivan P, Evian CI, Rosenberg ES, et al. Comparative longitudinal study of 2 methods of scheduling maintenance visits; 2 year data. Journal of Clinical Periodontology 1986;13(7):692-700.

Listgarten MA, Schifter CC, Sullivan P, George C, Rosenberg ES. Failure of a microbial assay to reliably predict disease recurrence in a treated periodontitis population receiving regularly scheduled prophylaxes. Journal of Clinical Periodontology 1986;13(8):768-73.

Listgarten MA, Sullivan P, George C, Nitkin L, Rosenberg EX, Chilton NW, et al. Comparative longitudinal study of 2 methods of scheduling maintenance visits: 4-year data. Journal of Clinical Periodontology 1989;16(2):105-15.

\section{Loesche 2002 \{published data only\}}

Loesche WJ, Giordano JR, Soehren S, Kaciroti N. The nonsurgical treatment of patients with periodontal disease: results after 5 years. Journal of the American Dental Association 2002;133(3):311-20.

\section{López 2005 \{published data only\}}

López NJ, De Silva I, Ipinza J, Gutiérrez J. Periodontal therapy reduces the rate of preterm low birth weight in women with pregnancy-associated gingivitis. Journal of Periodontology 2005;76:2144-53.

\section{Lunder 1994 \{published data only\}}

Lunder N. Effects of extended recall intervals for children between the ages of 7 and 13 [Forlengede innkallingsintervaller: effeckter pa ressursbruk og tannhelse hos et arskull barn fra 7 til 13 ar]. Nor Tannlaegeforenings Tidende 1994;104:100-2.

\section{Mishkin 1986 \{published data only\}}

Mishkin DJ, Engler WO, Javed T, Darby TD, Cobb RL, Coffman MA. A clinical comparison of the effect on the gingiva of the Prophy-Jet and the rubber cup and paste techniques. Journal of Periodontology 1986;57(3):151-4.

\section{Moëne 2010 \{published data only\}}

Moëne R, Décaillet F, Andersen E, Mombelli A. Subgingival plaque removal using a new air-polishing device. Journal of Periodontology 2010;81:79-88.

\section{Moimaz 2000 \{published data only\}}

Moimaz SAS, Guimaräes LOC, Saliba NA, Saliba O. Effect of professional prophylaxis and usual toothbrushing on dental plaque. Journal of Dental Research 2000;79(5):A146.

\section{Mojon 1998 \{published data only\}}

Mojon P, Rentsch A, Budtz-Jorgensen E, Baehni PC. Effects of an oral health program on selected clinical parameters and salivary bacteria in a long-term care facility. European Journal of Oral Science 1998;106(4):827-34. 
Nyman 1975 \{published data only\}

Nyman S, Rosling B, Lindhe J. Effect of professional tooth cleaning on healing after periodontal surgery. Journal of Clinical Periodontology 1975;2(2):80-6.

\section{Poulsen 1976 \{published data only\}}

Poulsen S, Agerbæk N, Melsen B, Korts DC, Glavind L, Rölla G. The effect of professional toothcleaning on gingivitis and dental caries in children after 1 year. Community Dentistry and Oral Epidemiology 1976;4:195-9.

\section{Powell 1999 \{published data only\}}

Powell LV, Persson RE, Kiyak HA, Hujoel PP. Caries prevention in a community dwelling older population. Caries Research 1999;33(5):333-9.

\section{Rask 1988 \{published data only\}}

Rask PI, Emilson CG, Krasse B, Sundberg H. Effect of preventative measures in 50-60 with high risk of dental caries. Scandinavian Journal of Dental Research 1988;96(6):500-4.

\section{Rosen 2004 \{published data only\}}

Rosen B, Olavi G, Baderstein A, Ronstrom A, Soderholm G, Egelberg J. Effect of different frequencies of preventive maintenance treatments on periodontal conditions: 5 year observations in general dentistry patients. Journal of Clinical Periodontology 1999;26(4):225-33.

* Rosen B, Olavi G, Birkhed D, Edvardsson S, Egelberg J. Effect of different frequencies of preventive maintenance treatment on dental caries: five-year observations in general dentistry patients. Acta Odontologica Scandinavica 2004;62(5):282-8.

\section{Rosling 1976 \{published data only\}}

Rosling B, Nyman S, Lindhe J. The effect of systematic plaque control on bone regeneration in infrabony pockets. Journal of Clinical Periodontology 1976;3(1):38-53.

\section{Rosling 1983 \{published data only\}}

Rosling B. Periodontally treated dentitions: their maintenance and prognosis. International Dental Journal 1983;33(2):147-51.

\section{Saliba 1997 \{published data only\}}

Saliba CA, Saliba NA, Moimaz SAS. Comparison of the efficacy of supervised toothbrushing and periodic professional prophylaxis on dental plaque control. Journal of Dental Research 1997;76(5):970.

\section{Sandig 1981 \{published data only\}}

Sandig HC, Eismann H. Clinical studies on the efficacy of regular periodontal health check-up [Klinische Untersuchungen uber die Wirksamkeit der periodontalhygienischen Dispensairebetreuung von Patienten mit abnehmbaren gegossenen Teilprothesen]. Stomatologie der DDR 1981;31(8):569-72.

\section{Sato 2008 \{published data only\}}

Sato T, Abe T, Ichikawa M, Fukushima Y, Nakamoto N, Koshikiya N, et al. A randomised controlled trial assessing the effectiveness of professional oral care by dental hygienists. International Journal of Dental Hygiene 2008;6(1):63-7.

\section{Schlagenhauf 1990 \{published data only\}}

Schlagenhauf U, Stellwag P, Fiedler A. Subgingival irrigation in the maintenance phase of periodontal therapy. Journal of Clinical Periodontology 1990;17:650-3.

Schulz 1989 \{published data only\}

Schulz R, Seefeld G. Therapy of gingivitis. Investigations of the effectiveness of preventive care program in dental practice [Untersuchungen uber die Effektivitat von praventiven betreuungsprogrammen unter den bedingungen einer stomatiologischen praxis]. Stomatologie der DDR 1989;39(1):12-6.

\section{Serrano 2011 \{published data only\}}

Serrano C, Torres N, Bejarano A, Cavie-des M, Castellanos ME. Clinical and microbiological comparison of three non surgical protocols for the initial treatment of chronic periodontitis. Journal of the International Academy of Periodontology 2011;13(1):17-26.

\section{Shaw 1991 \{published data only\}}

Shaw M, Shaw $L$. The effectiveness of differing dental health education programmes in improving the oral health of adults with mental handicaps attending Birmingham adult training centres. Community Dental Health 1991;8(2):139-45.

Smulow 1983 \{published data only\} Smulow JB, Turesky SS, Hill RG. The effect of supragingival plaque removal on anaerobic bacteria in deep periodontal pockets. Journal of the American Dental Association 1983;107(5):737-42.

\section{Suomi 1971 \{published data only\}}

Suomi JD, Greene JC, Vermillion JR, Doyle J, Chang JJ, Leatherwood EC. The effect of controlled oral hygiene procedures on the progression of periodontal disease in adults: results after third and final year. Journal of Periodontology 1971;42(3):152-60.

Suomi 1973 \{published and unpublished data\} Suomi JD, Smith LW, Chang JJ, Barbano JP. Study of the effect of different prophylaxis frequencies on the periodontium of young adult males. Journal of Periodontology 1973;44(7):406-10.

Tan 1978 \{published data only\}

Tan HH, Saxton CA. Effect of a single dental health care instruction and prophylaxis on gingivitis. Community Dentistry and Oral Epidemiology 1978;6:172-5.

\section{Tsuboi 2003 \{published data only\}}

Tsuboi S, Morita I, Nakagaki H, Uchibori N, Yasuda J, Kume H, et al. Effect of professional oral prophylaxis on the general health perceptions and lifestyles of workers of a worksite. San Ei Shi 2003;45:222-34.

\section{Van der Weijden 1994 \{published data only\}}

Van der Weijden GA, Timmerman MF, Danser MM, Nijboer A, Saxton CA, Van der Velden U. Effect of pre-experimental maintenance care duration on the development of gingivitis in a 
partial mouth gingivitis model. Journal of Periodontal Research 1994;29(3):168-73.

Wang 1992 \{published data only\}

Wang N, Marstrander P, Holst D, Ovrum L, Dahle T. Extending recall intervals - effect on resource consumption and dental health. Community Dentistry and Oral Epidemiology 1992;20(3):122-4.

\section{Wennström 2011 \{published data only\}}

Wennström JL, Dahlén G, Ramberg P. Subgingival debridement of periodontal pockets by air polishing in comparison with ultrasonic instrumentation during maintenance therapy. Journal of Clinical Periodontology 2011;38(9):820-7.

\section{Westfelt 1983 \{published data only\}}

Westfelt E, Nyman S, Socransky S, Lindhe J. Significance of frequency of professional tooth cleaning for healing following periodontal surgery. Journal of Clinical Periodontology 1983;10(2):148-56.

\section{Westfelt 1998 \{published data only\}}

Westfelt E, Rylander H, Dahlén G, Lindhe J. The effect of supragingival plaque control on the progression of advanced periodontal disease. Journal of Clinical Periodontology 1998;25:536-41.

\section{White 1996 \{published data only\}}

White DJ, Cox ER, Bacca L, Lanzalaco AC, Montgomery RM, Coyle-Rees M. A Quanticalc clinical comparison of professional efficiency in manual supraginival calculus debridement. Journal of Clinical Dentistry 1996;7:54-7.

\section{Zanatta 2011 \{published data only\}}

Zanatta FB, Pinto TM, Kantorski KZ, Rosing CK. Plaque, gingival bleeding and calculus formation after supragingival scaling with and without polishing: a randomised clinical trial. Oral Health and Preventive Dentistry 2011;9(3):275-80.

\section{Zee 2006 \{published data only\}}

Zee KY, Lee DH, Corbet EF. Repeated oral hygiene instructions alone, or in combination with metronidazole dental gel with or without subgingival scaling in adult periodontitis patients: a one year clinical study. Journal of the International Academy of Periodontology 2006;8(4):125-35.

\section{Zimmerman 1993 \{published data only\}}

Zimmerman M, Bornstein R, Martinsson T. Simplified preventive dentistry program for Chilean refugees: effectiveness of one versus two instructional sessions. Community Dentistry and Oral Epidemiology 1993;21(3):143-7.

\section{Additional references}

\section{AAP 1992}

American Academy of Periodontology. Glossary of Periodontal Terms. 3rd Edition. Chicago (IL): American Academy of Periodontology, 1992.

\section{AAP 2001}

American Academy of Periodontology. Position paper: guidelines for periodontal therapy. Journal of Periodontology 2001;72(11):1624-8.

\section{AAP 2015}

American Academy of Periodontology. American Academy of Periodontology Task Force report on the update to the 1999 classification of periodontal diseases and conditions: update to 1999 disease classification. Journal of periodontology 2015;86(7):835-8.

\section{Albandar 2002}

Albandar JM. Global risk factors and risk indicators for periodontal diseases. Periodontology 2000 2002;29:177-206.

\section{Bassetti 2016}

Bassetti RG, Mericske-Stern R, Enkling NI. Are there differences in the changes in oral health-related quality of life (OHRQOL) depending on the type (rigidity) of prosthetic treatment?. Quintessence International 2016;47(9):749-57.

\section{Bentley 1983}

Bentley JM, Cormier P, Oler J. The rural dental health program: the effect of a school-based dental health education program on children's utilization of dental services. American Journal of Public Health 1983;73(5):500-5.

\section{Bonito 2004}

Bonito A, Lohr K, Lux L, Sutton S, Jackman A, Whitener L, et al. Effectiveness of antimicrobial adjuncts to scaling and root planing therapy for periodontitis. Evidence Report Technology Assessment. Agency for Healthcare Research and Quality, 2004; Vol. 88:1-4. [AHRQ Publication No. 04-E014-3]

\section{Caton 2018}

Caton J, Armitage G, Berglundh T, Chapple ILC, Jepsen S, Kornman KS, et al. A new classification scheme for periodontal and peri-implant diseases and conditions - Introduction and key changes from the 1999 classification. Journal of Clinical Periodontology 2018;45(Suppl 20):S1-8.

\section{Corbet 2002}

Corbet EF, Zee KY, Lo EC. Periodontal diseases in Asia and Oceania. Periodontology 2000 2002;29:122-52.

\section{Dal-Ré 2018}

Dal-Ré R, Janiaud P, loannidis JPA. Real-world evidence: how pragmatic are randomized controlled trials labelled as pragmatic?. BMC Medicine 2018;16(1):49. [DOI: 10.1186/ s12916-018-1038-2]

\section{DoH 2000}

Department of Health. Modernising NHS Dentistry Implementing the NHS Plan. HMSO, 2000.

\section{Egger 1997}

Egger M, Davey Smith G, Schneider M, Minder C. Bias in meta-analysis detected by a simple graphical test. BMJ 1997;315(7109):629-34 


\section{Foster 2012}

Foster N, Little P. Methodological issues in pragmatic trials of complex interventions in primary care. British Journal of General Practice 2012;62(594):10-11.

\section{Frame 2000}

Frame PS, Sawai R, Bowen WH, Meyerowitz C. Preventive dentistry: practitioners' recommendations for low-risk patients compared with scientific evidence and practice guidelines. American Journal of Preventive Medicine 2000;18(2):159-62.

\section{Greenstein 1992}

Greenstein G. Periodontal response to mechanical non-surgical therapy: a review. Journal of Periodontology 1992;63(2):118-30.

\section{Higgins 2011}

Higgins JP, Green S, editor(s). Cochrane Handbook for Systematic Reviews of Interventions Version 5.1.0 (updated March 2011). The Cochrane Collaboration, 2011. Available from handbook.cochrane.org.

\section{Ismail 1994}

Ismail AI, Lewis DW, Dingle JL. Prevention of periodontal disease. Canadian Task Force on Preventive Health Care: Guide to Clinical Preventive Health Care. Ottawa: Health Canada, 1994:420-31.

\section{Jenkins 2003}

Jenkins B, Heasman P. The prevention and control of periodontal disease. In: Murray JJ, Nunn JH, Steele JG editor(s). The Prevention of Oral Disease. 4th Edition. Oxford: Oxford University Press, 2003.

\section{Kassebaum 2014}

Kassebaum NJ, Bernabé E, Dahiya M, Bhandari B, Murray CJL, Marcenes W. Global burden of severe periodontitis in 1990-2010: a systematic review and meta-regression. Journal of Dental Research 2014;93(11):1045-53.

\section{Lamont 2017}

Lamont TJ, Clarkson JE, Ricketts DN, Heasman PA, Ramsay CR. Core outcomes in periodontal trials: study protocol for core outcome set development. Trials 2017;18:436. [DOI: 10.1186/ s13063-017-2169-z.]

\section{Lang 2009}

Lang NP, Schatzle MA, Loe H. Gingivitis as a risk factor in periodontal disease. Journal of Clinical Periodontology 2009;36(10):3-8.

\section{Lefebvre 2011}

Lefebvre C, Manheimer E, Glanville J. Chapter 6: Searching for studies. In: Higgins JP, Green S, editor(s). Cochrane Handbook for Systematic Reviews of Interventions Version 5.1.0 (updated March 2011). The Cochrane Collaboration, 2011. Available from handbook.cochrane.org.

\section{Locker 2004}

Locker D, Jokovic A, Clarke M. Assessing the responsiveness of measures of oral health-related quality of life. Community Dentistry and Oral Epidemiology 2004;32:10-8.

\section{Loe 1967}

Loe $\mathrm{H}$. The gingival index, the plaque index and the retention index systems. Journal of Periodontology 1967;38(6):610-6.

\section{Mailoa 2015}

Mailoa J, Lin GH, Khoshkam V, MacEachern M, Chan HL, Wang HL. Long-term effect of four surgical periodontal therapies and one non-surgical therapy: a systematic review and meta-analysis. Journal of Periodontology 2015;86(10):1150-8.

\section{Mansournia 2017}

Mansournia MA, Higgins JPT, Sterne JAC, Hernan MA. Biases in randomized trials - a conversation between trialists and epidemiologists. Epidemiology 2017;28(1):54-9.

\section{Needleman 2002}

Needleman I, Tucker R, Giedrys-Leeper E, Worthington H. A systematic review of guided tissue regeneration for periodontal infrabony defects. Journal of Periodontal Research 2002;37(5):380-8.

\section{Needleman 2015}

Needleman I, Nibali L, Di lorio A. Professional mechanical plaque removal for prevention of periodontal diseases in adults - systematic review update. Journal of Clinical Periodontology 2015;42(Suppl 16):S12-35.

\section{NHS Dental Statistics for England 2017}

NHS Digital. NHS Dental Statistics for England 2016-17, Annual Report. NHS Health Service 2017. [digital.nhs.uk/catalogue/ PUB30069]

\section{Oxford Dictionary 1995}

Concise Oxford Dictionary. The Concise Oxford Dictionary of Current English. 9th Edition. Oxford: Oxford University Press, 1995.

\section{Pilot 1980}

Pilot T. Analysis of the overall effectiveness of treatment of periodontal disease. In: Shanley D editor(s). Efficacy of Treatment Procedures in Periodontics. Berlin: Quintessence Publishing Company, 1980:213-30.

\section{Primary Care Dentistry in Scotland 2017}

Information Services Division - National Services Scotland. Dental Statistics - NHS treatment and Fees. Primary Care Dentistry in Scotland Annual Report 2016/17. Information Services Division - National Services Scotland. [www.isdscotland.org/Health-Topics/Dental-Care/ Publications/2017-09-19/2017-09-19-DentalFees-Report.pdf]

\section{Ramfjord 1959}

Ramfjord SP. Indices for prevalence and incidence of periodontal disease. Journal of Periodontology 1959;30:51.

\section{Riley 2013}

Riley P, Worthington HV, Clarkson JE, Beirne PV. Recall intervals for oral health in primary care patients. Cochrane Database of Systematic Reviews 2013, Issue 12. [DOI: 10.1002/14651858.CD004346.pub4] 


\section{Ryan 2016}

Ryan R, Hills S. How to GRADE the quality of the evidence, Version 3.0 December 2016. Cochrane Consumers and Communications Group. Available from cccrg.cochrane.org/ author-resources.

\section{Schünemann 2009}

Schünemann HJ. GRADE: from grading the evidence to developing recommendations. A description of the system and a proposal regarding the transferability of the results of clinical research to clinical practice. Zeitschrift fur Evidenz, Fortbildung und Qualitat Im Gesundheitswesen 2009;103(6):391-400.

\section{Sheiham 1986}

Sheiham A, Smales FC, Cushing AM, Cowell CR. Changes in periodontal health in a cohort of British workers over a 14-year period. British Dental Journal 1986;160(4):125-7.

\section{Sheiham 2002}

Sheiham A, Netuveli GS. Periodontal diseases in Europe. Periodontology 2000 2002;29:104-21.

\section{Soldani 2018}

Soldani FA, Lamont T, Jones K, Young L, Walsh T, Lala R, et al. One-to-one oral hygiene advice provided in a dental setting for oral health. Cochrane Database of Systematic Reviews 2018, Issue 10. [DOI: 10.1002/14651858.CD007447.pub2]

\section{Sterne 2011}

Sterne JAC, Egger M, Moher D. Chapter 10: Addressing reporting biases. In: Higgins JPT, Green S, editor(s). Cochrane Handbook for Systematic Reviews of Interventions Version 5.1.0 (updated March 2011). The Cochrane Collaboration, 2011. Available from handbook.cochrane.org.

\section{Tonetti 2014}

Tonetti M, Jepsen S, on behalf of Working Group 2 of the European Workshop on Periodontology. Clinical efficacy of periodontal plastic surgery procedures: Consensus Report of Group 2 of the 10th European Workshop on Periodontology. Journal of Clinical Periodontology 2014;41(15):S36-43. [DOI: 10.1111/jcpe.12219]

\section{Wennstrom 1990}

Wennstrom JL, Papapanou PN, Grondahl K. A model for decision making regarding periodontal treatment needs. Journal of Clinical Periodontology 1990;17(4):217-22.

\section{White 2011}

White, D, Pitts N, Steele J, Sadler K, Chadwick B. Adult Dental Health Survey 2009: executive summary: disease and related

\section{CHARACTERISTICS OF STUDIES}

Characteristics of included studies [ordered by study ID] disorders. UK Office for National Statistics 2011. [file:///C:/ Users/tlamont/Downloads/adul-dent-heal-surv-summ-themthe2-2009-rep4.pdf]

\section{WHO 2004}

World Health Organization. Periodontal country profiles: an overview of CPITN data in the WHO Global Oral Data Bank for the age groups 15-19 years, 35-44 years and 65-74 years. www.dent.niigata-u.ac.jp/prevent/perio/contents.html (accessed prior to 23 July 2018).

\section{Worthington 2015}

Worthington $\mathrm{H}$, Clarkson J, Weldon J. Priority oral health research identification for clinical decision-making. Evidencebased Dentistry 2015;16(3):69-71.

\section{Zwarenstein 2008}

Zwarenstein M, Treweek S, Gagnier JJ, Altman DG, Tunis S, Haynes B, et al. Improving the reporting of pragmatic trials: an extension of the CONSORT statement. BMJ 2008;337:a2390. [DOI: 10.1136/bmj.a2390.]

\section{References to other published versions of this review \\ Beirne 2005}

Beirne P, Forgie A, Worthington HV, Clarkson JE. Routine scale and polish for periodontal health in adults. Cochrane Database of Systematic Reviews 2005, Issue 1. [DOI: 10.1002/14651858.CD004625.pub2]

\section{Beirne 2007}

Beirne P, Worthington HV, Clarkson JE. Routine scale and polish for periodontal health in adults. Cochrane Database of Systematic Reviews 2007, Issue 4. [DOI: 10.1002/14651858.CD004625.pub3]

\section{Forgie 2004}

Forgie A, Beirne P, Worthington HV, Clarkson JE. Routine scale and polish for periodontal health in adults. Cochrane Database of Systematic Reviews 2004, Issue 1. [DOI: 10.1002/14651858.CD004625]

\section{Worthington 2013}

Worthington HV, Clarkson JE, Bryan G, Beirne PV. Routine scale and polish for periodontal health in adults. Cochrane Database of Systematic Reviews 2013, Issue 11. [DOI: 10.1002/14651858.CD004625.pub4]

* Indicates the major publication for the study

Jones 2011

Methods Design: parallel-group 3-arm RCT

Location: UK 
Jones 2011 (Continued)

Setting: dental practices

Number of centres: 3

Recruitment period: not stated

Participants

Adults (aged 18 to 60 years) attending dental practice for scheduled dental check-up appointment. Generally fit and well with minimum of 20 natural teeth. All participants had S\&P at baseline.

Number of participants: 369 allocated, 305 analysed

$\begin{array}{ll}\text { Interventions } & \text { Group 1: S\&P every } 6 \text { months } \\ & 125 \text { allocated; } 106 \text { in analysis }\end{array}$

\section{Group 2: S\&P every 12 months}

122 allocated; 100 in analysis

\section{Group 3: no S\&P}

122 allocated; 99 in analysis

9 hygienists and therapists performed the interventions.

OHA given every 6 months to all participants during their routine appointment for dental examination.

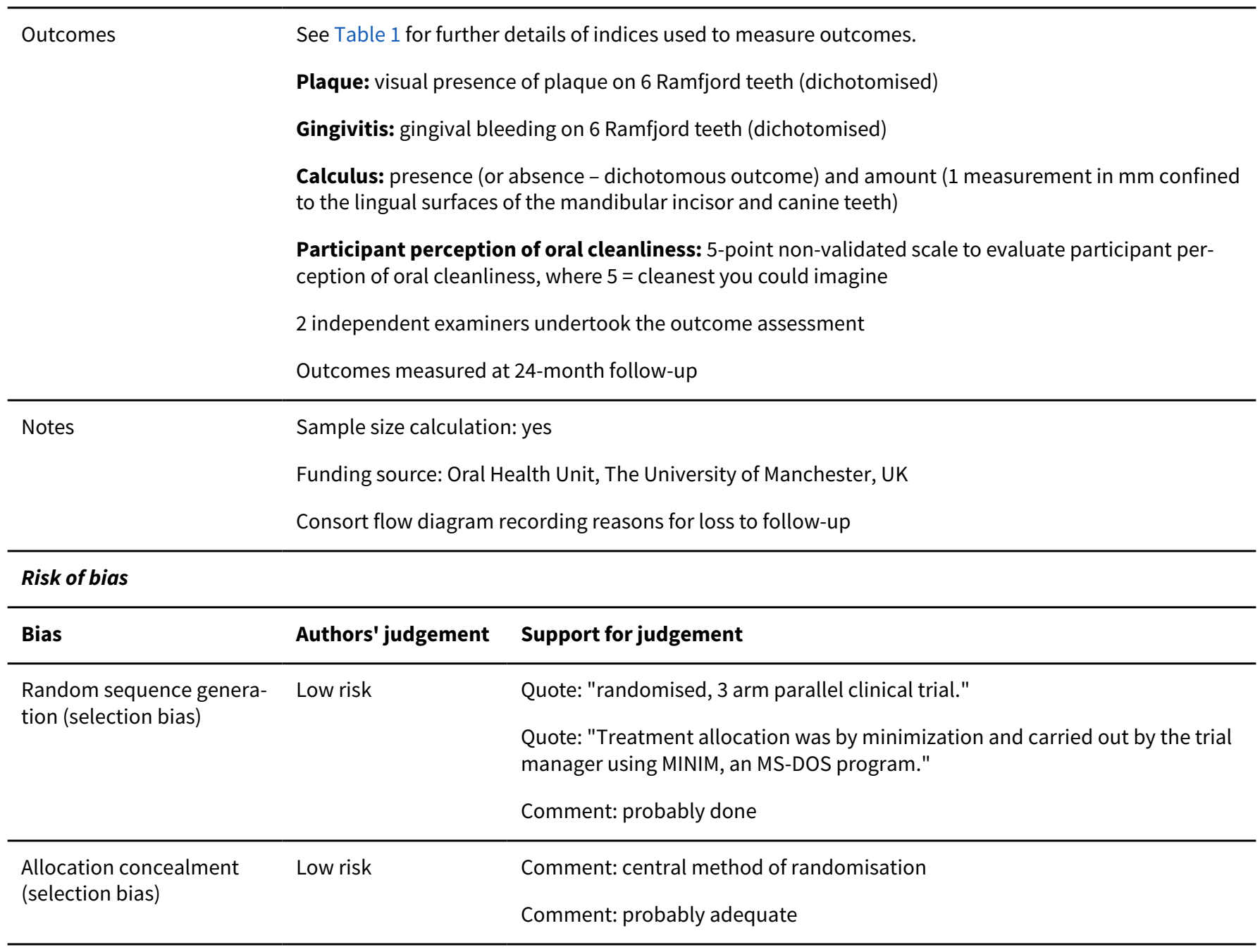


Jones 2011 (Continued)

Blinding of outcome as- Low risk Quote: "Participants were asked not to disclose their allocation group to their sessment (detection bias)

All outcomes dentist or to the outcome examiner."

Quote: "the same two examiners carried out all of the follow-up examinations blind to the allocation."

Comment: probably adequate, although possibility of accidental disclosure by participant could not be excluded.

\begin{tabular}{|c|c|c|}
\hline $\begin{array}{l}\text { Incomplete outcome data } \\
\text { (attrition bias) }\end{array}$ & Low risk & $\begin{array}{l}369 \text { participants randomised. Consort diagram and text explanation of with- } \\
\text { drawals/dropouts }\end{array}$ \\
\hline
\end{tabular}

Selective reporting (re- Low risk All outcomes stated in the methods presented in the results. porting bias)

Other bias Unclear risk

\begin{abstract}
Participants who had BPE $\geq 3$ at any interim examination were withdrawn and the outcome data for these participants were not collected (numbers were similar in 12-monthly and no S\&P groups). Authors noted an overall deterioration in gingival health of the trial population, which the authors suggested may be a result of interexaminer variation.

There were some baseline imbalances in the study groups: $54 \%$ of the participants in 6-month group were women compared with $65 \%$ in the 12 -month group and $72 \%$ in the 24 -month group.

A participant-reported outcome measure (perceived level of oral cleanliness) was measured using a non-validated 5-point scale.
\end{abstract}

\section{Ramsay 2018}

Methods Trial setting: general dental practices in Scotland and North East England

Number of centres: 63 dental practices in Scotland (44) and North East England (19)

48 practices (76\%) employed hygienists; 49 practices (78\%) had $\geq 3$ dentists.

Recruitment period: not specified for dental practices. Participants were recruited between February 2012 and May 2013.

Design: pragmatic, split-plot, multicentre, multilevel factorial trial with a combination of cluster and individual participant randomisation

Inclusion criteria: dentate adults aged $\geq 18$ years. BPE scores
least twice in the previous 2 years and received their dental
Exclusion criteria: people with severe periodontal disease (BP
(e.g. diabetes, immunocompromised)
Characteristics of trial participants at baseline:
- mean age 48 years; $65 \%$ women; $22.6 \%$ current smoker
- mean number of teeth present: 23.6
- highest sextant BPE score $3: 33.2 \%$
- highest sextant BPE score 2: $60.1 \%$
- highest sextant BPE score $1: 6.4 \%$
- mean clinical probing depth: $1.8 \mathrm{~mm}$


Ramsay 2018 (Continued) Interventions
Cluster randomisation with minimisation* of dental practices to:

- personalised OHA (34 practices allocated; 31 practices analysed)

The advice given was based on Social Cognitive Theory and Implementation Intention Theory. The content of the advice was personalised according to the dentist's or hygienist's assessment of participant needs and included advice and instruction in self-diagnosis (e.g. bleeding gums on brushing indicated reversible gingival inflammation) and advice and instruction on toothbrushing and interdental cleaning.

or

- routine (usual) OHA (34 practices allocated; 30 practices analysed)

The advice given was in accordance with usual practice. As described in the trial protocol "there is no published information describing "routine" OHA but anecdotal evidence suggests that this is often the provision of minimal advice (e.g. "you need to brush your teeth more frequently" or no advice)."

*Minimisation factors: employed dental hygienist (yes/no); had $\geq 3$ dentists (yes/no).

Individual randomisation with minimisation\# of 1010 participants within personalised OHA practices to:

- 6-monthly S\&P (337 participants allocated; 239 participants analysed for the primary outcome) or

- 12-monthly S\&P (339 participants allocated; 239 participants analysed for the primary outcome) or

- no S\&P (334 participants allocated; 234 participants analysed for the primary outcome)

Individual randomisation with minimisation\# of 867 participants within routine (usual) OHA practices to:

- 6-monthly S\&P (290 participants; 197 participants analysed (for primary outcome)) or

- 12-monthly S\&P (288 participants; 208 participants analysed (for primary outcome)) or

- no S\&P (289 participants; 210 participants analysed (for primary outcome))

\#Minimisation factors: absence of gingival bleeding on probing (yes/no); highest BPE score 3 (yes/no); current smoking (yes/no)

Participants assigned to the "no scale and polish group" attended their dentist at intervals determined by current practice. If a person allocated to this group did not attend their dentist for an appointment within 12 months, the dentist recalled them for a routine dental check-up.

The definition of a "scale and polish" treatment was that used in standard practice and could include the removal of plaque and calculus from the crown and root surfaces using manual or ultrasonic scalers, with no adjunctive subgingival therapy (e.g. antibiotics) and the appropriate management of plaque retention factors.

All trial participants received an S\&P at baseline.

Based on routine data, the mean (SD) number of S\&P treatments provided during the trial for participants in the 6-monthly group was 2.8 (SD 1.5); in the 12-monthly group 1.8 (SD 1.1); in the no S\&P group 1.0 (SD 1.2).

Outcomes

Only trial outcomes considered to be of relevance to the review (as defined in the Criteria for considering studies for this review section) are presented. Other outcomes measured in the trial are listed in the Notes section of this table.

\section{Clinical outcomes}

Primary

Gingival margin inflammation at 3-year follow-up: measured by running a UNC probe circumferentially around each tooth just within the gingival sulcus (Gingival Index of Löe). After 30 seconds, bleeding 
was recorded as present or absent on the buccal and lingual surfaces and reported as the percentage of sites (twice the number of teeth) with bleeding.

\section{Secondary}

Periodontal pocket depth at 3-year follow-up (clinical probing depth): probing depth was measured using a colour-coded UNC periodontal probe. Clinical probing depths were measured for all teeth, with the exception of third molars, at 6 sites per tooth. Clinical probing depth was calculated as the mean of the 6 different sites measured per tooth, presented in millimetres.

Calculus at 3-year follow-up: presence of calculus was assessed for all teeth, with the exception of third molars, using a colour-coded UNC periodontal probe. The calculus score was calculated by adding all the sites where calculus was observed and dividing by the number of teeth and presented as a percentage.

Additional periodontal instrumentation at 3-year follow-up: defined as those participants self-reporting in their annual questionnaire receiving any private S\&P treatment at any time during the trial (based on the participant's response to the question "In the last 12 months have you received a private scale and polish?").

\section{Participant-centred outcomes}

Oral hygiene self-efficacy at 3-year follow-up: measured on a 1 to 7 scale (1: not at all confident; 7: extremely confident)

Dental Quality of Life: measured using the OHIP-14. Score 0 to 56, with 56 being worst outcome.

Dental appearance: measured using responses to 4 different questions (how clean and pleasant do your teeth look and feel after you brush and after a S\&P?). Each scale ranged from 1 to 7 ("not at all clean/not at all pleasant" to "could not get any cleaner/extremely pleasant"), with 7 being best outcome.

\section{Economic outcomes}

Cost-benefit analysis, which considered: costs to NHS, participant costs and a willingness to pay estimation derived from a discrete choice experiment. For this review, we considered only costs to the NHS.

\section{Notes}

\section{Sample size calculation: yes}

Funding source: supported by a grant from the National Institute for Health Research Health Technology Assessment Programme (ref 09/01/45).

A modified CONSORT flow diagram was included in the trial report incorporating details of randomisation at cluster and individual level, losses to follow-up, withdrawals (numbers declining further follow-up) and exclusions.

The following outcomes were also measured in the trial, but were not considered relevant for this review:

- Patient-centred outcomes

- Perceived behaviour control: perceived ease or difficulty in performing different oral health behaviours. Measured on a 0 to 7 scale, with 7 being the best outcome.

- Attitude outcome: perceived consequences of the behaviour. Measured on a 0 to 7 scale, with 7 being the best outcome.

- Oral health behaviour: measured using responses to 3 questions about duration and frequency of brushing, frequency of flossing and frequency of interdental brush use. Score 0 to 9 , with 9 being best outcome.

- Intention outcome (motivation to perform a behaviour): measured using responses to 3 questions about duration and frequency of brushing and frequency of flossing. Score 0 to 9 , with 9 being best outcome.

- Referral (not defined in the trial report). 
Ramsay 2018 (Continued)

- Having a plan to brush or floss: participants were asked if they had a plan to brush better and if they had a plan to floss better. Participants were recorded as having a plan if they answered "yes" to either question.

- Sensitivity measured using 4 questions. First measured with the question "do you experience sensitivity in your teeth" (yes/no). Second, 3 different scales were used: 1 scale ranging from rarely sensitive to always sensitive (number of points on scale not specified); 1 scale varying from never to all the time (0 to 7 ); 1 scale ranging from no pain to worst imaginable (0 to 7).

- Self-reported bleeding assessed on a 1 (never) to 5 (very often) scale (described in trial report as a "post-hoc outcome").

- Provider-related outcomes

- Beliefs relating to giving OHA and maintenance of periodontal health. Based on questionnaire measurements of the following variables: self-efficacy, attitude, perceived behaviour change, intention, subjective norm, action planning. All measured on a 1 to 7 scale, except subjective norm (1 to 49 scale).

\section{Risk of bias}

Bias Authors' judgement Support for judgement

Random sequence genera- Low risk tion (selection bias)

Quote (from the trial report): "A computer-generated randomization system was used and managed by the Centre for Healthcare Randomised Trials (CHaRT), University of Aberdeen, UK. Both dentist and patient participants underwent randomization with even allocation. The minimization algorithms for the practice allocation were, employs dental hygienist (yes/no) and has 3 or more dentists (yes/no), and for patient allocation absence of gingival bleeding on probing (yes/no), highest BPE score 3 (yes/no) and current smoking (yes/ no)."

Comment: the investigators described a random component in the sequence generation process (minimisation). This judgement applied to the sequence generation for both the cluster randomisation and individual participant randomisation.

Allocation concealment Low risk (selection bias)
Quote (from the trial protocol): "Patient participants' allocation to the PI [periodontal instrumentation] trial arms will use the automated, central randomisation service at the Centre for Healthcare Randomised Trials (CHaRT), University of Aberdeen, with access both by telephone and web."

The Standard Operating Procedure book for CHaRT stated that, "All CHaRT trials utilise a proven, automated, centralised randomisation application. This is accessed by telephone or via the internet, e.g. through a desktop workstation, a handheld computing device or a mobile phone. The randomisation application is capable of employing a variety of designs, usually incorporating a minimisation algorithm, or stratification, or a mixture of the two. The randomisation procedure is tested for robustness prior to randomising the first participant."

Quotes (from the trial report): "...cluster-level randomisation was conducted using the automated, central randomisation service at the Centre for Healthcare Randomised Trials (CHaRT), University of Aberdeen, after the dental practice consent form was received at the Trial Coordinating Office in Dundee (TCOD) and before any potential participant was approached."

"Participants were allocated to the PI trial arms using the automated, central randomisation service at the $\mathrm{CHaRT}$, University of Aberdeen, with access by both telephone and web. Allocation took place once the OA [trial outcome assessor] had completed the baseline outcome assessment [....] OAs were informed that allocation had taken place but were blinded to allocation, with the actual allocation transmitted to the TCOD." 
Comment: allocation concealment was probably adequate for both cluster and individual participant randomisation.

Blinding of outcome as- Low risk sessment (detection bias) All outcomes

Quote (from the trial protocol): "Clinical outcomes will be measured at baseline and at three years follow-up by trained outcome assessors who are blinded to allocation."

Quote (from the trial report): "Clinical outcomes were recorded by blinded assessors at baseline and three years. Outcome assessor training was provided to ensure intra- and inter-assessor alignment."

Comment: blinding of clinical status outcome assessment was probably adequate, although the possibility of unintentional disclosure of group assignment by participants could not be excluded.

Participant-centred outcomes were measured using self-administered questionnaires. Blinding of trial participants was neither feasible nor desirable in this pragmatic trial where one of the aims was to measure the effects under real-world conditions of assigning different recall intervals between S\&P treatments.

The collection of economic measures was deemed unlikely to be influenced by knowledge of group assignment.

Incomplete outcome data Low risk (attrition bias)

All outcomes
Quotes (from the trial report): "The primary clinical outcome was collected at the 3-year clinical follow-up. Overall, $71 \%$ of the participants attended the appointment. Twelve participants were known to have died by the end of the 3-year follow-up. The main reasons for non-attendance were that the practice was unable to contact the participant $(41 \%)$, the participant was unable to attend $(30 \%)$ and the participant did not want to attend (13\%). There were no important differences between groups for the reasons of non-attendance."

"Approximately $77 \%$ of participants completed a follow-up questionnaire at 3 years. There were no substantive differences in response rates between the randomised groups"

"Possible mechanisms of missingness were investigated by modelling baseline predictors of participants missing the final examination. Only age was identified as a predictor. Clinial severity of disease indicators (bleeding, calculus and clinical pocket depths) were not predictors. There were no differences between randomised groups in the proportion of missing data. In addition, the main reason for missing the final examination was that the participant was no longer contactable by the dental practice and, therefore, unlikely to be related to the study interventions. Given these findings, no further missing data sensitivity analyses were undertaken".

Comment: the trial report included a CONSORT diagram documenting the numbers lost to follow-up, withdrawals and exclusions from intervention groups. Missing outcome data for the primary clinical outcome were balanced across the periodontal instrumentation groups (ranging from $27 \%$ to $32 \%$ ). Questionnaire response rates were also balanced across groups (year 3 response rates ranged from $75 \%$ to $79 \%$ ).

Taking into account the fact that 1) the proportions of missing outcome data and 2) the reasons for missing outcome data were similar across groups, there was no evidence to suggest that the missing outcome data were likely to have biased estimates of intervention effect.
Selective reporting (re- Low risk porting bias)
Comment: the trial protocol was available and all of the trial's prespecified primary and secondary clinical outcomes and participant-centred outcomes were reported in the prespecified way in the trial report. 
Ramsay 2018 (Continued)

Other bias

Low risk
As recommended in the Cochrane Handbook for Systematic Reviews of Interventions, we considered the following biases specifically relevant to trials involving cluster randomisation (Higgins 2011).

\section{Recruitment bias}

Quote (from the trial protocol): "...cluster level randomisation will be conducted after the dental consent form is received at the Trial Coordinating Office in Dundee (TCOD) and before any patient has been approached."

Comment: participants were recruited after the clusters were randomised. Knowledge regarding whether each cluster was a routine $\mathrm{OHA}$ or personalised OHA cluster could potentially have influenced the types of participants recruited. However, the baseline data demonstrates that the groups were well balanced for clinical and participant-centred factors. Low risk of bias.

\section{Baseline imbalance}

The trial report contained a table documenting the baseline characteristics of clusters. The trial authors noted that "personalised oral hygiene advice practices were less likely to employ hygienists compared with usual ( $73 \%$ versus $80 \%)$." There were no other baseline imbalances of note.

The baseline sociodemographic and clinical dental characteristics of individual trial participants were similar across groups.

Comment: low risk of bias.

\section{Loss of clusters}

Of the 34 practices originally randomised to routine $\mathrm{OHA}, 4$ dental practices were excluded postrandomisation. The final number of clusters analysed was 30 (mean cluster size 20.5; range 5 to 36 ).

Of the 34 practices originally randomised to personalised OHA, 1 was excluded postrandomisation and a further 2 clusters declined further follow-up and were not included in the final analysis. The final number of clusters analysed was 31 (mean cluster size 23; range 11 to 37 ).

The authors were contacted and confirmed: "The exclusions were due to a trial procedural error in the early recruitment phase of the study whereby practices were randomised when a dentist in a practice had verbally given consent to take part but before the practice principal dentist (usually the owner of the practice) had signed a consent form for the practice to take part in the trial. The principal dentist did not give permission to use their practice. The practice study intervention allocation was not known to any potential dentist, practice principal dentist (or patient) participants at the time of non-consent. Selection bias due to the post-randomisation exclusions was not therefore possible."

Comment: low risk of bias.

Did the analysis take clustering into account? (was there a unit of analysis error?)

Quote (from the trial protocol): "Reflecting the clustering in the data, the outcomes will be compared using multilevel models, with adjustment for minimisation variables."

Quote (from the trial report): "To analyse comparisons between groups, we used mixed effects models with adjustments for covariates in the minimization algorithm and, where possible, adjustments for baseline scores."

Comment: low risk of bias. Analyses were probably adequate and accounted for clustering. 


\title{
Compatibility with individually randomised trials
}

Comment: low risk of bias. The split-plot trial design involved both cluster randomisation (of dental practices to routine or personalised $\mathrm{OHA}$ ) and individual participant randomisation (to S\&P treatments at different recall intervals). In the absence of a significant interaction effect between the OHA and S\&P interventions, there is no reason to suspect that there would be substantive differences in effect sizes estimated in this trial and effect sizes estimated in other trials conducted in similar participant populations that employed randomisation exclusively at the individual level.

BPE: Basic Periodontal Examination; DCP: dental care professional; OHA: oral hygiene advice; OHI: oral hygiene instruction; OHIP-14: Oral Health Impact Profile-14; NHS: National Health Service; RCT: randomised controlled trial; S\&P: scale and polish; SD: standard deviation; UNC: University of North Carolina.

\section{Characteristics of excluded studies [ordered by study ID]}

\begin{tabular}{ll}
\hline Study & Reason for exclusion \\
\hline Adachi 2002 & Did not evaluate a routine S\&P intervention. None of the primary outcomes specified in our review. \\
& Evaluated the effectiveness of professional tooth cleaning by dental hygienists once a week for 24 \\
& months in a group of elderly people living in 2 nursing homes. Outcomes: fevers $>37.8^{\circ} \mathrm{C}$, preva- \\
& lence of aspiration pneumonia, numbers of Staphylococcus species and Candida albicans in oral \\
swab samples and the amount of methylmercaptan exhaled.
\end{tabular}

$\begin{array}{ll}\text { Addy } 1988 & \text { Not routine S\&P. Antimicrobial strips used in } 3 \text { out of } 4 \text { treatment groups. Remaining treatment } \\ \text { group received root planing. }\end{array}$

Aldridge 1995 Length of follow-up < 6 months. Data from 2 studies presented in the paper. In the first study, 41 participants were randomly allocated to receive oral hygiene instruction (small loop flossing, Bass technique brushing, scaling and adjustment of restorative margins) or no treatment. Participants in the intervention group returned for re-enforcement 1 month later. Excluded as follow-up $<6$ months (2 months). In the second study, 23 participants were randomised to receive non-surgical treatment (Bass technique brushing, flossing, scaling and root planing under local anaesthesia) or no-treatment control. Excluded due to the use of root planing (not routine S\&P).

Ashley 1982

Children with mixed dentition at baseline. Recruited schoolgirls aged 11 and 12 years old at baseline. Girls in intervention arm were randomly assigned by class to visit the hygienist every 2 weeks during term time for 3 years for oral hygiene reinforcement and professional prophylaxis. Girls in control group received the oral hygiene instruction normally given at school.

Unclear if randomised. Examined the effect of fluoride on caries in a programme involving meticulous plaque control. 82 participants of both sexes recruited (41 in each arm). Prophylactic treatment administered once every 2 weeks. During these sessions an abrasive paste containing 5\% sodium monofluorophosphate was used in control group, and a paste that did not contain fluoride was used in test group.

\section{Axelsson 1977}

\begin{abstract}
Children with mixed dentition at baseline. In this study, 216 Swedish school children aged 7-14 years were divided into test and control groups. Once a month, children in control group brushed their teeth with a $0.2 \%$ sodium fluoride solution under the supervision of a dental nurse. Participants in the treatment group received detailed information on the prevention of gingivitis, periodontitis and caries. During the first 2 years, participants in the treatment group also received detailed oral hygiene instruction and professional prophylaxis (including the application of sodium monofluorophosphate) at a dental nurse clinic every 2 weeks.
\end{abstract}

Axelsson 1981

Not a randomised controlled trial. 90 participants referred for treatment of advanced periodontal disease recruited. For first 2 months after surgery (Widman flap technique), participants were recalled every 2 weeks for professional tooth cleaning. Every third participant was referred back to 


\section{Study \\ Reason for exclusion}

the care of their dentist for maintenance. While the remaining 2 out of 3 were enrolled in a maintenance care programme at a university clinic (participants were recalled every 2 months and received oral health instruction, scaling and tooth cleaning). Participants were re-examined 3 and 6 years after baseline examination.

Axelsson 1987

Not routine S\&P. Involved 2 treatment groups (Groups 1 and 2) and 1 control group (Group 3). Group 1 received oral hygiene instruction, professional mechanical tooth cleaning including tongue scraping and chlorhexidine mouthrinse followed by application of $1 \%$ chlorhexidine gel (excluded from review due to adjunctive use of chlorhexidine). The entire prophylactic regimen was performed on days $1,3,5$ and 8 , followed by 1 single treatment every 6 months throughout the experimental period. Group 2 received only oral hygiene instructions given on days $1,3,5$ and 8 for approximately 10 minutes on each occasion (excluded from review as no S\&P provided). The instructions were repeated every 6 months. Group 3 received no treatment additional to the 1 based on individual needs given by the local dental health officers.

Axelsson 2004

Not a randomised controlled trial. The authors referred to an earlier paper for further details of the study participants. We retrieved this paper (Axelsson 1978; see under Axelsson 2004). Participants were recruited using the recall list of 3 general private practitioners and the waiting list of 3 large public dental health clinics. Potential participants for the test group were informed by letter of the purpose of the study and asked to volunteer for the trial. Potential members for the control group were informed that if they agreed to receive a very detailed oral examination they would be recalled for dental treatment to the public dental health clinic once a year during the next 3 years. Only those volunteers who had sought and received dental treatment annually during the last 5 years were selected.

Badersten 1984 Unclear if randomised. The incisors, cuspids and premolars received plaque control and supragingival and subgingival debridement using hand or ultrasonic scaling in a split-mouth design.

Bellini 1981

Children with mixed dentition at baseline. Examined the effect of monthly professional tooth cleaning on gingivitis in children aged $7-11$ years. Not routine S\&P. Compared 2 different methods of scaling (manual vs ultrasonic scaling).

Not routine S\&P. Evaluated the effects of routine and intensified dental care and disease prevention in people with HIV. Study involved 1 control group ('standard care group') and 1 treatment group ('enhanced care group'). The standard care group received free professional dental treatment as needed and desired, including semi-annual professional prophylaxes and check-ups (3 per participant, at baseline, 6 months and 1 year). The enhanced care group received standard care plus additional free professional prophylaxes (every 2 months) and twice-daily chlorhexidine antiseptic mouth rinses (excluded from review due to adjunctive use of chlorhexidine).

Not a randomised controlled trial. Examined the effects of an oral health programme on the occurrence of oral candidosis in residents in a long-term care facility. 2 groups of residents were formed in this study. The authors stated that random allocation was 'ruled out' and all the residents of each ward were assigned to 1 of the 2 groups. The study appeared to have been carried out in the same long-term care facility as Mojon 1998.

\begin{tabular}{ll}
\hline Chapple 1995 & Not routine S\&P. Split-mouth design: full power vs half power ultrasonic scaling. \\
\hline Chawla 1975 & $\begin{array}{l}\text { Randomisation not mentioned. } 1 \text { of the study authors was contacted by the review team but failed } \\
\text { to respond to a second e-mail request for further information. }\end{array}$ \\
\hline Cutress 1991 & $\begin{array}{l}\text { Not a randomised controlled trial. This was a field trial of a community-based periodontal disease } \\
\text { prevention programme in a low-income country. The authors stated that allocation of villages to } \\
\text { periodontal disease prevention programmes was on an 'arbitrary basis' and was also dependent } \\
\text { on the facilities available. }\end{array}$
\end{tabular}




\section{Study Reason for exclusion}

Feldman 1988

Not a randomised controlled trial. This study examined the long-term impact of 2 dental delivery systems on children's oral health. It was not possible to determine any differences in the provision of S\&P treatments to both groups. On reviewing an earlier paper describing the procedure for forming the 2 study groups (Bentley 1983), it became evident that the randomisation procedure used was compromised. After first siblings were randomly assigned, their brothers or sisters or both were removed from the subsequent assignment process and given the same assignment.

\begin{tabular}{ll} 
Glavind 1977 & Study included periodontal patients in maintenance phase. \\
\hline Godin 1976 & $\begin{array}{l}\text { Not routine S\&P. Participants randomised to receive the intervention were taught to self-scale us- } \\
\text { ing a dentiscope, a large plane mouth mirror and a scaler. The control group received scaling and } \\
\text { oral hygiene instruction limited to } 3 \text { hours over } 4 \text { or } 5 \text { visits. }\end{array}$
\end{tabular}

Greenwell 1985

Not routine S\&P. Compared the effectiveness of 2 oral hygiene regimens ('Keyes' method' vs 'conventional oral hygiene instruction').

Grimm 1986

Not a randomised controlled trial. Treatment and control groups were formed according to age of participants.

Gunay 1998

Not a randomised controlled trial. A 3-phase prospective study examining the effects of a long-term preventive programme for mothers and children starting during pregnancy; there were no randomised comparison groups.

\begin{tabular}{|c|c|}
\hline Hellström 1996 & All participants received a S\&P. No control group. \\
\hline Hill 1981 & $\begin{array}{l}\text { Not routine S\&P. In this study, each quadrant of a participant's dentition was randomly assigned to } \\
1 \text { of } 4 \text { treatment types: quadrant } 1 \text { (surgical pocket elimination); quadrant } 2 \text { (modified Widman flap } \\
\text { surgery); quadrant } 3 \text { (subgingival curettage); quadrant } 4 \text { (thorough scaling and root planing by the } \\
\text { periodontist as a principally 'non-surgical' control area). }\end{array}$ \\
\hline Hoffman 2005 & Not routine S\&P. This study compared the use of a Vector scaling system and a piezo-electric scaler. \\
\hline Hou 1989 & $\begin{array}{l}\text { Not a randomised controlled trial. Only } 1 \text { group of participants was formed and all received the } \\
\text { same level of treatment (ultrasonic scaling and root planing). }\end{array}$ \\
\hline Huber 1987 & $\begin{array}{l}\text { Not a randomised controlled trial. Study used a split-mouth experimental design. However, alloca- } \\
\text { tion to 'test' and 'control' sides was not random. }\end{array}$ \\
\hline Hugoson 2007 & $\begin{array}{l}\text { Interventions confounded by other problems. } 1 \text { group had a S\&P on } 2 \text { quadrants so a split-mouth } \\
\text { design. }\end{array}$ \\
\hline Kaldahl 1988 & $\begin{array}{l}\text { Not routine S\&P. Used coronal scaling as a 'control' in } 1 \text { quadrant (quadrant A) for } 3 \text { 'treatment' } \\
\text { quadrants: quadrant B: coronal and subgingival scaling and root planing; quadrant C: coronal and } \\
\text { subgingival scaling and root planing followed by modified Widman surgery; quadrant D: coronal } \\
\text { and subgingival scaling and root planing followed by flap with osseous resection surgery. }\end{array}$ \\
\hline Katay 1990 & Participants had partial dentures. \\
\hline Ketomaki 1993 & $\begin{array}{l}\text { Not a randomised controlled trial. Participants were assigned (not a random assignment) either to } \\
\text { 'individualised recall' or to 'annual recall' examinations. }\end{array}$ \\
\hline Kinane 2000 & $\begin{array}{l}\text { Not routine S\&P. Participants were randomised to } 4 \text { treatment groups: } 1 \text {. scaling and root planing } \\
\text { alone, } 2 \text {. scaling and root planing plus antimicrobial therapy (minocycline gel), } 3 \text {. scaling and root } \\
\text { planing plus antimicrobial therapy (tetracycline fibres), and } 4 \text {. scaling and root planing plus antimi- } \\
\text { crobial therapy (metronidazole gel). }\end{array}$ \\
\hline
\end{tabular}




\begin{tabular}{ll}
\hline Study & Reason for exclusion \\
\hline Klein 1985 & $\begin{array}{l}\text { Not a randomised controlled trial. Examined the cost and effectiveness of various types and com- } \\
\text { binations of school-based preventive dental care procedures. Schools (rather than individual chil- } \\
\text { dren) were assigned to regimens in a way that balanced baseline decay level, numbers of children } \\
\text { and racial mix across treatment regimens. }\end{array}$
\end{tabular}

Knöfler $2007 \quad$ Not routine S\&P. Compared scaling and root planing to full mouth scaling in a sample of 37 male
participants with moderate chronic periodontitis.

Kwan-Yat 2006

Not routine S\&P. Compared oral hygiene instructions alone or in combination with metronidazole $25 \%$ gel or subgingival scaling with or without metronidazole gel in the treatment of new, residual or recurrent periodontal pockets in people previously treated for periodontitis.

\begin{tabular}{|c|c|}
\hline Lee 2009 & $\begin{array}{l}\text { Not a randomised controlled trial. Pseudo-randomised: order of outpatient visits used to randomly } \\
\text { assign participants to intervention and control groups. }\end{array}$ \\
\hline Lembariti 1998 & Randomised split-mouth design on contralateral quadrants, single intervention given once. \\
\hline Lightner 1971 & Interventions tested not representative of routine S\&P treatment. \\
\hline Lim 1996 & $\begin{array}{l}\text { Unclear if randomised. } 550 \text { employees of both sexes aged } 25-44 \text { years were selected using "strat- } \\
\text { ified random sampling criteria." Participants were then "divided" into } 4 \text { groups. Group A: oral hy- } \\
\text { giene group ( } 195 \text { participants); group B: scaling ( } 148 \text { participants); group C: scaling and oral hy- } \\
\text { giene ( } 145 \text { participants); group D: control ( } 62 \text { participants). }\end{array}$ \\
\hline Listgarten 1985 & Interventions tested not representative of routine S\&P treatment. \\
\hline Listgarten 1986 & $\begin{array}{l}\text { Study included participants with treated periodontal disease and were on different maintenance } \\
\text { schedules. }\end{array}$ \\
\hline Loesche 2002 & $\begin{array}{l}\text { Not routine S\&P. Participants were randomly assigned (following debridement) to receive metron- } \\
\text { idazole or doxycycline or placebo. }\end{array}$ \\
\hline Lunder 1994 & $\begin{array}{l}\text { Not a randomised controlled trial. Participants were allocated to treatment (18-month recall) and } \\
\text { control (12-month recall) groups alphabetically according to their surname. Authors also stated } \\
\text { that "when allocating the children into the } 2 \text { groups geography and caries-activity was taken into } \\
\text { consideration." }\end{array}$ \\
\hline López 2005 & $\begin{array}{l}\text { Not routine S\&P. Randomised } 870 \text { pregnant women with gingivitis to periodontal treatment be- } \\
\text { fore } 28 \text { weeks' gestation or a control group who received periodontal treatment after delivery. Pe- } \\
\text { riodontal therapy consisted of plaque control, scaling and daily rinsing with } 0.12 \% \text { chlorhexidine. } \\
\text { Maintenance therapy was provided every } 2 \text { or } 3 \text { weeks until delivery. Excluded due to the use of } \\
\text { chlorhexidine. }\end{array}$ \\
\hline Mishkin 1986 & Not routine S\&P. Split-mouth. S\&P vs waterjet \\
\hline Moimaz 2000 & $\begin{array}{l}\text { Randomisation not mentioned (abstract). This study divided participants into } 2 \text { groups. Group } 1 \text { re- } \\
\text { ceived prophylaxis and maintained usual oral hygiene while group } 2 \text { carried out usual oral hygiene } \\
\text { only. }\end{array}$ \\
\hline Mojon 1998 & $\begin{array}{l}\text { Not a randomised controlled trial. Evaluated the effectiveness of a comprehensive oral health pro- } \\
\text { gramme for residents of a long-term care facility. } 2 \text { groups were formed: } 1 \text { group comprised of resi- } \\
\text { dents from } 5 \text { wards; the other group comprised of residents from } 7 \text { wards. The assignment of wards } \\
\text { to each group took into account the location of the ward. } 1 \text { of the groups was then randomly select- } \\
\text { ed as the experimental group. The study appeared to have been carried out in the same long-term } \\
\text { care facility as Budtz-Jorgensen } 2000 \text {. }\end{array}$ \\
\hline
\end{tabular}




\begin{tabular}{ll}
\hline Study & Reason for exclusion \\
\hline Moëne 2010 & $\begin{array}{l}\text { Not routine S\&P. Compared the subgingival application of amino acid glycerine powder to scaling } \\
\text { and root planing. }\end{array}$
\end{tabular}

Nyman 1975 Study included participants postperiodontal surgery.

Poulsen 1976

Children with mixed dentition at baseline. Randomised 7-year old children to 2 groups: the intervention group received mechanical tooth cleaning every 2 weeks and the control group were untreated.

Powell 1999

Not routine S\&P. In this study participants were randomly assigned to 1 of 4 experimental groups or a control group. The control group (Group 1) received 'usual care' from a public health department or private practitioner. Group 2 received an educational programme of 2 hours duration implemented twice a year. Group 3 received the educational programme plus a chlorhexidine rinse weekly. Group 4 received the education and chlorhexidine interventions and a fluoride varnish application by a dental hygienist twice a year. Group 5 received all of the above interventions as well as scaling and root planing by a dental hygienist every 6 months throughout the 3-year study.

Rask 1988 Interventions not relevant. Randomised controlled trial was designed to test the effectiveness (in people at high risk of caries) of an intensified preventive regimen. The effects of scaling and polishing were not examined.

Rosen 2004

Not a randomised controlled trial. Following the initial examination, 391 participants were divided into 4 experimental groups. First, 3 age groups were formed and within each of these age groups equal numbers of people were matched into the 4 experimental groups based on the number of remaining teeth, number of decayed and filled tooth surfaces, number of decayed surfaces, full mouth plaque scores and mean probing depth.

Rosling $1976 \quad$ Study included people with advanced periodontal disease.

Rosling 1983

Not routine S\&P. 2 studies. In study 1 (2-year clinical study), 75 people were randomly distributed into intervention (professional cleaning) and control groups. Participants were additionally randomly distributed to receive 1 of 5 surgical procedures: the apically repositioned flap operation including elimination of bony fragments, the apically repositioned flap operation including curettage of bony defects but without removal of bone, the Widman flap technique including elimination of bony defects, the Widman flap technique including curettage of bony defects but without removal of bone and gingivectomy. After surgery, the teeth of participants in the intervention arm were professionally cleaned once every 2 weeks during a 2-year period. The participants in the control arm were recalled once a year for supragingival scaling and polishing. No data from this study were reported in this article. Only the 50 participants in the treatment arm of the 2-year clinical study progressed to the 6-year clinical study, while the 25 control participants were withdrawn.

Saliba 1997

Randomisation not mentioned (abstract). 45 school children were divided into 3 groups. Group A received toothbrushing and dental floss use under supervision. Group B received professional prophylaxis. Group C received non-supervised toothbrushing.

Sandig 1981

Unclear if study was randomised (paper in German). This study was partially translated (Material and methods section) with a view to determining its eligibility. However, we were unable to ascertain if it was a randomised trial. The authors stated that, "2 comparable groups of 18 or 20 patients were studied. A year ago those patients were treated with cast removable partial dentures at the department of Stomatology of the medical academy Erfurt."

Sato 2008

No S\&P. Compared professional oral care performed by a hygienist (15 minutes of instructions on mouth cleaning and on Bass toothbrushing method) with toothbrushing and mouth rinsing by participants themselves. 


\section{Study \\ Reason for exclusion}

Schulz 1989

Unclear if study was randomised. Unable to contact authors to determine if the study was a randomised controlled trial (paper in German).

This study was fully translated with a view to determining its eligibility. However, we were unable to ascertain if it was a randomised trial. In addition, the interventions and comparison groups were poorly described. The authors stated that, " 55 test persons participated in this study. They had gingivitis caused by plaque at the age 15 and 25 years (17.7 years on average). Not included were pregnant women, patients with internal diseases, with prosthetic restorations and untreated caries. 15 test persons took part in 3 different programmes, over a period of 3 months that had the following objectives: oral hygiene instructions and motivation (dental nurse) as well as professional tooth cleaning (dentist). 1 group made up of 10 test persons (group IV) served as the control group. The programme of group III with 1 motivation session without teeth cleaning training was designed to check which results the frequent examination with an oral hygiene pass/check book produces. From the results of the test group we expected indications of the motivating effect of the professional teeth cleaning and of the importance for the reduction of gingivitis as such."

Serrano 2011

Not routine S\&P. Compared 3 protocols for non-surgical periodontal therapy. Participants were randomised to receive scaling and root planing quadrant by quadrant at weekly intervals (control group), full mouth scaling and root planing performed over 2 consecutive days (FM group), or full mouth scaling and root planing performed over 2 consecutive days combined with the administration of antibiotics (FMa group).

Shaw 1991

4 centres randomised to 4 interventions. Cluster-randomised controlled trial with single cluster per intervention so unable to use data.

Smulow 1983

Not routine S\&P. Participants were randomised to 4 groups. Group 1 received initial scaling and daily polishing, group 2 received daily polishing without initial scaling, group 3 received initial scaling without daily polishing and group 4 received no treatment.

Suomi 1971

Not a randomised controlled trial. Carried out "to test the hypothesis that the development and progression of gingival inflammation and destructive periodontal disease are retarded in an oral environment in which high levels of hygiene are maintained." 2 groups (experimental and control) were matched on the basis of periodontal and oral hygiene status, past caries experience, age and sex. The experimental group were given a series of frequent oral prophylaxes combined with oral hygiene instruction and dental health education. Participants in the control groups received no attention from the study team except for annual examinations.

Suomi 1973 Unclear how groups were formed; unlikely to be randomised.

Tan 1978

Follow-up $<6$ months. 120 Dutch army recruits in 2 camps were randomised to receive no treatment (group A), professional prophylaxis (group B), dental health instruction (group C) or both prophylaxis and dental health instruction (group D). Participants were examined at initiation of the study, after 1 month and 3 months.

\begin{tabular}{ll}
\hline Tsuboi 2003 & Not a randomised controlled trial (after translation from Japanese). \\
\hline Van der Weijden 1994 & No S\&P. Looked at the effect of pre-experimental maintenance on the development of gingivitis. \\
\hline Wang 1992 & $\begin{array}{l}\text { Interventions not relevant. In this randomised controlled trial, participants were randomly allocat- } \\
\text { ed to recall examination at either } 12 \text { months or } 24 \text { months. S\&P treatments (if any) provided at re- } \\
\text { call were not reported in this paper. Outcomes reported were clinical examination time, treatment } \\
\text { time and the Decayed Missing Filled Surfaces increment during the 2-year study period. }\end{array}$
\end{tabular}

Wennström 2011

Not routine S\&P. Compared air polishing to ultrasonic instruments in a split-mouth study.

Westfelt 1983

Participants had periodontal surgery. 


\begin{tabular}{ll}
\hline Study & Reason for exclusion \\
\hline Westfelt 1998 & $\begin{array}{l}\text { Not routine S\&P. Split-mouth study. } 2 \text { quadrants of each participant were designated test group, } \\
\text { while the other } 2 \text { were identified as control. Participants in the test group received supragingival } \\
\text { plaque control. Participants in the control group received subgingival scaling and root planing. }\end{array}$ \\
\hline White 1996 & $\begin{array}{l}\text { Length of follow-up < } 6 \text { months. Single episode of scaling. Participant characteristics not present- } \\
\text { ed. Examined the efficiency of } 2 \text { professionals (1 dentist, } 1 \text { dental hygienist) in removing supragin- } \\
\text { gival calculus. Participants were concomitantly participating in a tartar control dentifrice trial. Out- } \\
\text { comes: total developed force, mean force per stroke, total strokes and Volpe-Manhold-Index grad- } \\
\text { ing. }\end{array}$ \\
\hline Zanatta 2011 & $\begin{array}{l}\text { Length of follow-up < } 6 \text { months. Split-mouth study. } 67 \text { participants received supragingival scaling } \\
\text { on the } 6 \text { mandibular teeth. Quadrants were then randomly selected to be polished or not with a } \\
\text { rubber cup and pumice. Outcomes assessed at } 1,2 \text { and } 3 \text { weeks post-treatment. }\end{array}$ \\
\hline Zee 2006 & $\begin{array}{l}\text { Not routine S\&P. Split-mouth study. Active treatment included subgingival scaling, metronidazole } \\
\text { 25\% gel and subgingival scaling plus metronidazole } 25 \% \text { gel. A control group was also used. }\end{array}$ \\
\hline Zimmerman 1993 & $\begin{array}{l}\text { All participants received S\&P. Examined the effectiveness of } 1 \text { vs } 2 \text { preventive advice sessions. Both } \\
\text { treatment and control groups were given 30-minute S\&P treatments. }\end{array}$ \\
\hline
\end{tabular}

S\&P: scale and polish.

DATA AND ANALYSES

Comparison 1. Scale and polish versus no scale and polish

\begin{tabular}{|c|c|c|c|c|}
\hline $\begin{array}{l}\text { Outcome or subgroup ti- } \\
\text { tle }\end{array}$ & No. of studies & $\begin{array}{l}\text { No. of partici- } \\
\text { pants }\end{array}$ & Statistical method & Effect size \\
\hline $\begin{array}{l}1 \text { Gingivitis at } 24-36 \\
\text { months }\end{array}$ & 2 & & Std. Mean Difference (IV, Fixed, 95\% CI) & Subtotals only \\
\hline $\begin{array}{l}1.16 \text {-monthly scale and } \\
\text { polish (S\&P) }\end{array}$ & 2 & 1087 & Std. Mean Difference (IV, Fixed, 95\% CI) & $-0.01[-0.13,0.11]$ \\
\hline 1.2 12-monthly S\&P & 2 & 1091 & Std. Mean Difference (IV, Fixed, 95\% CI) & $-0.04[-0.16,0.08]$ \\
\hline $\begin{array}{l}2 \text { Calculus at } 24-36 \\
\text { months }\end{array}$ & 2 & & Std. Mean Difference (IV, Fixed, 95\% Cl) & Subtotals only \\
\hline 2.16-monthly S\&P & 2 & 1084 & Std. Mean Difference (IV, Fixed, 95\% CI) & $-0.32[-0.44,-0.20]$ \\
\hline 2.2 12-monthly S\&P & 2 & 1088 & Std. Mean Difference (IV, Fixed, 95\% CI) & $-0.19[-0.31,-0.07]$ \\
\hline 3 Plaque at 24 months & 1 & & Mean Difference (IV, Fixed, 95\% CI) & Totals not selected \\
\hline 3.1 6-monthly S\&P & 1 & & Mean Difference (IV, Fixed, 95\% CI) & $0.0[0.0,0.0]$ \\
\hline 3.2 12-monthly S\&P & 1 & & Mean Difference (IV, Fixed, 95\% CI) & $0.0[0.0,0.0]$ \\
\hline $\begin{array}{l}4 \text { Probing depths at } 36 \\
\text { months }\end{array}$ & 1 & & Mean Difference (IV, Fixed, 95\% CI) & Totals not selected \\
\hline
\end{tabular}




\begin{tabular}{|c|c|c|c|c|}
\hline $\begin{array}{l}\text { Outcome or subgroup ti- } \\
\text { tle }\end{array}$ & No. of studies & $\begin{array}{l}\text { No. of partici- } \\
\text { pants }\end{array}$ & Statistical method & Effect size \\
\hline 4.1 6-monthly S\&P & 1 & & Mean Difference (IV, Fixed, 95\% CI) & $0.0[0.0,0.0]$ \\
\hline 4.2 12-monthly S\&P & 1 & & Mean Difference (IV, Fixed, 95\% CI) & $0.0[0.0,0.0]$ \\
\hline $\begin{array}{l}5 \text { Participant perception } \\
\text { of oral cleanliness at } 24 \\
\text { months }\end{array}$ & 1 & & Risk Ratio (M-H, Fixed, 95\% Cl) & Totals not selected \\
\hline 5.16-monthly S\&P & 1 & & Risk Ratio (M-H, Fixed, 95\% Cl) & $0.0[0.0,0.0]$ \\
\hline 5.212 -monthly S\&P & 1 & & Risk Ratio (M-H, Fixed, 95\% Cl) & $0.0[0.0,0.0]$ \\
\hline $\begin{array}{l}6 \text { Quality of life at } 36 \\
\text { months }\end{array}$ & 1 & & Mean Difference (IV, Fixed, 95\% CI) & Totals not selected \\
\hline 6.1 6-monthly S\&P & 1 & & Mean Difference (IV, Fixed, 95\% CI) & $0.0[0.0,0.0]$ \\
\hline 6.2 12-monthly S\&P & 1 & & Mean Difference (IV, Fixed, 95\% CI) & $0.0[0.0,0.0]$ \\
\hline $\begin{array}{l}7 \text { Cost (NHS perspective) } \\
\text { at } 36 \text { months }\end{array}$ & 1 & & Mean Difference (IV, Fixed, 95\% CI) & Totals not selected \\
\hline 7.1 6-monthly S\&P & 1 & & Mean Difference (IV, Fixed, 95\% CI) & $0.0[0.0,0.0]$ \\
\hline 7.2 12-monthly S\&P & 1 & & Mean Difference (IV, Fixed, 95\% CI) & $0.0[0.0,0.0]$ \\
\hline
\end{tabular}

\section{Analysis 1.1. Comparison 1 Scale and polish versus no scale and polish, Outcome 1 Gingivitis at 24-36 months.}

\begin{tabular}{|c|c|c|c|c|c|c|c|}
\hline \multirow[t]{2}{*}{ Study or subgroup } & \multicolumn{2}{|c|}{ Routine S\&P } & \multicolumn{2}{|c|}{ Control } & \multirow{2}{*}{$\begin{array}{c}\text { Std. Mean Difference } \\
\text { Fixed, } 95 \% \mathrm{Cl}\end{array}$} & \multirow[t]{2}{*}{ Weight } & \multirow{2}{*}{$\begin{array}{c}\text { Std. Mean Difference } \\
\text { Fixed, } 95 \% \mathrm{Cl}\end{array}$} \\
\hline & $\mathbf{N}$ & $\operatorname{Mean}(\mathrm{SD})$ & $\mathbf{N}$ & $\operatorname{Mean}(\mathrm{SD})$ & & & \\
\hline \multicolumn{8}{|c|}{ 1.1.1 6-monthly scale and polish (S\&P) } \\
\hline Jones 2011 & 107 & $0.4(0.3)$ & 100 & $0.4(0.3)$ & & $19.02 \%$ & $-0.06[-0.34,0.21]$ \\
\hline Ramsay 2018 & 436 & $0.4(0.2)$ & 444 & $0.4(0.2)$ & & $80.98 \%$ & $0[-0.13,0.13]$ \\
\hline Subtotal $* \star \star$ & 543 & & 544 & & & $100 \%$ & $-0.01[-0.13,0.11]$ \\
\hline \multicolumn{8}{|c|}{ Heterogeneity: $\mathrm{Tau}^{2}=0 ; \mathrm{Chi}^{2}=0.16, \mathrm{df}=1(\mathrm{P}=0.69) ; \mathrm{I}^{2}=0 \%$} \\
\hline \multicolumn{8}{|c|}{ Test for overall effect: $Z=0.2(P=0.84)$} \\
\hline \multicolumn{8}{|c|}{ 1.1.2 12-monthly S\&P } \\
\hline Jones 2011 & 100 & $0.4(0.3)$ & 100 & $0.4(0.3)$ & & $18.33 \%$ & $-0.03[-0.31,0.24]$ \\
\hline Ramsay 2018 & 447 & $0.4(0.3)$ & 444 & $0.4(0.2)$ & & $81.67 \%$ & $-0.05[-0.18,0.09]$ \\
\hline Subtotal $* \star \star$ & 547 & & 544 & & & $100 \%$ & $-0.04[-0.16,0.08]$ \\
\hline \multicolumn{8}{|c|}{ Heterogeneity: $\operatorname{Tau}^{2}=0 ; \mathrm{Chi}^{2}=0.01, \mathrm{df}=1(\mathrm{P}=0.94) ; \mathrm{I}^{2}=0 \%$} \\
\hline
\end{tabular}


Analysis 1.2. Comparison 1 Scale and polish versus no scale and polish, Outcome 2 Calculus at 24-36 months.

\begin{tabular}{|c|c|c|c|c|c|c|c|}
\hline \multirow[t]{2}{*}{ Study or subgroup } & \multicolumn{2}{|c|}{ Routine S\&P } & \multicolumn{2}{|c|}{ Control } & \multirow{2}{*}{$\begin{array}{c}\text { Std. Mean Difference } \\
\text { Fixed, } 95 \% \mathrm{Cl}\end{array}$} & \multirow[t]{2}{*}{ Weight } & \multirow{2}{*}{$\begin{array}{l}\text { Std. Mean Difference } \\
\text { Fixed, } 95 \% \mathrm{Cl}\end{array}$} \\
\hline & $\mathbf{N}$ & $\operatorname{Mean}(\mathrm{SD})$ & $\mathbf{N}$ & Mean(SD) & & & \\
\hline \multicolumn{8}{|l|}{ 1.2.1 6-monthly S\&P } \\
\hline Jones 2011 & 106 & $0.7(1)$ & 99 & $1(1)$ & $\because$ & $19 \%$ & $-0.24[-0.52,0.03]$ \\
\hline Ramsay 2018 & 435 & $0.3(0.2)$ & 444 & $0.4(0.3)$ & . & $81 \%$ & $-0.34[-0.47,-0.2]$ \\
\hline Subtotal $\star \star \star$ & 541 & & 543 & & & $100 \%$ & $-0.32[-0.44,-0.2]$ \\
\hline \multicolumn{8}{|c|}{ Heterogeneity: $\mathrm{Tau}^{2}=0 ; \mathrm{Chi}^{2}=0.37, \mathrm{df}=1(\mathrm{P}=0.54) ; \mathrm{I}^{2}=0 \%$} \\
\hline \multicolumn{8}{|c|}{ 1.2.2 12-monthly S\&P } \\
\hline Jones 2011 & 100 & $0.9(1)$ & 99 & $1(1)$ & —- & $18.37 \%$ & $-0.06[-0.34,0.22]$ \\
\hline Ramsay 2018 & 445 & $0.3(0.3)$ & 444 & $0.4(0.3)$ & + & $81.63 \%$ & $-0.22[-0.35,-0.09]$ \\
\hline Subtotal $\star \star \star$ & 545 & & 543 & & 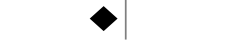 & $100 \%$ & $-0.19[-0.31,-0.07]$ \\
\hline \multicolumn{8}{|c|}{ Heterogeneity: Tau $^{2}=0 ; \mathrm{Chi}^{2}=1, \mathrm{df}=1(\mathrm{P}=0.32) ; \mathrm{I}^{2}=0 \%$} \\
\hline
\end{tabular}

Analysis 1.3. Comparison 1 Scale and polish versus no scale and polish, Outcome 3 Plaque at 24 months.

\begin{tabular}{|c|c|c|c|c|c|c|}
\hline \multirow{2}{*}{ Study or subgroup } & \multicolumn{2}{|c|}{ Routine S\&P } & \multicolumn{2}{|c|}{ Control } & \multirow{2}{*}{$\begin{array}{c}\text { Mean Difference } \\
\text { Fixed, } 95 \% \mathrm{Cl}\end{array}$} & \multirow{2}{*}{$\begin{array}{c}\text { Mean Difference } \\
\text { Fixed, } 95 \% \mathrm{Cl}\end{array}$} \\
\hline & $\mathbf{N}$ & Mean(SD) & $\mathbf{N}$ & Mean(SD) & & \\
\hline \multicolumn{7}{|l|}{ 1.3.1 6-monthly S\&P } \\
\hline Jones 2011 & 107 & $0.4(0.3)$ & 100 & $0.4(0.3)$ & + & $-0.04[-0.13,0.05]$ \\
\hline \multicolumn{7}{|l|}{ 1.3.2 12-monthly S\&P } \\
\hline Jones 2011 & 100 & $0.4(0.3)$ & 100 & $0.4(0.3)$ & + & $-0[-0.1,0.09]$ \\
\hline
\end{tabular}

Analysis 1.4. Comparison 1 Scale and polish versus no scale and polish, Outcome 4 Probing depths at 36 months.

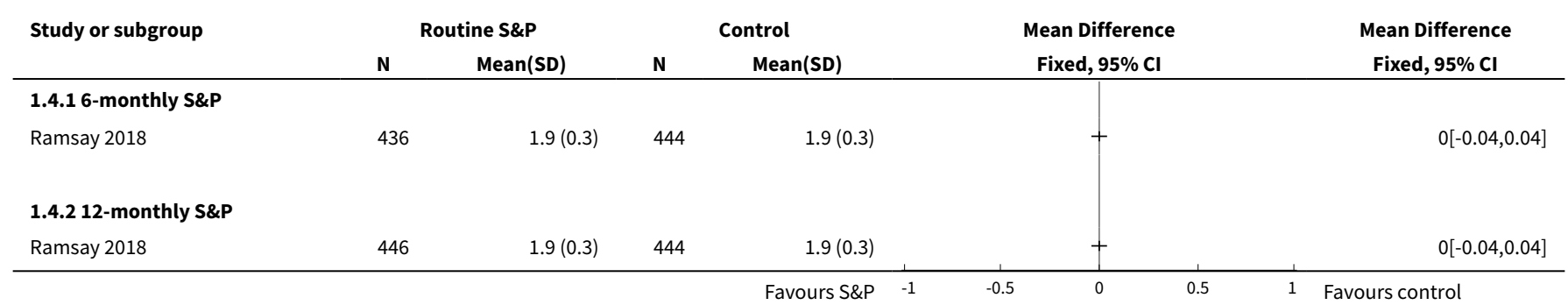

Analysis 1.5. Comparison $1 \mathrm{Scale}$ and polish versus no scale and polish, Outcome 5 Participant perception of oral cleanliness at 24 months.

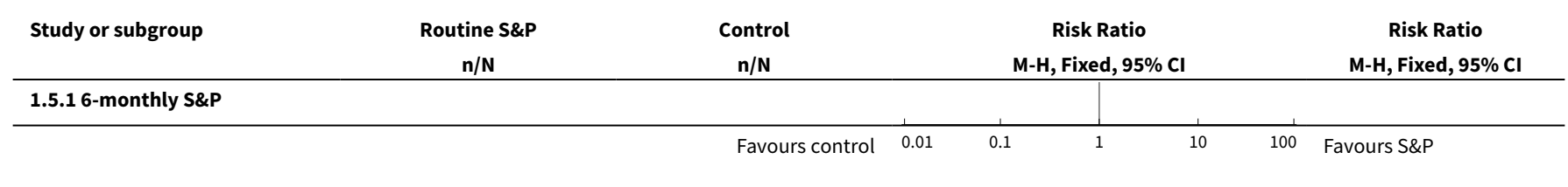




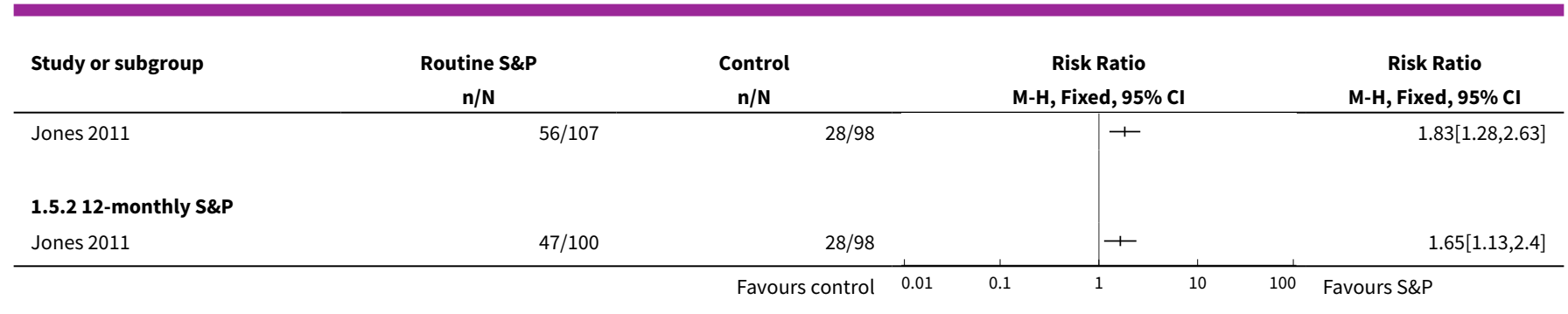

\section{Analysis 1.6. Comparison 1 Scale and polish versus no scale and polish, Outcome 6 Quality of life at 36 months.}

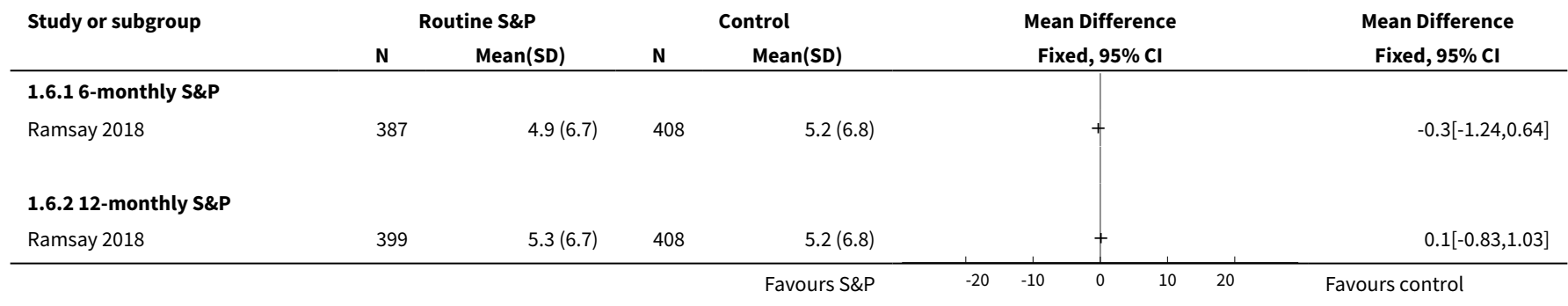

Analysis 1.7. Comparison 1 Scale and polish versus no scale and polish, Outcome 7 Cost (NHS perspective) at 36 months.

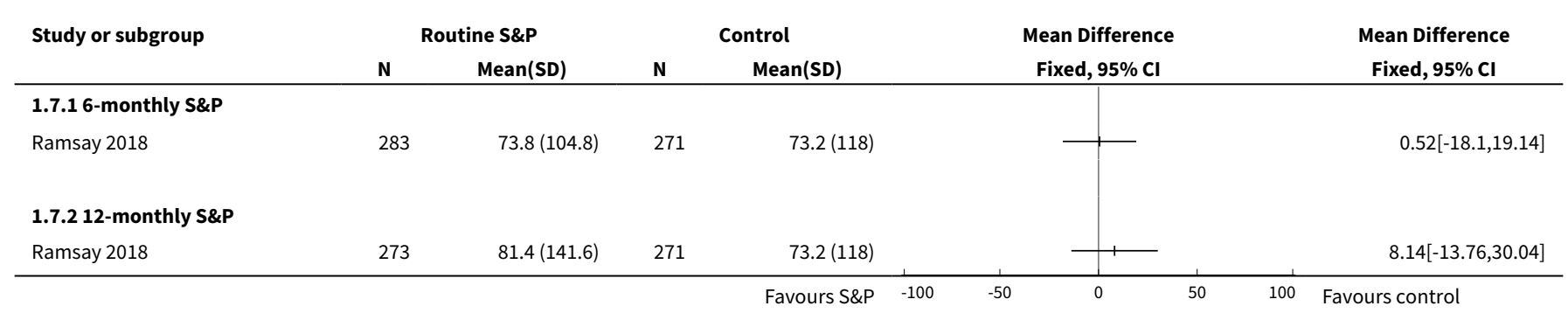

Comparison 2. Scale and polish at a fixed interval versus scale and polish at a different fixed interval

\begin{tabular}{lllll}
\hline Outcome or subgroup title & No. of studies & $\begin{array}{l}\text { No. of partici- } \\
\text { pants }\end{array}$ & Statistical method & Effect size \\
\hline 1 Gingivitis at 24-36 months & 2 & 1090 & $\begin{array}{l}\text { Std. Mean Difference (IV, Fixed, } \\
95 \% \mathrm{Cl} \text { ) }\end{array}$ & 0.03 [-0.09, 0.15] \\
\hline 2 Calculus at 24-36 months & 2 & 1086 & $\begin{array}{l}\text { Std. Mean Difference (IV, Fixed, } \\
95 \% \text { Cl) }\end{array}$ & -0.13 [-0.25, -0.01] \\
\hline 3 Plaque at 24 months & 1 & Mean Difference (IV, Fixed, 95\% Cl) & Totals not selected \\
\hline 4 Probing depths at 36 months & 1 & Mean Difference (IV, Fixed, 95\% Cl) & Totals not selected \\
\hline $\begin{array}{l}5 \text { Participant perception of } \\
\text { oral cleanliness at 24 months }\end{array}$ & 1 & Risk Ratio (M-H, Fixed, 95\% Cl) & Totals not selected \\
\hline
\end{tabular}




\begin{tabular}{lllll}
\hline Outcome or subgroup title & No. of studies & $\begin{array}{l}\text { No. of partici- } \\
\text { pants }\end{array}$ & Statistical method & Effect size \\
\hline 6 Quality of life at 36 months & 1 & Mean Difference (IV, Fixed, 95\% Cl) & Totals not selected \\
\hline $\begin{array}{l}7 \text { Cost (NHS perspective) at } 36 \\
\text { months }\end{array}$ & 1 & Mean Difference (IV, Fixed, 95\% Cl) & Totals not selected \\
\hline
\end{tabular}

Analysis 2.1. Comparison 2 Scale and polish at a fixed interval versus scale and polish at a different fixed interval, Outcome 1 Gingivitis at 24-36 months.

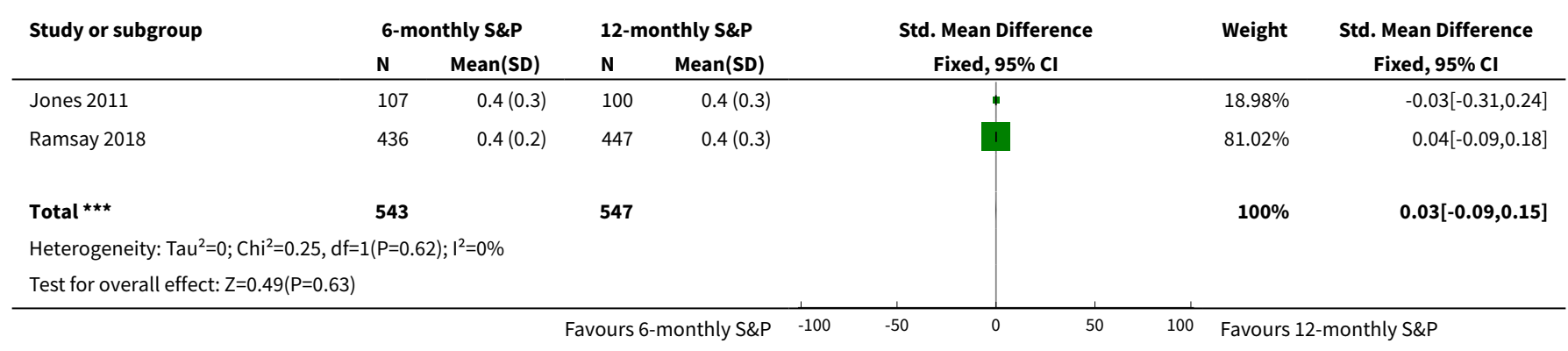

Analysis 2.2. Comparison 2 Scale and polish at a fixed interval versus scale and polish at a different fixed interval, Outcome 2 Calculus at 24-36 months.

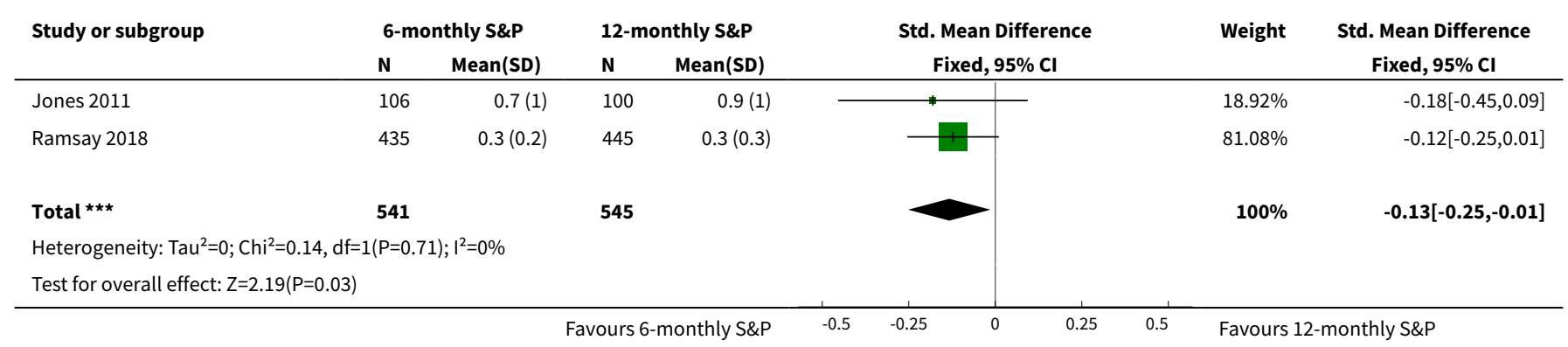

Analysis 2.3. Comparison 2 Scale and polish at a fixed interval versus scale and polish at a different fixed interval, Outcome 3 Plaque at 24 months.

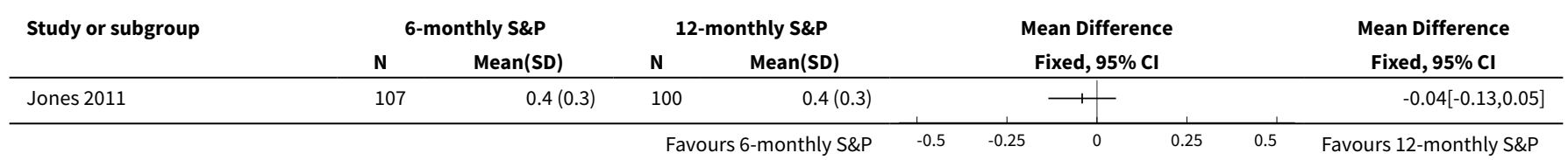


Analysis 2.4. Comparison 2 Scale and polish at a fixed interval versus scale and polish at a different fixed interval, Outcome 4 Probing depths at 36 months.

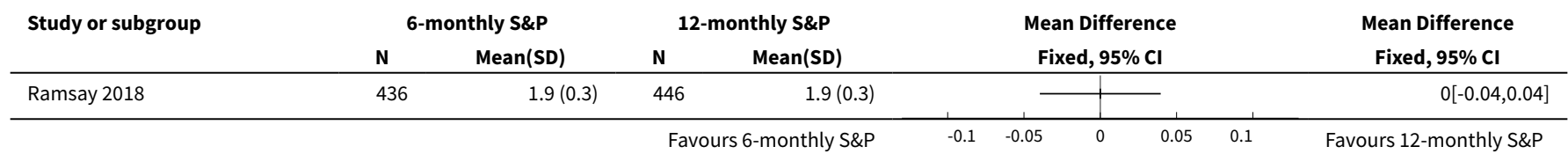

Analysis 2.5. Comparison 2 Scale and polish at a fixed interval versus scale and polish at a different fixed interval, Outcome 5 Participant perception of oral cleanliness at 24 months.

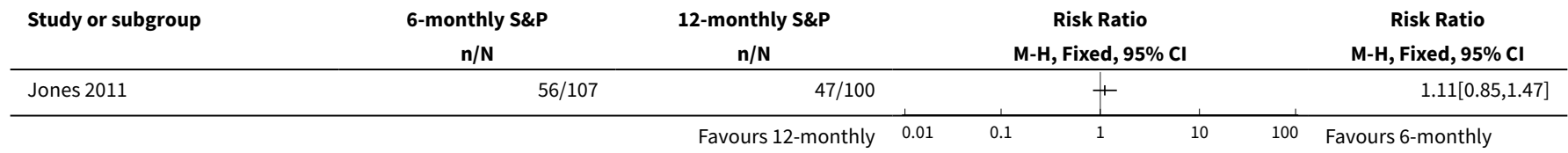

Analysis 2.6. Comparison 2 Scale and polish at a fixed interval versus scale and polish at a different fixed interval, Outcome 6 Quality of life at 36 months.

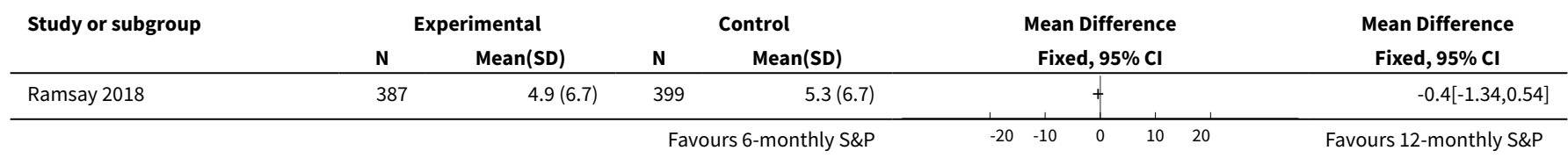

Analysis 2.7. Comparison 2 Scale and polish at a fixed interval versus scale and polish at a different fixed interval, Outcome 7 Cost (NHS perspective) at 36 months.

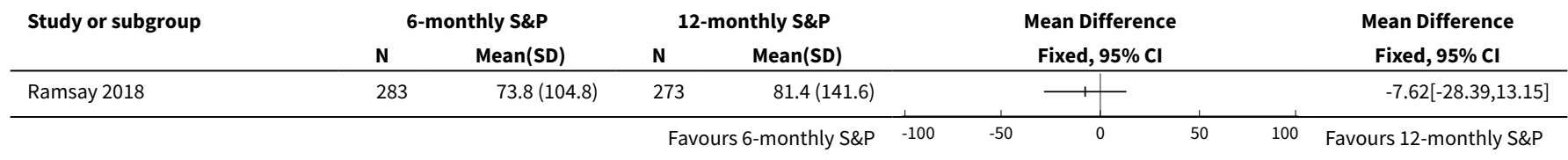




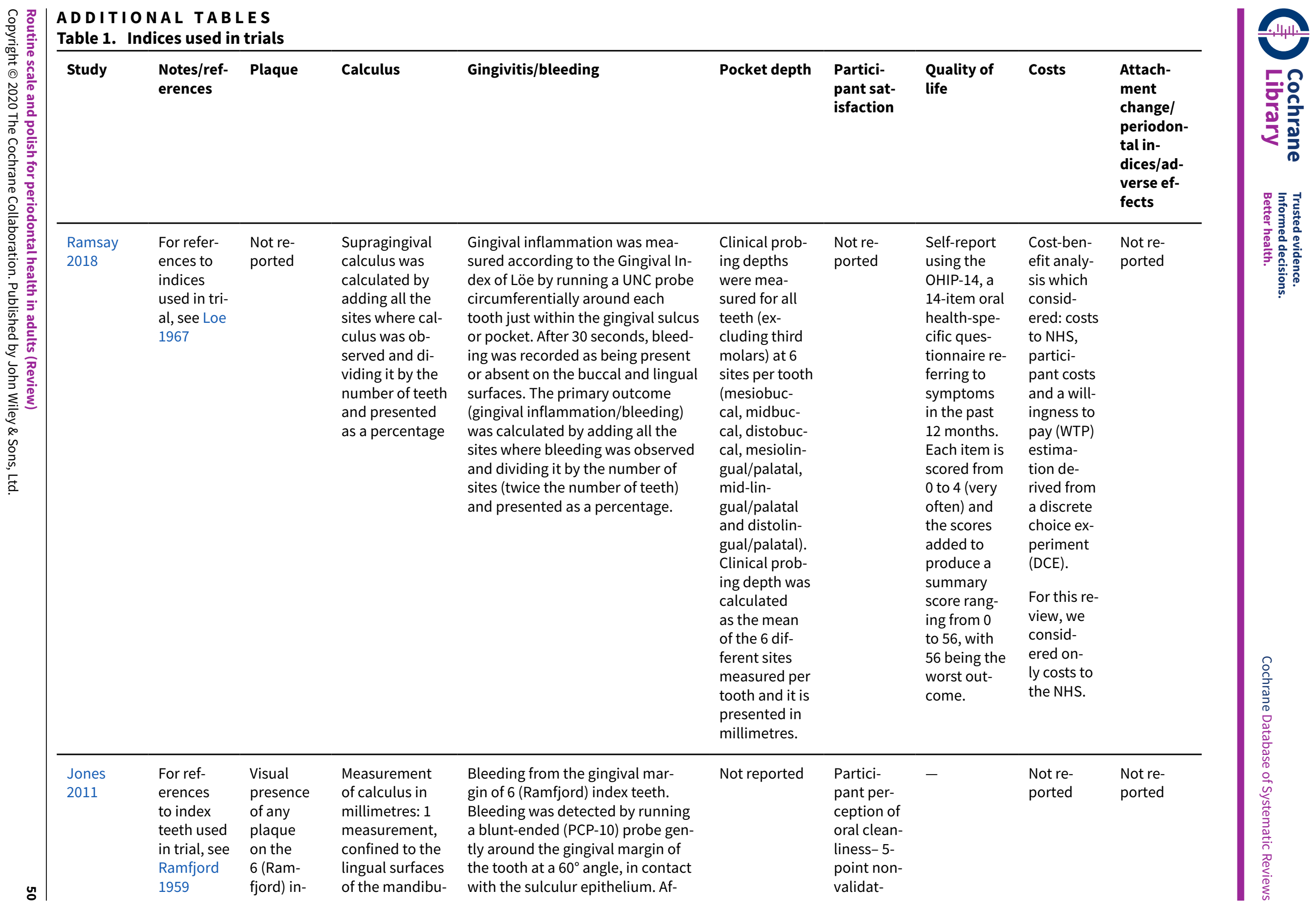


Table 1. Indices used in trials (Continued)

\begin{tabular}{|c|c|c|}
\hline $\begin{array}{l}\text { dex teeth } \\
\text { accord- } \\
\text { ing to a } \\
\text { dichoto- } \\
\text { mous } \\
\text { scale: } \\
\text { plaque } \\
\text { present/ } \\
\text { not } \\
\text { present }\end{array}$ & $\begin{array}{l}\text { lar incisor and } \\
\text { canine teeth. A } \\
\text { PCP-10 } \\
\text { probe was used } \\
\text { to measure } \\
\text { along the verti- } \\
\text { cal axis of } \\
\text { the tooth with } \\
\text { the most calcu- } \\
\text { lus. }\end{array}$ & $\begin{array}{l}\text { ter approximately } 30 \text { seconds, any } \\
\text { bleeding elicited was recorded ac- } \\
\text { cording to a dichotomous scale for } \\
\text { each tooth: present/not present. }\end{array}$ \\
\hline
\end{tabular}

OHIP-14: Oral Health Impact Profile-14; UNC: University of North Carolina.

Table 2. Comparison 1: scale and polish versus no scale and polish (outcomes, data points, scale and polish frequency)

\begin{tabular}{|c|c|c|c|c|c|c|c|c|}
\hline $\begin{array}{l}\text { Frequency of scale and } \\
\text { polish }\end{array}$ & Data points & Plaque & Calculus & $\begin{array}{l}\text { Gingivitis/bleed- } \\
\text { ing }\end{array}$ & $\begin{array}{l}\text { Pocket } \\
\text { depth }\end{array}$ & Quality of life & $\begin{array}{l}\text { Participant per- } \\
\text { ception of oral } \\
\text { cleanliness }\end{array}$ & Costs \\
\hline 6 months & 12 & - & - & - & - & - & - & - \\
\hline 12 months & 12 & - & - & - & - & - & - & - \\
\hline 6 months & 24 & Jones 2011 & Jones 2011 & Jones 2011 & - & Ramsay 2018 & Jones 2011 & - \\
\hline 12 months & 24 & Jones 2011 & Jones 2011 & Jones 2011 & - & Ramsay 2018 & Jones 2011 & - \\
\hline 6 months & 36 & - & Ramsay 2018 & Ramsay 2018 & $\begin{array}{l}\text { Ramsay } \\
2018\end{array}$ & Ramsay 2018 & - & $\begin{array}{l}\text { Ramsay } \\
2018\end{array}$ \\
\hline 12 months & 36 & - & Ramsay 2018 & Ramsay 2018 & $\begin{array}{l}\text { Ramsay } \\
2018\end{array}$ & Ramsay 2018 & - & $\begin{array}{l}\text { Ramsay } \\
2018\end{array}$ \\
\hline
\end{tabular}

Data points measured in months.

Table 3. Comparison 3: scale and polish versus scale and polish at different intervals (outcomes, data points, scale and polish frequency)

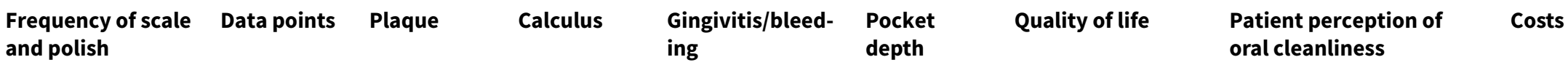




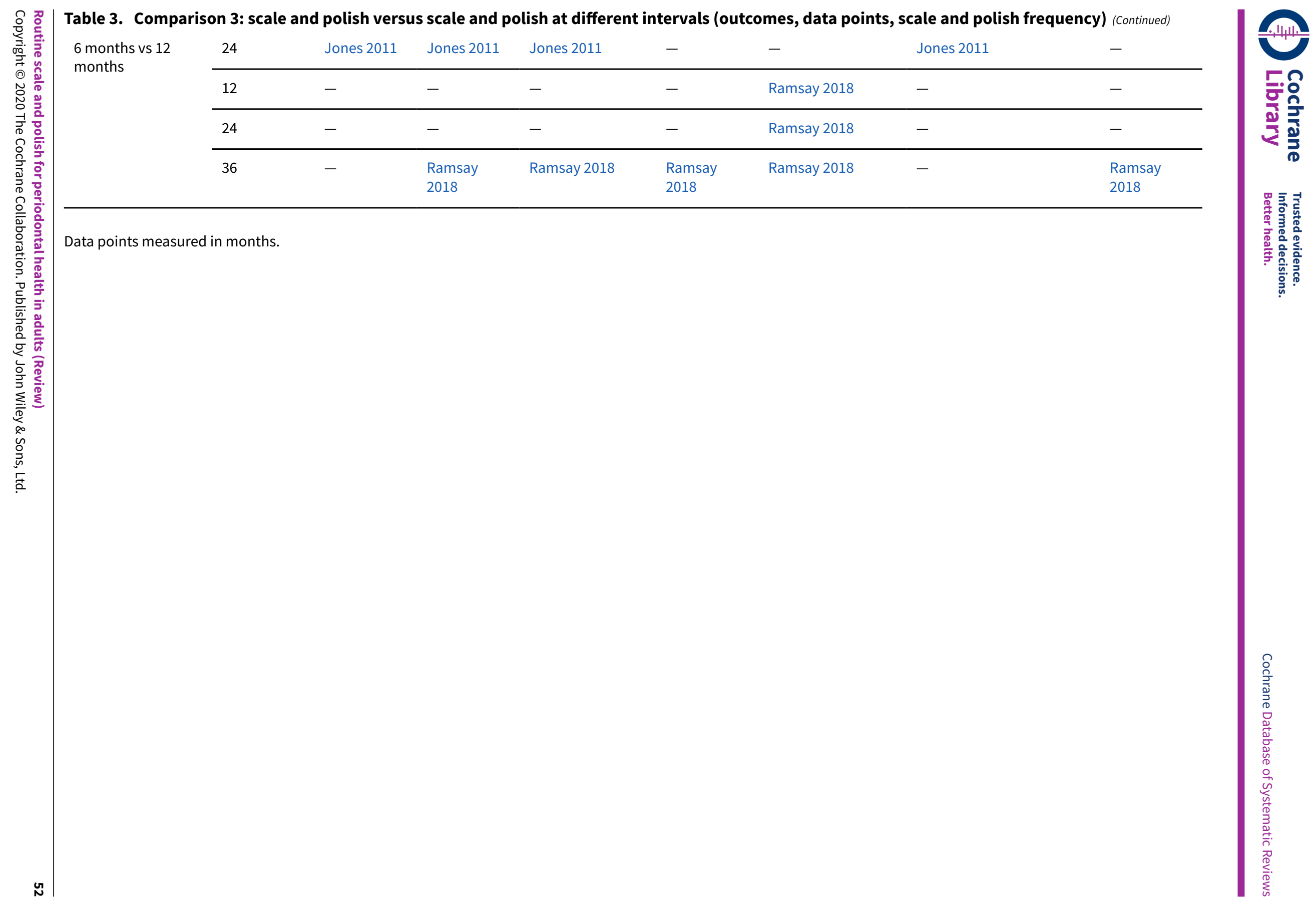




\section{AP P E N DICES}

\section{Appendix 1. Cochrane Oral Health Trials Register search strategy}

From July 2013, searches of the Cochrane Oral Health Group's Trials Register were undertaken using the Cochrane Register of Studies and the search strategy below:

\#1 ((routine* or recall* or regular* or periodic* or "six month*" or six-month* or "6 month*" or 6-month* or "three month*" or three-month* or "3 month*" or 3-month*):ti,ab) AND (INREGISTER)

\#2 ((scaling or "scale and polish" or "dental prophylaxis" or "oral prophylaxis"):ti,ab) AND (INREGISTER)

\#3 (\#1 and \#2) AND (INREGISTER)

Searches previous to July 2013 were undertaken using the Procite software and the search strategy below:

( ((scaling OR "scale and polish" OR "dental prophylaxis" OR "oral prophylaxis" OR periodont*) AND (periodic* OR routine* OR recall* OR sixmonth* OR three-month")) OR (("periodic check-up*" OR "regular check-up" OR "regular examination" OR "regular care" OR "routine care" OR "routine* recall*" OR "six-month* check-up" OR "six-month* inspect*" OR "six-month* recall*" OR "6 month* check-up " OR "6 month* inspect*" OR "6 month* recall " OR "three-month* check-up*" OR "three-month* inspect*" OR "three month* recall*" OR "3 month* checkup" OR "3 month* inspect*" OR "3 month* recall*")))

\section{Appendix 2. Cochrane Central Register of Controlled Trials (CENTRAL) search strategy}

\#1 MeSH descriptor Periodontal Diseases explode all trees

\#2 (peridonti* in Title, Abstract or Keywords or (periodont ${ }^{*}$ in Title, Abstract or Keywords near/3 disease ${ }^{\star}$ in Title, Abstract or Keywords) ) \#3 gingivitis in Title, Abstract or Keywords

\#4 ( (gingiva* in Title, Abstract or Keywords near/5 inflam* in Title, Abstract or Keywords) or (gingiva* in Title, Abstract or Keywords near/5 disease $^{\star}$ in Title, Abstract or Keywords) or (gingiva* in Title, Abstract or Keywords near/5 bleed* in Title, Abstract or Keywords) or (gingiva* in Title, Abstract or Keywords near/5 swell* in Title, Abstract or Keywords) )

\#5 ( (gum* in Title, Abstract or Keywords near/5 inflam* in Title, Abstract or Keywords) or (gum* in Title, Abstract or Keywords near/5 disease $^{\star}$ in Title, Abstract or Keywords) or (gum ${ }^{\star}$ in Title, Abstract or Keywords near/5 bleed ${ }^{\star}$ in Title, Abstract or Keywords) or (gum ${ }^{\star}$ in Title, Abstract or Keywords near $/ 5$ swell* in Title, Abstract or Keywords) )

\#6 MeSH descriptor Dental plaque this term only

\#7 MeSH descriptor Dental calculus this term only

\#8 ( (tooth in Title, Abstract or Keywords near/5 plaque in Title, Abstract or Keywords) or (teeth in Title, Abstract or Keywords near/5 plaque in Title, Abstract or Keywords) or (dental in Title, Abstract or Keywords near/5 plaque in Title, Abstract or Keywords) )

\#9 ( (tooth in Title, Abstract or Keywords near/5 calculus in Title, Abstract or Keywords) or (teeth in Title, Abstract or Keywords near/5 calculus in Title, Abstract or Keywords) or (dental in Title, Abstract or Keywords near/5 calculus in Title, Abstract or Keywords) )

$\# 10$ (\#1 or \#2 or \#3 or \#4 or \#5 or \#6 or \#7 or \#8 or \#9)

\#11 MeSH descriptor Dental prophylaxis explode all trees

\#12 ( (dental in Title, Abstract or Keywords near $/ 5 \mathrm{scal}^{*}$ in Title, Abstract or Keywords) or (tooth in Title, Abstract or Keywords near/5 scal $^{*}$ in Title, Abstract or Keywords) or (teeth in Title, Abstract or Keywords near/5 scal* in Title, Abstract or Keywords) or (dental in Title, Abstract or Keywords near $/ 5$ polish* in Title, Abstract or Keywords) or (tooth in Title, Abstract or Keywords near/5 polish* in Title, Abstract or Keywords) or (teeth in Title, Abstract or Keywords near $/ 5$ polish* in Title, Abstract or Keywords) or (dental in Title, Abstract or Keywords near/5 prophylax* in Title, Abstract or Keywords) or (tooth in Title, Abstract or Keywords near/5 prophylax* in Title, Abstract or Keywords) or (teeth in Title, Abstract or Keywords near/5 prophylax* in Title, Abstract or Keywords))

$\# 13$ (periodont* in Title, Abstract or Keywords near $/ 5 \mathrm{scal}^{*}$ in Title, Abstract or Keywords)

$\# 14$ (\#11 or \#12 or \#13)

$\# 15$ (\#10 and \#14)

\section{Appendix 3. MEDLINE Ovid search strategy}

1. exp Periodontal Diseases/

2. (periodonti\$ or (periodont\$ adj3 disease\$)).ti,ab.

3. gingivitis.ti,ab.

4. ((gingiva\$ or gum\$) adj5 (inflam\$ or disease $\$$ or bleed\$ or swell\$)).ti,ab.

5. Dental plaque/

6. Dental calculus/

7. ((tooth or teeth or dental) adj5 (plaque or calculus)).ti,ab.

8. or/1-7

9. exp Dental prophylaxis/

10. ((dental or tooth or teeth) and (scal\$ or polish\$ or prophylax\$)).ti,ab.

11. (periodont\$ adj5 scal\$).ti,ab.

12. or/9-11 


\section{8 and 12}

This subject search was linked to the Cochrane Highly Sensitive Search Strategy (CHSSS) for identifying randomised trials in MEDLINE: sensitivity-maximising version (2008 revision) as referenced in Chapter 6.4.11.1 and detailed in box 6.4.c of The Cochrane Handbook for Systematic Reviews of Interventions, Version 5.1.0 (updated March 2011) (Lefebvre 2011).

1. randomized controlled trial.pt.

2. controlled clinical trial.pt.

3. randomized.ab.

4. placebo.ab.

5. drug therapy.fs.

6. randomly.ab.

7. trial.ab.

8. groups.ab.

9. or/1-8

10. exp animals/ not humans.sh.

11.9 not 10

\section{Appendix 4. Embase Ovid search strategy}

1. exp Periodontal Disease/

2. (periodonti\$ or (periodont\$ adj3 disease\$)).ti,ab.

3. gingivitis.ti,ab.

4. ((gingiva $\$$ or gum\$) adj5 (inflam\$ or disease\$ or bleed $\$$ or swell\$)).ti,ab.

5. Tooth plaque/

6. Tooth calculus/

7. ((tooth or teeth or dental) adj5 (plaque or calculus)).ti,ab.

8. or/1-7

9. ((dental or tooth or teeth) and (scal\$ or polish\$ or prophylax\$)).ti,ab.

10. (periodont\$ adj5 scal\$).ti,ab.

11.9 or 10

12. 8 and 11

The above subject search was linked to adapted version of the Cochrane Embase Project filter for identifying RCTs in Embase Ovid (see www.cochranelibrary.com/help/central-creation-details.html for information):

1. Randomized controlled trial/

2. Controlled clinical study/

3. Random\$.ti,ab.

4. randomization/

5. intermethod comparison/

6. placebo.ti,ab.

7. (compare or compared or comparison).ti.

8. ((evaluated or evaluate or evaluating or assessed or assess) and (compare or compared or comparing or comparison)).ab.

9. (open adj label).ti,ab.

10. ((double or single or doubly or singly) adj (blind or blinded or blindly)).ti,ab.

11. double blind procedure/

12. parallel group $\$ 1 . t i, a b$.

13. (crossover or cross over).ti,ab.

14. ((assign\$ or match or matched or allocation) adj5 (alternate or group\$1 or intervention\$1 or patient $\$ 1$ or subject $\$ 1$ or participant

\$1)).ti,ab.

15. (assigned or allocated).ti,ab.

16. (controlled adj7 (study or design or trial)).ti,ab.

17. (volunteer or volunteers).ti,ab.

18. trial.ti.

19. or/1-18

20. (exp animal/ or animal.hw. or nonhuman/) not (exp human/ or human cell/ or (human or humans).ti.)

21. 19 not 20

\section{Appendix 5. US National Institutes of Health Ongoing Trials Register (ClinicalTrials.gov) search strategy}

routine and "scale and polish"

recall and "scale and polish" 
regular and "scale and polish"

\section{Appendix 6. World Health Organization International Clinical Trials Registry Platform search strategy}

routine and "scale and polish"

recall and "scale and polish"

regular and "scale and polish"

WHAT'S NEW

\begin{tabular}{lll}
\hline Date & Event & Description \\
\hline 6 April 2020 & Amended & $\begin{array}{l}\text { Minor edit to description of GRADE in 'Summary of findings' ta- } \\
\text { bles }\end{array}$ \\
\hline
\end{tabular}

\section{HISTORY}

Protocol first published: Issue 1, 2004

Review first published: Issue 1, 2005

\begin{tabular}{lll}
\hline Date & Event & Description \\
\hline 18 April 2018 & $\begin{array}{l}\text { New citation required and conclusions } \\
\text { have changed }\end{array}$ & $\begin{array}{l}\text { High-certainty evidence is now available, which shows that rou- } \\
\text { tine scaling and polishing does not reduce gingivitis or probing } \\
\text { depths in adults without severe periodontitis. }\end{array}$ \\
\hline
\end{tabular}

10 January $2018 \quad$ New search has been performed $\quad$ Updated search to 10 January 2018.

One new study included.

Two studies from the previous edition of this Cochrane review (Worthington 2013) have now been excluded. The Lightner 1971 and Listgarten 1985 studies are not representative of the intervention or study population being compared in this review.

The objective: "To compare the beneficial and harmful effects of routine scaling and polishing with or without oral hygiene instruction" from the previous versions has been removed from this update. This question is more relevant to the Cochrane Review of one-to-one oral hygiene advice in a dental setting (Soldani 2018).

$\begin{array}{ll}5 \text { November } 2013 & \begin{array}{l}\text { New citation required but conclusions } \\ \text { have not changed }\end{array}\end{array}$
have not changed
New methods including risk of bias implemented. Inclusion criteria modified to exclude patients with severe periodontitis, splitmouth studies and studies that included only a single visit for scale and polish treatment. 1 new study and only 2 of the original included studies now included in the review. Summary of findings tables added.

\begin{tabular}{lll}
\hline 15 July 2013 & New search has been performed & Search strategy amended and updated to 15 July 2013. \\
\hline 19 June 2008 & Amended & Converted to new review format. \\
\hline
\end{tabular}




\begin{tabular}{lll}
\hline Date & Event & Description \\
\hline 10 August 2007 & $\begin{array}{l}\text { New citation required and conclusions } \\
\text { have changed }\end{array}$ & $\begin{array}{l}\text { Substantive amendment. 1 new trial (Westfelt 1983) has been in- } \\
\text { cluded in this update bringing the total number of included trials } \\
\text { up to 9. }\end{array}$ \\
\hline
\end{tabular}

\section{CONTRIBUTIONS OF AUTHORS}

All four current authors were involved in the final decisions on inclusion and exclusion for this update. PB and HW undertook risk of bias assessments. TL, PB, JC and HW undertook data extraction and analysis. The review update was written by TL, HW, JC and PB.

For the original version of the review, PB and Andrew Forgie (AF) decided which studies were eligible.

$\mathrm{PB}, \mathrm{HW}, \mathrm{JC}$ and $\mathrm{AF}$ wrote the protocol.

\section{DECLARATIONS OF INTEREST}

TL: was involved with one of the included studies (Ramsay 2018), but was not involved with the data extraction from this study or assessment of its risk of bias for this review. Thomas Lamont is an Editor with Cochrane Oral Health.

HW: was involved with one of the included studies (Ramsay 2018), but was not involved with the data extraction from this study or assessment of its risk of bias for this review. Professor Worthington is a Co-ordinating Editor with Cochrane Oral Health.

JC: was involved with one of the included studies (Ramsay 2018), but was not involved with the data extraction from this study or assessment of its risk of bias for this review. Professor Clarkson is a Co-ordinating Editor with Cochrane Oral Health.

PB: no interests to declare. The original review published in 2005 was supported by funding from the Health Research Board, Dublin, under the Island of Ireland Cochrane Fellowship scheme. The updated review published in 2007 was supported by funding from the Department of Health England, under the Cochrane Incentive Scheme.

\section{SOURCES OF SUPPORT}

\section{Internal sources}

- The School of Dentistry, The University of Manchester, Manchester Academic Health Sciences Centre (MAHSC) and the NIHR Manchester Biomedical Research Centre, UK.

- The University of Dundee, UK.

- NHS Education for Scotland, UK.

- University College Cork, Ireland.

\section{External sources}

- National Institute for Health and Care Excellence, UK.

- Cochrane Fellowship - Health Research Board, Ireland.

- Department of Health Cochrane Review Incentive Scheme, UK.

- Cochrane Oral Health Group Global Alliance, Other.

The production of Cochrane Oral Health reviews has been supported financially by our Global Alliance since 2011 (oralhealth.cochrane.org/partnerships-alliances). Contributors over the past year have been the American Association of Public Health Dentistry, USA; AS-Akademie, Germany; the British Association for the Study of Community Dentistry, UK; the British Society of Paediatric Dentistry, UK; the Canadian Dental Hygienists Association, Canada; the Centre for Dental Education and Research at All India Institute of Medical Sciences, India; the National Center for Dental Hygiene Research \& Practice, USA; New York University College of Dentistry, USA; and the Swiss Society for Endodontology, Switzerland.

- National Institute for Health Research (NIHR), UK.

This project was supported by the NIHR, via Cochrane Infrastructure funding to Cochrane Oral Health. The views and opinions expressed herein are those of the review authors and do not necessarily reflect those of the Systematic Reviews Programme, the NIHR, the NHS or the Department of Health. 


\section{DIFFERENCES BETWEEN PROTOCOLAND REVIEW}

In the original review protocol and in earlier versions of this review, we adopted broader selection criteria and included trials where S\&P treatments were provided in non-primary care settings or were delivered in a manner that did not reflect the usual mode of delivery in general dental practice. These versions of the review served to highlight the deficiencies in the available evidence base and provided an impetus for the commissioning of research to evaluate the effects of S\&P treatments in 'real world' primary care settings.

In the intervening years, the evidence landscape has changed considerably with the publication of two trials evaluating routine S\&P treatments provided in general dental practice settings. In light of this new evidence, we no longer considered it appropriate to include in the updated review trials where the intervention was delivered in a setting or in a manner that is not representative of everyday primary care clinical practice. Therefore, we have now excluded two trials that were included in previous versions of this review (Lightner 1971; Listgarten 1985). Lightner 1971 involved male US Air Force Academy Cadets (mean age 22 years) and the S\&P treatments were delivered to some trial participants at a frequency and intensity that is not reflective of general dental practice (e.g. some S\&P treatments were given in two 30-minute appointments, five to 11 days apart with 10 minutes of toothbrushing instruction at each session). In Listgarten 1985, participants were recruited from a Dental Hygiene Clinic at a University Dental School. The S\&P treatments were administered according to a variable schedule based on the outcome of tests (differential darkfield microscopic (DDFM) tests) that are not typically used in general dental practice. In addition to excluding this trial, we also deleted the comparison under which this trial appeared in previous versions of the review (i.e. we deleted the comparison labelled as "Comparison 2" in the 2013 version of the review (Worthington 2013)).

In this updated review, we have removed the following objective: "To compare the beneficial and harmful effects of routine scaling and polishing with or without oral hygiene instruction". The comparison specified in this objective was evaluating the effects of oral hygiene instruction rather than routine scaling and polishing. This objective was deemed redundant for our updated review as the effects of oral hygiene instruction are addressed in another Cochrane Review (Soldani 2018).

In previous versions of the review, the reason given for exclusion of Adachi 2002 related to the outcomes measured. We have now clarified in the Characteristics of excluded studies table that the primary reason for exclusion was that the trial did not evaluate a routine S\&P intervention.

\section{N D X T ERMS}

\section{Medical Subject Headings (MeSH)}

Dental Calculus [therapy]; Dental Plaque [therapy]; Dental Polishing [*adverse effects]; Dental Prophylaxis [ ${ }^{*}$ adverse effects]; Dental Scaling [adverse effects]; Gingivitis [prevention \& control]; Patient Satisfaction; Periodontal Diseases [*prevention \& control]; Quality of Life; Randomized Controlled Trials as Topic; Time Factors

\section{MeSH check words}

Adult; Humans 